\title{
Coletânea de Estudos em
}

Integração Sensorial

Ana Irene Alves de Oliveira

Danielle Alves Zaparoli

Marcilene Alves Pinheiro

(Organizadoras)
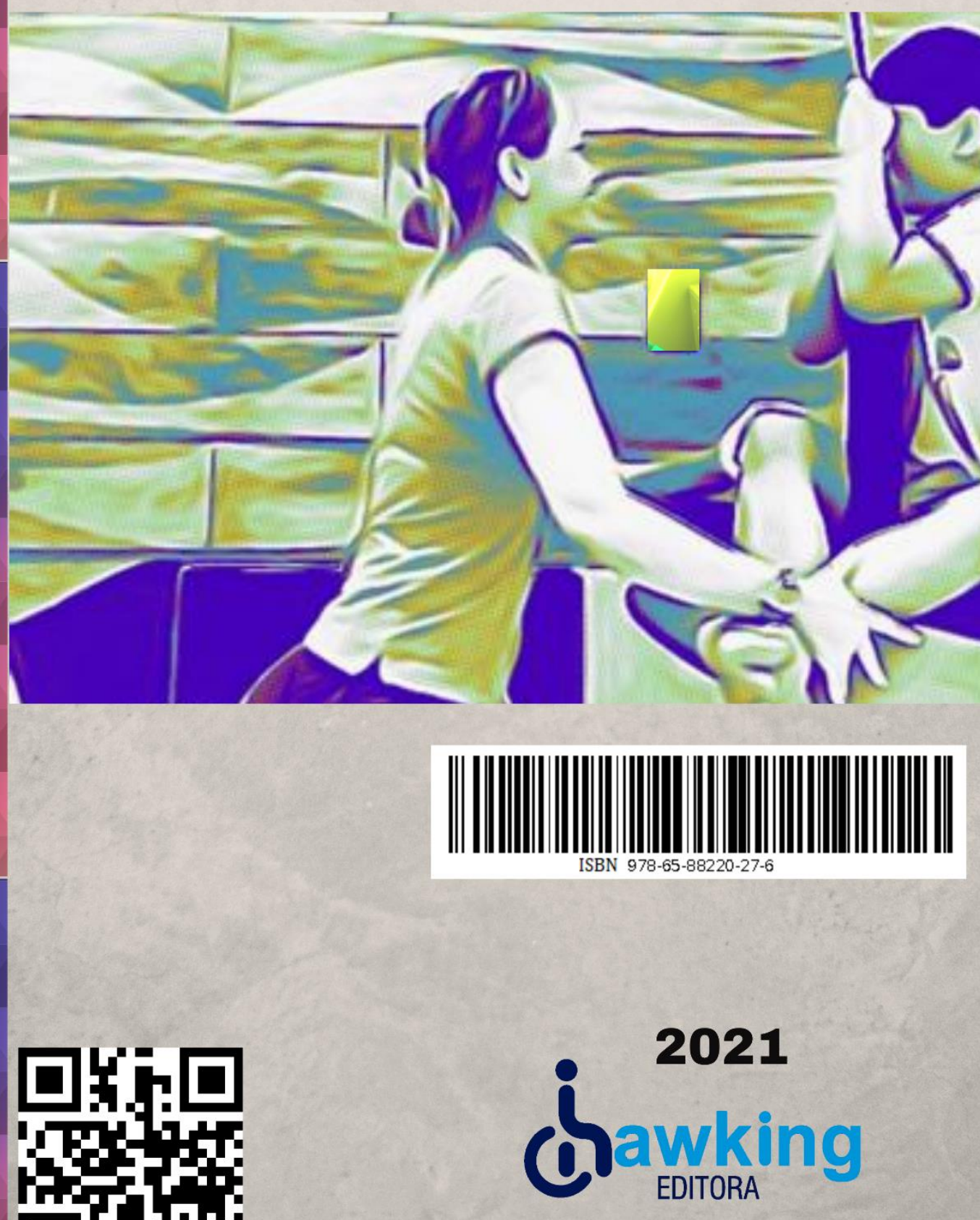
Ana Irene Alves de Oliveira

Danielle Alves Zaparoli

Marcilene Alves Pinheiro

(Organizadoras)

\title{
Coletânea de Estudos em Integração Sensorial
}

\author{
$1^{\circ}$ edição
}

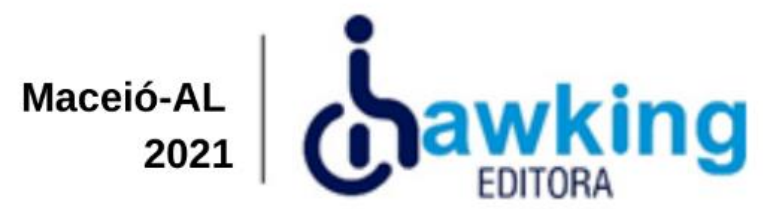


DIREÇÃO EDITORIAL: Betijane Soares de Barros

REVISÃO ORTOGRÁFICA: Editora Hawking

DIAGRAMAÇÃO: Adriana Marques Vanderlei Ferreira

DESIGNER DE CAPA: Editora Hawking

IMAGENS DE CAPA: Editora Hawking

O padrão ortográfico, o sistema de citações e referências bibliográficas são prerrogativas do autor.

Da mesma forma, o conteúdo da obra é de inteira e exclusiva responsabilidade de seu autor.

\section{Creative Todos os livros publicados pela Editora Hawking estão sob os direitos da Creative Commons 4.0 ccommons \\ https://creativecommons.org/licenses/by/4.0/deed.pt_BR}

2021 Editora HAWKING

Rua Luiz Clemente de Vasconcelos, 725B, Clima Bom I. Maceió/AL. CEP 57071-040

www.editorahawking.com.br

editorahawking@gmail.com

\section{Catalogação na publicação}

Elaborada por Bibliotecária Janaina Ramos - CRB-8/9166

O48

Oliveira, Ana Irene Alves de

Coletânea de estudos em integração sensorial / Ana Irene Alves de Oliveira; Danielle Alves Zaparoli (Organizadora), Marcilene Alves Pinheiro (Organizadora). - Maceió: Hawking, 2021.

Livro em PDF

163 p., il.

ISBN 978-65-88220-27-6

1. Terapia ocupacional. 2. Integração sensorial. 3. Transtorno do espectro autista. I. Oliveira, Ana Irene Alves de. II. Zaparoli, Danielle Alves (Organizadora). III. Pinheiro, Marcilene Alves (Organizadora). IV. Título.

CDD 616.89

Índice para catálogo sistemático

I. Terapia ocupacional: Transtorno do espectro autista, Integração Sesnorial 


\section{Direção Editorial}

Dra. Betijane Soares de Barros, Instituto Multidisciplinar de Maceió - IMAS (Brasil).

\section{Conselho Editorial}

Dra. Adriana de Lima Mendonça/Universidade Federal de Alagoas - UFAL (Brasil), Universidade Tiradentes - UNIT (Brasil).

Dra. Ana Marlusia Alves Bomfim/ Universidade Federal de Alagoas - UFAL (Brasil).

Dra. Ana Paula Morais Carvalho Macedo /Universidade do Minho (Portugal).

Dra. Andrea Marques Vanderlei Fregadolli/Universidade Federal de Alagoas - UFAL (Brasil).

Dr. Eduardo Cabral da Silva/Universidade Federal de Pernambuco - UFPE (Brasil).

Dr. Fábio Luiz Fregadolli//Universidade Federal de Alagoas - UFAL (Brasil).

Dra. Maria de Lourdes Fonseca Vieira/Universidade Federal de Alagoas - UFAL (Brasil).

Dra. Jamyle Nunes de Souza Ferro/Universidade Federal de Alagoas - UFAL (Brasil).

Dra. Laís da Costa Agra/Universidade Federal do Rio de Janeiro- UFRJ (Brasil).

Dra. Lucy Vieira da Silva Lima/Universidade Federal de Alagoas - UFAL (Brasil).

Dr. Rafael Vital dos Santos/Universidade Federal de Alagoas - UFAL (Brasil), Universidade Tiradentes - UNIT (Brasil).

Dr. Anderson de Alencar Menezes/Universidade Federal de Alagoas - UFAL (Brasil).

Dr. Patrocínio Solon Freire/Instituto Federal de Pernambuco - IFPE (Brasil). 


\title{
Equipe técnica (mídia) e administrativa (secretaria geral)
}

\author{
Miguel Formigosa Siqueira Ferreira \\ Rogério Ferreira Bessa
}

\section{Revisores}

ANA AMÉLIA CARDOSO RODRIGUES: Graduada em Terapia Ocupacional pela Universidade Federal de Minas Gerais (2003) e mestre (2006) e doutora em Ciências da Reabilitação (2011) pela mesma universidade. Professora Adjunta do Departamento de Terapia Ocupacional da Universidade Federal de Minas Gerais. Possui Certificação Internacional em Integração Sensorial pela University of Southern California (USC). Docente permanente do curso de Mestrado em Estudos da Ocupação e da Especialização em Transtornos do Espectro do Autismo, ambos da UFMG. Tem experiência na área de Terapia Ocupacional, docência e pesquisa, com ênfase em Desenvolvimento Infantil, atuando principalmente nos seguintes temas: Transtorno do Espectro Autista, transtorno do desenvolvimento da coordenação, transtorno do déficit de atenção e hiperatividade, avaliação do desenvolvimento e desempenho infantil, Integração Sensorial, inclusão. escolar, transtornos de aprendizagem. Coordenadora do PRAIA - Programa de Atenção Interdisciplinar ao Autismo. Docente do curso de Certificação Brasil Integração Sensorial.

ANA IRENE ALVES DE OLIVEIRA: Graduada em Terapia Ocupacional, Bacharel em Psicologia, Doutorado em Psicologia - Teoria e Pesquisa do Comportamento pela Universidade Federal do Pará/UFPA, Mestre em Motricidade Humana pela Universidade do Estado do Pará/ UEPA, Especialista em Desenvolvimento Infantil no conceito Neuro evolutivo Bobath. Curso com Certificação em Integração Sensorial, certificado pela Clínica Integre/SP. Curso Avançado em Combining Sensory Integration with Evolutionary Neuro Concept - Mary Hallway. Docente 
fundadora do curso de Terapia Ocupacional da UEPA. Coordenadora do Curso de Pós-Graduação Lato Senso em Desenvolvimento Infantil, que está no se sétimo ano de execução consecutiva. Fez estágio na cidade de New Jersey (USA) em 1997, em 2004, fez intercâmbio, através dos Partners of América em St. Louis / Missouri (USA). Desenvolveu o Software com acessibilidade Desenvolver® em 2004, ganhou em 2005, o Prêmio FINEP, Região Norte na Categoria Inovação Social, em 2007 ganhou menção honrosa no Prêmio FINEP e ganhou o Prêmio Nacional Direitos Humanos da Presidência da República na categoria defesa dos direitos da Pessoa com Deficiência. Participa do Comitê Pará Missouri de forma voluntária. Autora de diversos livros e capítulos e artigos publicados. Membro da Sociedade Internacional de Comunicação alternativa - ISAAC Brasil. Coordenadora do Centro Especializado em Reabilitação CER III/UEAFTO/UEPA e do NEDETA (Núcleo de Tecnologia Assistiva e Acessibilidade). Coordenadora Acadêmica do Curso de Certificação Brasileira em Integração Sensorial.

ARLA LOBO: Graduada em Terapia Ocupacional pela Universidade do Estado do Pará,Ergothérapeutes du Québec - OEQ, Pós-graduada em Educação e Reeducação Psicomotora pela UERJ, Curso Básico Neuroevolutivo Infantil Conceito Bobath (Instrutora: Monika Müller), Curso Básico de Avaliação e Tratamento do Paciente Hemiplégico - Conceito Bobath (Instrutora: Sheena Irwin Carruther - África do Sul), Curso de Integração Sensorial: Supporting Outcomes Thru Sensory Integration (Instrutora: Madonna Nash - E.U.A.), Ministrante do Curso (teórico/prático): Vivenciando a Prática do Conceito Neuroevolutivo Bobath com Crianças que apresentam Disfunção Neuromotora,, Ministrante da Aula de Terapia Ocupacional do Curso de Avaliação e Tratamento do Paciente Hemiplégico Adulto (Centro de Estudos Drª . Monika Müller/RJ,Em formação à Instrutora do Curso do Curso do Conceito Neuro Evolutivo Bobath /ABDAN. Docente do cur: Certificação Brasileira em Integração Sensorial.

DANIELLE ALVES ZAPAROLI: Terapeuta Ocupacional graduada pela Universidade de Fortaleza (2001). Possui experiência na área da Terapia Ocupacional, com ênfase em Atendimento Ocupacional Adulto, Neuro-Pediátrico (Autismo), Residência em Saúde Mental, Bobath, Therasuit, Certificação Internacional em Integração Sensorial (USC- Universidade do Sul da Califórnia), Adequação Postural e Seating, 
Prescrição de Recursos Assistivos. Presidente da Comissão de Ética do CREFITO6. Coordenadora técnica - Administrativa do Curso de Certificação Brasileira em Integração Sensorial.

LÍVIA DE CASTRO MAGALHÃES: Graduada em Terapia Ocupacional pela Faculdade de Ciências Médicas de Minas Gerais (1979), mestrado em Terapia Ocupacional na Boston University (1987), doutorado em Educação - University of Illinois (1995) e pós-doutorado em Terapia Ocupacional - Universidade de McMaster. Atualmente, é professora Emérita do Departamento de Terapia Ocupacional da Universidade Federal de Minas Gerais. Pesquisadora Nível 2 do CNPq. Docente permanente do Programa de Pós-graduação em Ciências da Reabilitação e do mestrado em Estudos da Ocupação da Universidade Federal de Minas Gerais (UFMG). Tem experiência na área de Terapia Ocupacional, com ênfase no desenvolvimento de testes e medidas para avaliar o desenvolvimento motor e desempenho ocupacional em crianças, e em estratégias de intervenção com crianças com problemas de coordenação motora. Coordena programa de acompanhamento do crescimento e desenvolvimento de recém-nascidos pré-termo e os tópicos de interesse em pesquisa são: impacto da prematuridade no desenvolvimento infantil, Terapia Ocupacional com crianças, avaliação da coordenação motora e estratégias para tratamento do transtorno da coordenação motora. Docente do curso de Certificação Brasileira em Integração Sensorial.

MARCELO MARQUES CARDOSO: Terapeuta Ocupacional pela Universidade do Estado do Pará (UEPA, 2001-2005), Doutor pelo Programa de Pós-Graduação em Neurociências e Biologia Celular (PPGNeuroBC), Instituto de Ciências Biológicas (ICB) da Universidade Federal do Pará/ UFPA (2008-2010). Docente da Faculdade de Fisioterapia e Terapia Ocupacional, Instituto de Ciências da Saúde da Universidade Federal do Pará (FFTO - ICS - UFPA). Docente do curso c Certificação Brasileira em Integração Sensorial.

MARCILENE ALVES PINHEIRO: Terapeuta Ocupacional graduada pela Universidade do Estado do Pará. Mestre em Teoria e Pesquisa do Comportamento pela Universidade Federal do Pará. Certificação Internacional em Integração Sensorial (WPS/University Southern of California). Pesquisadora bolsista do Núcleo 
de Desenvolvimento em Tecnologia Assistiva e Acessibilidade (NEDETA). Foi bolsista da CAPES e participa do Grupo de Pesquisa (CNPQ) Inovação Tecnológica e Inclusão Social da Universidade do Estado do Pará. Docente do curso de Certificação Brasileira em Integração Sensorial.

RAFAEL LUIZ MORAIS DA SILVA: Graduação em Terapia Ocupacional pela Universidade do Estado do Pará (2006). Especialização em Desenvolvimento Infantil (2008), com Formação em Estimulação e Educação Psicomotora (2009). Mestre em Teoria e Pesquisa do Comportamento/UFPA (2011). Doutor em Ciências da Reabilitação (UNINOVE/SP). Certificação Internacional em Integração Sensorial (WPS/University Southern of California). Terapeuta Ocupacional na Unidade de Ensino-Assistência de Fisioterapia e Terapia Ocupacional (UEAFTO-UEPA). É Professor Assistente do Departamento de Terapia Ocupacional (DETO) da Universidade do Estado do Pará e Diretor da Clínica Sense Kids Terapias Especializadas e Play Sense Terapia Ocupacional Pediátrica. Membro do grupo de pesquisa Inovação Tecnológica e Inclusão Social. É membro da ISAAC-Brasil (Sociedade Internacional de Comunicação Alternativa e Aumentativa). Desenvolve atuação clínica e de pesquisa sobre os seguintes temas: ocupações na infância, desenvolvimento infantil atípico, avaliação e intervenção terapêutica e Integração Sensorial. Docente do curso de Certificação Brasileira em Integração Sensorial. 
SAMARA DE ARAÚJO COSTA: Graduação em Terapia Ocupacional pela Universidade Federal de Minas Gerais (2015); Mestrado em Ciências da Reabilitação pela UFMG (2018); Certificação completa em Integração Sensorial pelo Programa USC Chan de Certificação e Educação Continuada da Universidade do Sul da Califórnia; Curso Prático de Experiência em Avaliação e Tratamento em Integração Sensorial pela Therapy West Inc. \& pLAy Studio (EUA); Experiência no exterior pelo programa Ciência Sem Fronteiras CAPES/IIE (EUA); Experiência em Terapia Ocupacional pediátrica, principalmente com crianças com Transtorno do Espectro Autista (TEA), Transtorno do Desenvolvimento da Coordenação (TDC) e outras dificuldades de aprendizagem. Amplo domínio em diversas avaliações do desenvolvimento e desempenho infantil, como Escala Bayley III, Teste Movimento ABC, Teste Beery VMI, Perfil Sensorial, Medida do Processamento Sensorial (SPM), Observações Clínicas Estruturadas de Integração Sensorial, dentre outras. Docente do curso de Certificação Brasileira em Integração Sensorial. 


\section{SUMÁRIO}

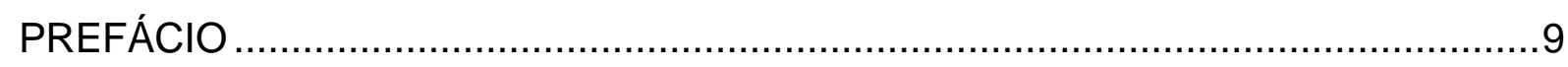

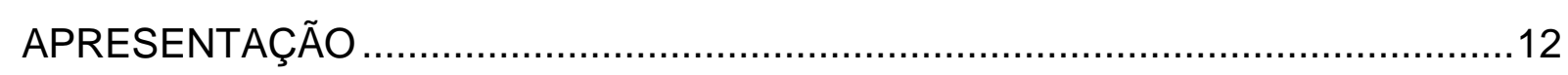

A AÇÃO PROPRIOCEPTIVA DOS TRAJES COMPRESSIVOS NO TRANSTORNO

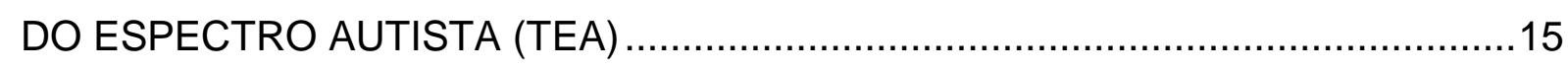

INTERVENÇÃO DA TERAPIA OCUPACIONAL COM CRIANÇAS COM TRANSTORNO DO ESPECTRO AUTISTA (TEA) QUE APRESENTAM SELETIVIDADE ALIMENTAR USANDO A ABORDAGEM DE INTEGRAÇÃO SENSORIAL: uma revisão da literatura.

EQUOTERAPIA SOBRE A PERSPECTIVA DA INTEGRAÇÃO SENSORIAL: revisão de literatura 32

A ABORDAGEM DE INTEGRAÇÃO SENSORIAL NO TRATAMENTO DE CRIANÇAS COM PARALISIA CEREBRAL. 48

OS IMPACTOS DA HIPER-RESPONSIVIDADE TÁTIL NO DESENVOLVIMENTO DE CRIANÇAS COM TRANSTORNO DO ESPECTRO AUTISTA. 60

MAPEAMENTO DE RESULTADOS EM INTERVENÇÕES BASEADAS NA INTEGRAÇÃO SENSORIAL EM FUNÇÕES NEUROLÓGICAS RELACIONADAS AO EQUILÍBRIO E À LINGUAGEM

RELAÇÃO ENTRE INTEGRAÇÃO SENSORIAL E O BRINCAR EM CRIANÇAS COM TEA

A ESCRITA SOB O OLHAR DA TEORIA DE INTEGRAÇÃO SENSORIAL DE AYRES .95

REFLEXÕES SOBRE AS POSSÍVEIS PRIVAÇÕES SENSORIAIS CAUSADAS PELA PANDEMIA DO COVID-19 E SUAS REPERCUSSÕES PARA O DESENVOLVIMENTO INFANTIL

O TRATAMENTO DA SELETIVIDADE ALIMENTAR EM CRIANÇAS COM TRANSTORNO DO ESPECTRO AUTISTA (TEA), SOB A PERSPECTIVA DA INTEGRAÇÃO SENSORIAL: uma revisão da literatura 130 


\section{PREFÁCIO}

"Da verdade, assim como do infinito, podemos sempre aproximar, mas nunca alcançar." (Ayres, 1972, p. 4).

Faz mais de 40 anos que comecei a me interessar pelos trabalhos de A. Jean Ayres e a Terapia de Integração Sensorial. No segundo ano de faculdade tive aulas com a Terapeuta Ocupacional norte americana Roselyn Ruth Van Benschoten Armstrong, ou Rose, na época fazendo serviço voluntário no Brasil, nas quais ela apresentou os princípios da terapia e, mais que isso, falou sobre o trabalho de pesquisa de Ayres. Num curso bastante voltado para a área médica, no qual tínhamos pouco acesso a referenciais teóricos e estudos específicos de Terapia Ocupacional, essas aulas acenderam uma luz - existe pesquisa em Terapia Ocupacional? Como vamos fazer para aprender mais sobre isso? Na época, juntamente com duas colegas também encantadas pelo novo conhecimento, embarcamos de corpo e alma, até o final do curso, em estágio oferecido por Rose num instituto com internato para crianças com deficiência visual.

Aprendemos muito sobre Terapia Ocupacional. Atuávamos com crianças com histórias de vida complexas, com situações de privação afetiva e sensorial, que se manifestavam por problemas severos de comportamento, que íamos reinterpretando com a ajuda de Rose: será que Pedro é tão "agressivo" por que não suporta contato físico ou a proximidade de outras crianças? Será que a Maria, que só come do mingau matinal, tem aversão a textura dos alimentos? Será que baixa discriminação tátil ajuda a explicar porquê João não consegue identificar a posição dos pontinhos no Braile? O que será que a Aninha procura ao balançar o corpo para frente e para trás de maneira tão vigorosa? Fomos aos poucos aprendendo a "ver" comportamento ou movimento e "pensar" sensação, conhecimento que transformávamos em desafios na "medida certa", na terapia individual com as crianças, e em informações que ajudavam a equipe e cuidadores do instituto a ver as crianças de uma nova forma. As mudanças observadas com a intervenção, associadas ao acesso aos trabalhos originais de Ayres, que traduzíamos com ajuda do dicionário, palavra por palavra, nos tornaram entusiastas da integração sensorial e conscienciosas da importância de divulgar e zelar pelo conhecimento nessa área. 
Embora eu tenha dedicado muitos anos à clínica e sempre mantenha algum tipo de atendimento, mergulhei na pesquisa, por acreditar que não existe clínica sem pesquisa. O que me encantou na Integração Sensorial foi a disciplina e firmeza de Ayres em se tornar pesquisadora, numa época em que a profissão ainda era eminentemente técnica, e seu empenho em tentar desvendar os mistérios do cérebro para promover oportunidades adequadas de aprendizado a crianças que tinham dificuldade escolar. Quando a conheci, a Dra. Ayres, como a tratávamos respeitosamente na clínica, também despertou minha admiração por seu rigor científico e, ao mesmo tempo, pela simplicidade ao nos mostrar os equipamentos de terapia que construía com a ajuda do marido, ao experimentar os balanços antes de usar ou ao cruzar a sala agilmente no carrinho de rolimã, brincando com algum cliente. Ela tratava cada criança como única, nos fazia perguntas complicadas e exigia a busca pelos conhecimentos mais recentes para entender as crianças, nos estimulando a fazer o que hoje denominamos prática baseada em evidências.

É isso que acredito que estamos fazendo ao editar esta coletânea de textos. Quando fui convidada, juntamente com colegas do Brasil, a ministrar aulas sobre protocolos de pesquisa no I Curso de Certificação Brasileira em Integração Sensorial, não pude recusar. Sempre acreditei ser vital incentivar o desenvolvimento de recursos locais e valorizar colegas que se capacitaram e querem compartilhar conhecimento. A decisão foi acertada, a primeira turma não só concluiu o curso com sucesso, mas também aceitou o desafio de produzir conhecimento.

Cada grupo, sob orientação de docentes do curso, identificou uma pergunta clínica relevante para seu contexto de trabalho, e saiu em busca de evidências para a prática clínica. Não satisfeitos, compartilham essas evidências em artigos de revisão de literatura escritos com muito esforço, nas horas "vagas", entre atendimentos, ou depois que as crianças foram deitar. Confesso que, a princípio, não achei que fosse possível, mas Ana Irene é persistente e, assim como Ayres, enfrentou desafios, improvisou orientadores e estimulou a turma a produzir os dez trabalhos aqui apresentados. Como primeira produção do curso, aprendemos fazendo. O tempo foi curto, há pontos fortes e fracos, mas, indiscutivelmente, os trabalhos expressam o esforço para produzir conhecimento local, para ir além das aulas e do "saber fazer", avançando, mesmo que de maneira tímida, para embasar a prática em pesquisa e compartilhar o que foi aprendido. 
Estamos todos de parabéns! Espero que estudantes e colegas terapeutas apreciem estes trabalhos. Espero que eles inspirem os novos alunos do curso ou, quem sabe, as perguntas levantadas estimulem o interesse pelo mestrado e doutorado, para contribuir de maneira mais consistente para a construção de conhecimento em Terapia Ocupacional. Terapia de Integração Sensorial não é a solução para todas as crianças ou clientes que nos procuram, nem a estratégia única para determinados diagnósticos, mas seu uso consciencioso, apoiado em evidências científicas, juntamente com outros referenciais teóricos e recursos da terapia ocupacional, nos dão uma base sólida para avaliar, intervir e, especialmente, mudar de estratégia ou interromper o tratamento quando os resultados esperados não são alcançados.

Assim como Ayres, que, ao afirmar que podemos nos aproximar da verdade, mas nunca alcançar, reconhecia a complexidade e o caráter provisório da Teoria de Integração Sensorial, as revisões aqui apresentadas expõem as limitações do conhecimento na área, a necessidade de mais pesquisas e de nos mantermos atualizados para prestar serviços de qualidade às crianças e famílias que nos procuram. Há muitos anos trabalhando na área e ciente da necessidade de mais materiais de qualidade em português, espero que este seja apenas o início. Que as novas turmas aceitem o desfio e produzam trabalhos ainda mais interessantes e relevantes para a prática da Terapia Ocupacional.

Profa. Dra.Lívia de Castro Magalhães 


\section{APRESENTAÇÃO}

A presente coletânea de pesquisa em Integração Sensorial, ora publicada sob o título Coletânea de Estudos em Integração Sensorial, reúne um conjunto de trabalhos científicos conduzidos por professores e discentes do I CURSO DE CERTIFICAÇÃO BRASILEIRA EM INTEGRAÇÃO SENSORIAL, promovido pela Integris Terapias, Cursos e Eventos, em parceria com a Universidade do Estado do Pará (UEPA).

Trata-se de um produto originário das pesquisas científicas dos grupos de alunos que participaram deste curso que abordam temas de interesse na área com resultados que demonstram a investigação científica de temas que abordam a interação com a Integração Sensorial. Como característica da obra, os diversos assuntos abordados são tratados de forma aprofundada e com amplo embasamento na bibliografia da área, o que confere a cada capítulo a qualidade científica pela qual todo trabalho acadêmico deve primar.

A coletânea é composta por dez capítulos, frutos de revisão bibliográfica e estudos teóricos. Os autores e coautores pertencem a Instituições diversas com atuação clínica em Terapia Ocupacional, com base na Teoria de Integração Sensorial da Jean Ayres.

Assim, no capítulo 1, Annelise Soares Rodrigues, Francisco Geison Lopes de Morais, Jérsica Carvalho Falcão de Souza e Ana Irene Alves de Oliveira, abordam a ação proprioceptiva dos trajes compressivos no Transtorno do Espectro Autista (TEA), temática considerada de grande relevância, uma vez que se observa na prática clínica os benefícios do uso de trajes compressivos em crianças com Transtorno do Espectro Autista (TEA) e também devido à existência de poucos estudos relacionados a este tema.

No capítulo 2, Roseane Mesquita da Silva Pantoja, Suane Nascimento de Sousa, Tatyane Mieli Pamplona Porto e Vanessa Rafaelle Brasil de Souza, realizaram uma revisão da literatura sobre a intervenção da Terapia Ocupacional com crianças com Transtorno do Espectro Autista (TEA), que apresentam seletividade alimentar, usando a abordagem de Integração Sensorial. $O$ estudo aponta que as crianças com TEA apresentam comportamentos tendenciosos na 
seletividade alimentar e a intervenção precoce do Terapeuta Ocupacional no tratamento contribui para amenizar as questões da seletividade alimentar.

No capítulo 3, Débora Cristina dos Santos Pereira Tavares, Lenicy de Fátima Pina Ferreira, Raquel Bezerra da Silva e Marcilene Alves Pinheiro, realizam uma revisão integrativa da literatura com um estudo descritivo, exploratório e retrospectivo, investigam a Equoterapia sobre a perspectiva da Integração Sensorial, constatando a importância de incentivo à publicação científicas relacionadas à temática.

No capítulo 4, Gyselle da Silva Coutinho, Isabelly Nair Barbosa Camelo, Mariane da Silva Miranda e Arla Lobo Fonseca, através de uma revisão bibliográfica de natureza básica, com caráter exploratório, realizaram um estudo sobre a abordagem de Integração Sensorial no tratamento de crianças com Paralisia Cerebral, onde ressalta a possibilidade de combinação da abordagem de Integração Sensorial com outros métodos de tratamento para essas crianças.

No capítulo 5, Brenda Monteiro Maia, Tatiane Costa dos Santos e Samara de Araújo Costa, após o estudo de revisão bibliográfica, concluíram que crianças com TEA que apresentam hiper-responsividade tátil podem ter dificuldades com aceitação do toque social, ansiedade, dificuldades de aprendizagem, entre outras, que geram impactos no desenvolvimento.

No capítulo 6, Anne Caroline Cesar Ribeiro, Elizabeth S. F. S. Farias, Maria L. P. dos Santos, Patrícia X. Mente, Vanessa M. Perin e Marcelo Marques Cardoso, realizaram o mapeamento de resultados em intervenções baseadas na Integração Sensorial em funções neurológicas relacionadas ao equilíbrio e à linguagem, concluindo que as intervenções que utilizam a Integração Sensorial a partir de variáveis relacionadas à linguagem e/ou equilíbrio manifestam desfechos promissores, apesar da baixa evidência entre as publicações disponíveis.

No capítulo 7, Tatiane Lima Menezes Barreto, Nayara Couto de Carvalho, Michele de Sena Cruz, Alexsarah de Souza Monteiro, Daniele da Costa Soares e Ana Amélia Cardoso, realizaram uma revisão narrativa da literatura sobre estudos que descrevam o impacto dos transtornos de processamento sensorial no brincar das crianças com TEA, e sugerem que a Terapia da Integração Sensorial é uma abordagem de intervenção da Terapia Ocupacional, que pode ter efeitos positivos no desenvolvimento da aprendizagem desses indivíduos. 
No capítulo 8, Alice Vicentin Nieton, Maria Socorro Aquino Silva Neuza Soraya Teixeira Coelho Fontes, Kellen Nunes de Souza Borges e Rafael Luiz Morais da Silva, investigaram através de uma revisão bibliográfica, a escrita sob o olhar da Teoria de Integração Sensorial de Ayres, revelando a importância de avaliações apropriadas relativas ao desempenho da função motora fina, sensorial e perceptiva da criança.

No capítulo 9, Maria Carolina Ferreira Neves, Maria de Fátima Góes da Costa e Ana Irene Alves de Oliveira, através de pesquisa bibliográfica do tipo revisão narrativa, com caráter descritivo e exploratório e abordagem qualitativa, apontaram as possíveis privações sensoriais causadas pela pandemia do COVID-19 e suas repercussões para o desenvolvimento infantil, identificando mudanças, com comprometimento de sistemas sensoriais, inferindo possíveis repercussões para o desenvolvimento infantil.

No capítulo 10, Brenda Maíra Fernandes de Andrade, Bruna Leal Lopes, Cristiane Pinheiro Matias, Vanessa Rafaelle Brasil, realizaram uma revisão de literatura do tipo revisão narrativa, abordando a temática sobre tratamento da seletividade alimentar em crianças com Transtorno do Espectro Autista (TEA), sob a perspectiva da Integração Sensorial, evidenciando o risco de problemas nutricionais nas crianças que apresentam seletividade alimentar, sugerindo a necessidade de estudos abordando o tema e a necessidade de intervenção específica e o uso da Integração Sensorial nas sessões de Terapia Ocupacional.

Os textos escritos, certamente, servirão como referência para o desenvolvimento de pesquisas futuras, no bojo de novos projetos e na continuidade de temas de pesquisas consolidadas.

Prof. Dra. Ana Irene Alves de Oliveira Prof. Esp. Danielle Alves Zaparoli Prof. Ms. Marcilene Alves Pinheiro 


\title{
A AÇÃO PROPRIOCEPTIVA DOS TRAJES COMPRESSIVOS NO TRANSTORNO DO ESPECTRO AUTISTA (TEA)
}

\author{
Annelise Soares Rodrigues ${ }^{1}$ \\ Francisco Geison Lopes de Morais ${ }^{1}$ \\ Jérsica Carvalho Falcão de Souza ${ }^{1}$ \\ Ana Irene Alves de Oliveira ${ }^{2}$
}

\begin{abstract}
RESUMO
A presente pesquisa aborda uma temática considerada de grande relevância, uma vez que se tem observado na prática clínica os benefícios do uso de trajes compressivos em crianças com Transtorno do Espectro Autista (TEA) e também devido à existência de poucos estudos relacionados a este tema. Embora trajes compressivos destinados à ação proprioceptiva sejam bastante utilizados como recurso terapêutico no TEA, identifica-se que o conhecimento sobre seus benefícios para esses indivíduos ainda é limitado. A temática do estudo, objetiva contribuir para o entendimento da utilização de trajes compressivos no tratamento de pessoas com TEA, seus prováveis resultados e suas ações proprioceptivas. $E$, ainda, embasar o uso terapêutico dessas vestes para atendimento aos diversos encaminhamentos médicos para a utilização desse procedimento. Procurou-se compreender as bases sensoriais, motoras e os comportamentos observados, além das funções influenciadas pelo uso desse tipo de traje. O método é de revisão de literatura, do tipo Scoping Review, por meio de busca e seleção de materiais e artigos científicos em periódicos nas bases de dados SciELO (Scientific Eletronic Library of Medicine) e Google Acadêmico. Não foram encontrados muitos estudos relacionados ao tema, o que tornou sua construção mais complexa. Os artigos localizados tratam da verificação e esclarecimento acerca das funções dos trajes compressivos e suas ações proprioceptivas em TEA. Conclui-se que há pouca evidência sobre a eficácia do uso de trajes compreensivos em pessoas com TEA, apesar de, na nossa prática clínica, visualizarmos possível eficácia.
\end{abstract}

Palavras-chave: Alterações Sensoriais. Propriocepção. Trajes Compressivos. Transtorno do Espectro Autista.

\section{INTRODUÇÃO}

O Transtorno do Espectro Autista (TEA) caracteriza-se por uma série de alterações, onde destacamos. principalmente, alterações comportamentais, nos parâmetros sociais e de comunicação, necessitando de um diagnóstico clínico por meio de avaliação minuciosa do comportamento e do desenvolvimento,

\footnotetext{
${ }^{1}$ Terapeutas Ocupacionais.

2Terapeuta Ocupacional/UNIFOR, Doutora em Teoria e Pesquisa do Comportamento/UFPA, Coordenadora do Curso de Certificação Brasileira em IS - Integris/UEPA, Orientadora do trabalho.
} 
possibilitando a realização das intervenções para que mudanças positivas e significativas ocorram (PAULINO, 2015).

Nos últimos anos, as pesquisas e as buscas por assuntos relacionados ao TEA veem aumentando e visam cada vez mais a ampliação do conhecimento sobre o que é o TEA e suas causas, além da busca de novas estratégias de tratamento, do aprimoramento de técnicas já existentes e a detecção cada vez mais precoce do diagnóstico, o que nos permite entender de forma mais precisa, eficaz e precocemente, favorecendo, assim, o desenvolvimento de meios mais adequados para as intervenções terapêuticas.

Temos observado um grande número de diagnósticos de crianças acometidas com TEA. Essa crescente demanda tem provocado uma busca contínua de formas de tratamento que contemplem a questão. A atividade profissional desenvolvida pelos autores deste artigo propiciou a confirmação no aumento de encaminhamentos médicos para programas de tratamento que envolva trajes compressivos. O desconhecimento de trabalhos científicos que propiciem clareza nos resultados desta forma de abordagem, despertou o interesse de pesquisar o que já havia de discussão acerca do tema. Pelo fato da temática abordada, ser bem ampla e desenvolver diversos pontos, nesta pesquisa, foram delimitadas as contribuições e características dos trajes compressivos e suas ações nas funções proprioceptivas da criança com TEA (BRITES, 2016).

A literatura confirma que alterações sensoriais são bastante comuns em caso de TEA (SCHMIDT, 2012). Em um trabalho comparativo realizado com 281 crianças com TEA e 281 crianças sem o diagnóstico, na faixa etária de 3 a 6 anos, Tomchek e Dunn, citados por Mattos (2019), demonstraram que a maioria das crianças com TEA apresenta alterações no processamento sensorial. Essa reatividade sensorial, confirmada em muitos estudos que relatam indivíduos com TEA, pode ser a chave para entender muitos de seus comportamentos atípicos, constituindo-se num importante aspecto a ser observado nos processos de tratamento. No arcabouço das descrições dos sistemas sensoriais, neste estudo, destacamos o sistema proprioceptivo.

O entendimento do sistema proprioceptivo se faz necessário para uma análise da utilização de trajes compressivos e sua correlação com este sistema. Os numerosos receptores sensoriais situados pelo corpo transmitem ao nosso cérebro as informações acerca dos movimentos e a posição deste no espaço, estando 
também relacionado a outros sistemas sensoriais. É através da propriocepção que podemos colocar a mão no nariz sem vê-lo, de andar pela sala, também no escuro, esbarrar com os móveis, de gerenciarmos um alimento na boca para mastigar e engolir, e muitas outras ações que esse sistema pode estar envolvido.

Schmidt (2012) relata que o contato físico direto com outras pessoas consiste em uma experiência sensorial extremamente desagradável, praticamente insuportável, para uma pessoa com TEA. Temple Grandin, diagnosticada com Autismo de alta funcionalidade, em meados da década de 1950, através das suas experiências pessoais, criou a máquina do abraço, numa tentativa de minimizar os infortúnios decorrentes das alterações sensoriais em si e em outras pessoas com problemas semelhantes. Alguns estudos científicos se dedicaram a verificar a eficácia desta máquina de Temple Grandin, demonstrando uma sensível redução sobre os níveis de tensão, ansiedade, estereotipias e comportamentos disruptivos em pessoas com TEA.

\subsection{Caracterizando o Transtorno do Espectro Autista (TEA)}

O Transtorno do Espectro Autista (TEA) é um transtorno do desenvolvimento que, geralmente, é diagnosticado por volta dos três anos de idade, sendo um distúrbio neurológico que compromete a habilidade de comunicação, de interação com o meio e na maneira convencional de aprender. Além disso, também é caracterizado por comportamentos, atividades e interesses restritos, repetitivos e estereotipados (SILVA, 2012).

Cardoso e Blanco (2019) apresentam uma definição para o TEA como sendo um conjunto de aspectos diagnósticos, os quais podemos destacar dificuldades comunicativas (verbais e não verbais), sociais, de participação, comportamentos estereotipados e isolados que interferem diretamente no desempenho ocupacional do indivíduo.

\footnotetext{
Segundo a Organização Mundial de Saúde (OMS, 1993), caracteriza-se por anormalidades qualitativas nas três áreas seguintes: interação social, comunicação e comportamentos, que é restrito e repetitivo e atividades estereotipadas. (SOARES; BRAGA, 2014, p. 80).
}

Sua prevalência é de cinco casos em cada dez mil nascimentos. Caso se adote um critério de classificação mais rigoroso, a prevalência é três vezes maior se consideramos casos correlatados, isto é, que necessitam do mesmo tipo de 
atendimento (BRITO, 2015). As causas para o TEA ainda são desconhecidas, apesar de existirem vários estudos e pesquisas na busca de desvendar a origem deste transtorno tão complexo e incapacitante. Este transtorno é identificado pelos sintomas e características que surgem ao longo do desenvolvimento.

As primeiras descrições do Autismo foram feitas nos anos 1940, no âmbito educacional, e a influência dos modelos explicativos sobre o Autismo, ao longo da história, determinou as primeiras iniciativas de intervenção no ensino que, entretanto, foram muito específicas e distanciadas daquelas desenvolvidas no meio social naquela época.

É de fundamental importância ressaltar que cada pessoa com TEA tem características e limitações próprias, isso significa que uma pessoa com TEA dificilmente se comportará igual à outra com o mesmo diagnóstico. Outro fator que também precisa ser mencionado é o fato de que o TEA não tem cura, no entanto, observa-se melhora significativa com o tratamento adequado (PRAÇA, 2011).

Esse tratamento também é algo que não pode ser feito de uma maneira única, ou seja, não existe tratamento único ou específico para o TEA, por isso, o mesmo pode ser realizado através de modificação do comportamento, educação e, ainda, a base de medicações, dietas, suplementos e Terapia de Integração Sensorial de Ayres (Ayres Sensory Integration - ASI), sendo esta última uma das abordagens mais utilizadas pelos Terapeutas Ocupacionais (PRAÇA, 2011).

Indivíduos com TEA apresentam quadro clínico com características de déficits na comunicação e interação, sendo interessante ressaltar as alterações sensoriais as quais nem sempre são percebidas devido à falta de comunicação dessas pessoas, pode-se destacar que diversos tipos de alterações sensoriais podem estar presentes no mesmo indivíduo ao mesmo tempo (POSAR; VISCONTI, 2018).

\subsection{A Integração Sensorial de Ayres e os Sistemas Sensoriais}

A Integração Sensorial foi desenvolvida na década de cinquenta, por Anna Jean Ayres, Terapeuta Ocupacional, psicóloga educacional e neurocientista, tornando-se uma das primeiras teorias formuladas na prática da Terapia Ocupacional com evidencias científicas validando sua prática (ROLEY et al., 2007). Ayres definiu a Integração Sensorial como o "[...] processo neurológico que organiza as sensações do próprio corpo e do ambiente, e torna possível usar o corpo eficientemente no meio. As sensações nos fornecem informações sobre a condição 
física do nosso corpo e do nosso ambiente." É um processo inconsciente que organiza as informações obtidas com o auxílio dos sentidos (paladar, visão, audição, olfato, tato, propriocepção e vestibular), dá significado aos sentimentos que vivenciamos ao filtrar as informações e escolher o que focar, permite-nos agir de forma significativa e reagir à situação em que nos encontramos (resposta adaptativa); e constitui a base para a aprendizagem teórica e comportamento social (AYRES,1989).

Sabe-se que, inicialmente, esta terapia foi destinada a pessoas com distúrbios de aprendizagem e hoje é utilizada para o tratamento de várias patologias que apresentem algum tipo de disfunção no processamento sensorial (WATANABE et al., 2015).

Segundo Mendes e Costa (2017), a Integração Sensorial é o processo neurológico que organiza as sensações entre o corpo de um indivíduo e do ambiente e torna o uso eficiente do corpo no ambiente. Recebemos diariamente informações sensoriais por sete sistemas diferentes: olfato, paladar, audição, visão, tato, proprioceptivo e vestibular. Sendo estes dois últimos menos conhecidos, porém, de importância fundamental. No processo de Integração Sensorial, os sistemas vestibular, proprioceptivo, tátil e visual possuem alta importância.

Os sistemas sensoriais, de acordo com Serrano (2018), apresentam características que contribuem para o processamento das informações externas.

a. O sistema tátil, o qual se localiza em toda a extensão da pele, é responsável por produzir e controlar reações a tudo que tocamos, tendo extrema importância para nosso desenvolvimento;

b. O sistema vestibular apresenta receptores no ouvido interno, o qual é ativado pelos movimentos e responsável pelo equilíbrio e por transmitir informações de estabilidade ou de movimentação ao corpo;

c. O sistema proprioceptivo nos proporciona uma consciência corporal, seus receptores encontram-se nos músculos, articulações e ligamentos, o mesmo é responsável por dar informações acerca de intensidade na qual executamos uma atividade;

d. O sistema gustativo localiza-se na boca tendo seus receptores na língua e é responsável por identificar uma diversidade de sabores;

e. O sistema auditivo também tem seus receptores no ouvido interno, todavia, o mesmo recebe as ondas sonoras e as transformam em 
informações que serão levadas ao tronco cerebral e, posteriormente, redirecionadas a outros hemisférios cerebrais;

f. O sistema olfativo tem seus receptores localizados no nariz e nos permitem uma capacidade de sentir cheiros. O mesmo está intimamente ligado ao sistema gustativo;

g. O sistema visual apresenta seus receptores nos olhos, é classificado como um dos mais complexos, pois o mesmo está intimamente ligado ao processo de aprendizado;

h. O sistema vestibular, dentro do desenvolvimento das habilidades sensoriais, é um dos mais básicos. Trata-se de um sistema responsável por informar ao cérebro sobre movimento e posição da cabeça no espaço. Enquanto a propriocepção informa sobre a posição das articulações do corpo, permitindo respostas de estabilidade articular, graduação de força, direção e ritmo do movimento.

Já os demais sistemas, mais conhecidos no senso comum, permitem discriminar informações do ambiente e produzir uma sequência de ações a partir disso, Molleri et al. (2010) relata que o Processo de Integração Sensorial acontece em cinco estágios:

1. Registro sensorial: é o reconhecimento da sensação;

2. Orientação e atenção: é a atenção seletiva específica ao estímulo;

3. Interpretação: é o significado da sensação. Este componente é cognitivo, uma vez que interpretamos a sensação à luz da experiência e aprendizados anteriores, além de atribuirmos o caráter emocional às sensações;

4. Organização da resposta: organizada cognitivamente, afetiva e motoramente;

5. Execução da resposta: o último estágio da Integração Sensorial é o único que pode ser diretamente observado. Isso traz fundamentos para se pensar nos comportamentos resultantes dos processos de Integração Sensorial e nas bases sensoriais de autorregulação.

A chave do tratamento utilizando a Terapia de Integração Sensorial está em promover uma aliança com a criança, seguir sua liderança e propor desafios na medida certa para apoiar a sua participação em brincadeiras e experiências com movimento e diferentes sensações que auxiliam o desenvolvimento do esquema 
corporal e consciência ambiental, para que ela possa, assim, ter sucesso em atividades escolares, de autocuidado e lazer (GAMA, 2018).

Segundo Parham et al. (2011), oferecer oportunidades sensoriais, apresentar desafios "na medida certa", favorecer a participação da criança na escolha das atividades, guiar a auto-organização, assegurar a segurança física, criar um ambiente motivador e estruturar a aliança terapêutica são elementos essenciais no processo de intervenção na Integração Sensorial.

\subsection{Entendendo o Sistema Proprioceptivo}

Dentre as variáveis em distúrbios sensoriais, neste trabalho, focou-se na busca da ação proprioceptiva. Este sistema promove a orientação do corpo no espaço (consciência corporal), sendo formado por músculos, articulações e tendões. Assim, sendo primordial na execução da práxis ou planejamento motor, orientando o planejamento e execução de diferentes tarefas motoras (SERRANO, 2018; MOMO; SILVESTRE, 2011).

Para um adequado funcionamento do sistema proprioceptivo, faz-se importante o recebimento de informações precisas dos sistemas sensoriais e que essas informações sejam além de recebidas, processadas adequadamente. Todo este ciclo está vinculado a impulsos de proprioceptores existentes nas cápsulas das articulações, que enviam dados sobre a posição relativa das várias partes do corpo e impulsos de exteroceptores cutâneos, especialmente os de tato e pressão.

Para entendimento, os ajustamentos de equilíbrio adequado devem ser feitos sempre que o corpo se angula no tórax ou no abdômen, ou em qualquer outro local, todas essas informações são algebricamente somadas no cerebelo e na substância reticular e núcleos vestibulares do tronco cerebral, determinando ajustes adequados nos músculos posturais (GUYTON; HALL, 2017).

Serrano (2018) relata que propriocepção refere-se à consciência do nosso próprio corpo. Por meio deste sentido que sabemos a posição do corpo no espaço, se estão se movimentando ou parado. Também é o sistema proprioceptivo que nos informa sobre a graduação de força e postura necessárias quando realizamos as atividades.

Quando as informações dos sistemas proprioceptivo e vestibular unem-se no cérebro é possível regular a postura e o tônus muscular. Em conjunto, estes dois sistemas nos permitem saber se estamos assentados ou de pé, se nossos membros 
estão esticados ou encolhidos, se estamos encostados. Já quando o sistema proprioceptivo une-se ao sistema tátil, temos a noção do corpo e do esquema corporal (SERRANO, 2018).

\subsection{Desordens Sensoriais no TEA}

No TEA ocorrem dificuldades e desafios frente ao processamento e relação de sensações, o que poderá causar efeitos negativos em outros segmentos. Posar e Visconti (2018) apontam que as alterações sensoriais são comuns e em grande parte dos casos invalidam o indivíduo com TEA.

Caminha (2013), na pesquisa intitulada Investigação de Problemas Sensoriais em Crianças Autistas: relações com o grau de severidade do transtorno, dedicou-se a estudar a incidência do transtorno do processamento sensorial em crianças com TEA. Em seu trabalho, a autora aplicou o teste Short Sensory Profile em 28 crianças com TEA, cujo resultado evidenciou que 82,1\% delas apresentaram transtornos sensoriais. Além disso, quando aplicado na população de autistas severos, o índice chegou a 94,4\% (BACARO; MORI, 2020).

Os prejuízos advindos de alterações no processamento sensorial apresentam números significativos em pessoas com diagnóstico de TEA, afetando seu desempenho funcional, além de estar classificado no Manual Diagnóstico e Estatístico de Transtornos Mentais (DSM-5) como aspecto diagnóstico (SOUZA; NUNES, 2019).

Stevenson (2017) aduz sobre a necessidade da avaliação formal quanto a função sensorial, e esse processo condiciona fatores neurocomportamentais dos indivíduos com TEA e outros sintomas mais perceptíveis e periódicos.

O Quadro 1 apresenta os aspectos sensoriais predominantes e comportamentos associados às alterações do processamento das informações e suas inferências para a intervenção terapêutica. 
Quadro 1 - Comportamentos relacionados as alterações sensoriais TEA

\begin{tabular}{|c|c|}
\hline MODALIDADES SENSORIAIS & $\begin{array}{c}\text { EXEMPLOS DE COMPORTAMENTOS } \\
\text { RELACIONADOS ÀS ALTERAÇÕES } \\
\text { SENSORIAIS }\end{array}$ \\
\hline Visual & $\begin{array}{l}\text { Atração por fontes de luz, encarar objetos } \\
\text { que rodam como as máquinas de lavar, } \\
\text { rodas, hélices; o reconhecimento das } \\
\text { expressões faciais com maior } \\
\text { complexidade; evita olhares; recusa } \\
\text { alimentos devido à coloração. }\end{array}$ \\
\hline Auditiva & $\begin{array}{l}\text { Surdez perceptível, pois a criança não } \\
\text { atende aos chamados verbais, intolerância } \\
\text { a alguns sons diferentes, emitem sons } \\
\text { repetitivos. }\end{array}$ \\
\hline Somatossensorial & $\begin{array}{l}\text { Alta tolerância à dor; aparente falta de } \\
\text { sensibilidade ao calor ou frio; } \\
\text { autoagressividade; não gosta de contato } \\
\text { físico de pessoas e até mesmo alguns } \\
\text { itens de vestuário; atração por superfícies } \\
\text { ásperas. }\end{array}$ \\
\hline Olfativa & $\begin{array}{l}\text { Gosta de cheirar coisas que não são } \\
\text { comestíveis; recusa certos alimentos } \\
\text { devido ao odor. }\end{array}$ \\
\hline Paladar, sensibilidade bucal & $\begin{array}{l}\text { Explora objetos por meio da boca; } \\
\text { seletividade alimentar oriunda da recusa } \\
\text { devido a determinadas cores. }\end{array}$ \\
\hline Vestibular & $\begin{array}{l}\text { Movimento iterativo de balanço; não tem o } \\
\text { equilíbrio adequado. }\end{array}$ \\
\hline Proprioceptiva & $\begin{array}{l}\text { Gosta de andar com as pontas dos pés, } \\
\text { além de ser desajeitado. }\end{array}$ \\
\hline
\end{tabular}

Fonte: Posar e Visconti (2018).

De acordo com Magalhães (2004), Jean Ayres, em 1979, definiu a disfunção de Integração Sensorial como uma inabilidade em processar determinada informação recebida pelos sistemas sensoriais. E que quando uma criança tem disfunção de Integração Sensorial, ela pode ser incapaz de responder a determinadas informações sensoriais, uma vez que o desempenho das habilidades funcionais seja eficaz é necessária a integração de múltiplas experiências sensoriais (WATANABE et al., 2015).

\subsection{Trajes Terapêuticos}

No entendimento da necessidade de ajustes táteis, vestibulares e, por consequência, proprioceptivos, os trajes compressivos foram criados e elaborados com o intuito de beneficiar positivamente na ação global em pessoas com TEA. 
Sabemos que as sensações táteis são projetadas por meio de integrações somatossensoriais, integração esta onde as sensações táteis e proprioceptivas estão associadas e integradas e desempenham um papel importante no desenvolvimento, principalmente da práxis, e estudos apresentam sua eficácia e seu uso como um recurso terapêutico no tratamento delas (ANDRADE, 2020). Assim, projetamos a importância e os efeitos positivos dos trajes compressivos que são apontados no decorrer desta pesquisa.

Em tese, a Integração Sensorial no TEA é uma base de adequação para o comportamento adaptativo, devido à dinamização no apoio à movimentação, e consequentemente, a interação em ambientes, amenizando os sintomas deste transtorno. Compreendendo a necessidade de intervenção da pessoa com TEA, inúmeros modelos terapêuticos são desenvolvidos. Passamos, a seguir, a descrever acerca desses modelos terapêuticos encontrados na literatura pesquisada.

Segundo Amigo Panda (2020), encontramos dois grandes grupos desses trajes, aqueles ligados por bandas elásticas e as órteses únicas. Os trajes ligados por bandas elásticas são conhecidos como "PenguinSuit" e/ou "SuitTherapy". Foram desenvolvidos entre as décadas de 1960/1970, pelo programa espacial da Rússia, para serem usados por astronautas em voos espaciais, com a finalidade de neutralizar os efeitos da ausência da gravidade e hipocinesia sobre o corpo, principalmente relacionada à perda da densidade óssea, alterações nas respostas sensoriais e desequilíbrios (OLIVEIRA, 2017).

Os programas que utilizam os Suits Vests têm como objetivo 0 restabelecimento mais próximo do considerado típico alinhamento postural, desempenhando um papel crucial na reorganização do tônus muscular e do ciclo de realinhamento e antecipação entre as informações sensoriais e as respostas motoras (BAILES et al., 2010).

Costa (2015) refere que estes tipos de órteses geralmente promovem a melhora na propriocepção, na redução de reflexos patológicos, prevê uma estabilização externa, dando suporte à diminuição da força muscular, corrigindo o alinhamento biomecânico, proporcionando, assim, uma melhora no desempenho ocupacional desses indivíduos.

Neste entendimento, observamos que os métodos que utilizam órteses corporais consideradas como dinâmicas, conhecidas como SUITS (Pediasuit, Therasuit, AdeliSuit, Treining, entre outros), favorecem um alinhamento 
biomecânico. Estas órteses são leves e flexíveis, compostas por touca, colete, short, joelheira, tênis adaptado, sendo interligadas por bandas elásticas.

Dentre as órteses únicas, como a roupa Biocinética, Evolvik, Flexcorp, Teratogs, Spio Works, entre outras, notadamente, auxiliam em atividades funcionais, sendo utilizadas no dia a dia, onde um responsável é treinado para fazer o manuseio da mesma, em casa. Estas roupas devem ser usadas diretamente na pele, aumentando a sensação proprioceptiva e tátil. Geralmente, são fabricadas com lycra, neoprene, materiais com propriedades elásticas. Assim como os Suitsvests, este tipo de roupa também parte do princípio do alinhamento biomecânico e da estimulação somatosensorial.

Importante o entendimento da diferenciação de aplicabilidade entre estas órteses. As órteses consideradas dinâmicas (Suits) são utilizadas, normalmente, por profissionais capacitados em sua aplicação, em sessões de terapia intensiva. Sendo as órteses únicas, manuseadas, normalmente, por um acompanhante treinado para vestir, e utilizar na pratica diária, para a execução de tarefas.

Figura 1 - Modelo de Traje com bandas elásticas

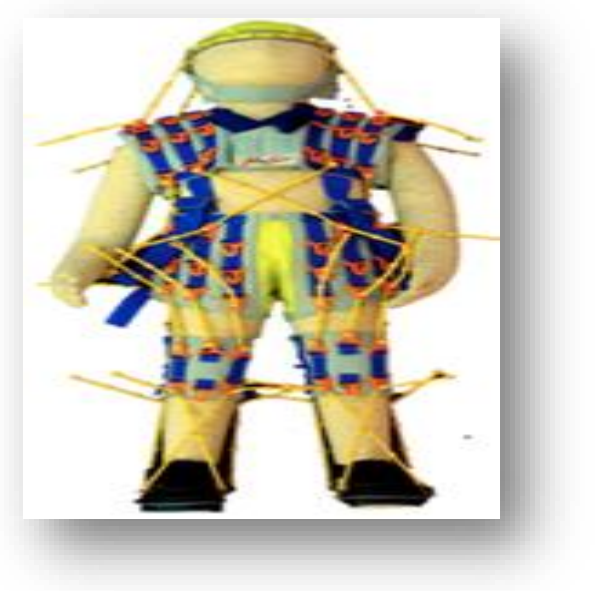

Fonte: Posar e Visconti (2018).
Figura 2 - Modelo Traje Compressivo

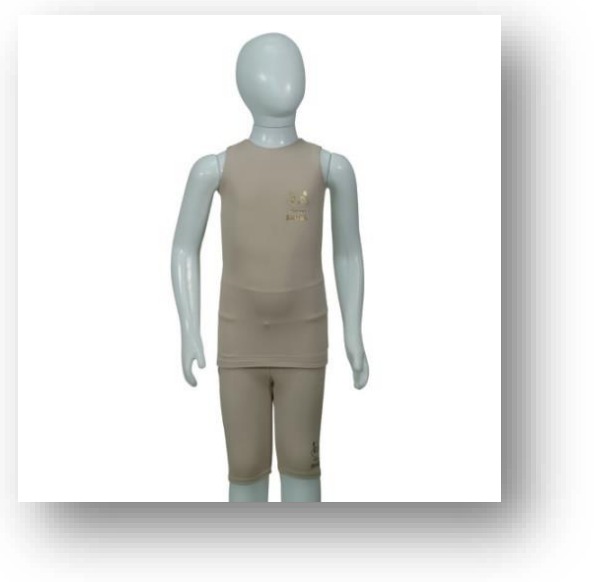

Fonte: Oliveira (2017).

\section{METODOLOGIA}

A pesquisa foi realizada por meio de uma revisão do tipo ScopingReview, que corresponde a uma revisão sistemática de literatura, com caráter exploratório, com o objetivo de levantar as principais fontes e evidências do tema abordado na pesquisa, com apresentação das técnicas e dos procedimentos utilizados no levantamento do conteúdo e desenvolvimento contextual, apontando caracterizações e contribuições da temática. Ressaltamos que não existem muitos estudos sobre o tema abordado, 
apenas breves referências ou textos que possuem o mesmo sentido contextual, sendo assim, esse modelo de revisão foi válido, pois ainda não estão claras as questões específicas relacionadas.

Inicialmente, os autores tinham a intenção de realizar uma revisão narrativa, porém, devido aos poucos artigos encontrados, resolveu-se que seria realizada uma revisão do que já foi publicado, aplicando técnicas interpretativas, baseando-se em estudos que abordam a temática, compreendendo, assim, os fenômenos oriundos sobre os trajes compressivos e suas características, assim como a coleta de dados textuais.

Dessa forma, a pesquisa bibliográfica foi feita inicialmente com base em periódicos, artigos científicos, revistas, teses e demais materiais digitais, com informações mais recentes, entre os anos de 2006 e 2020, sendo que os materiais foram obtidos nas principais bases de dados, como SciELO (Scientific Eletronic Library Online), Google Acadêmico e o banco de Teses e Dissertações da Coordenação de Aperfeiçoamento de Pessoal de Nível Superior (CAPES). Devido à necessidade de discorrer sobre os sistemas sensoriais, Integração Sensorial de Ayres e demais assuntos relacionados ao tema, houve uma busca por livros e publicações de referência com datas anteriores a este período.

Este estudo foi realizado em duas fases, primeiramente, buscou-se e selecionou-se estudos e materiais que mencionavam a utilização dos trajes compressivos em pessoas com TEA, na segunda fase, foi realizada uma análise dos textos no intuito de extrair conhecimento relevante almejado para a produção desta revisão.

A pesquisa, em sua maioria, foi realizada pelo Google Acadêmico, empregando os descritores "trajes compressivos", "ação proprioceptiva" e "TEA". Para a busca avançada no Google Acadêmico foram feitos os seguintes cruzamentos dos descritores: "Trajes compressivos x TEA", "TEA x Propriocepção", "Propriocepcão $x$ Trajes compressivos".

A coleta de dados contou com os seguintes critérios de inclusão e exclusão:

- Critérios de Inclusão: artigos e teses e monografias disponíveis em textos completos, publicados em português e inglês, com espaço temporal delimitado de 2006 a 2020.

- Critérios de Exclusão: artigos, teses e dissertações que não correspondiam com os objetivos do estudo proposto e com a pergunta 
norteadora: "Trajes compressivos e sua ação proprioceptiva no Transtorno do Espectro Autista (TEA)."

\section{RESULTADOS E DISCUSSÃO}

O sistema proprioceptivo é responsável pela consciência e organização corporal. Quando está devidamente ativado, a criança percebe com mais clareza a posição do seu corpo no espaço, respondendo com mais segurança e concentração. Este sistema se mostra como um centro muito importante que recebe, processa, integra e envia de volta toda a informação que chega de músculos, articulações e tendões. Isso influencia o tônus muscular, o equilíbrio e a posição do corpo no espaço. O sistema proprioceptivo demonstra necessidade em ser trabalhado e estimulado continuamente, objetivando um melhor gerenciamento das informações sensoriais, que são enviadas ao sistema nervoso central, propiciando, assim, respostas adaptativas (SANTIAGO; BARBOSA; SOUZA, 2020).

Os trajes compressivos, já tão amplamente discutidos na sua função de posicionamento e postura, demonstram relevância considerável, na organização proprioceptiva nas pessoas com TEA. Observamos que estes trajes funcionam como acionadores proprioceptivos, auxiliando no tratamento dos indivíduos que tenham dificuldades sensoriais, relacionadas ao TEA, numa busca de proporcionar a esses indivíduos melhorias, sendo indicados como auxiliares no processo de reabilitação, buscando uma melhora na funcionalidade e na qualidade de vida desses.

Cabe apontar que os trajes são recursos terapêuticos, que podem ser utilizados juntamente com a Terapia Ayres Sensory Integration (ASI), mais conhecida no Brasil como a Terapia de Integração Sensorial, terapia esta, que está intrinsecamente relacionada a pessoas com o TEA, objetivando entender as bases sensoriais e motoras desses indivíduos, cabendo ao profissional de Terapia Ocupacional buscar e desenvolver teorias e estratégias que ajudem essas pessoas na compreensão e relações, quanto aos seus déficits sensoriais (LANE et al., 2019).

Diante do exposto, referimos que estas vestimentas objetivam normalizar o tônus muscular da pessoa, além de propagar a variedade dos movimentos ativos, aumentando a força e a resistência no controle referente à musculatura, o que faz com que ganhe força, permitindo que as habilidades sejam aprimoradas.

Somos sabedores que crianças que são muito agitadas e parecem hiperativas são buscadores proprioceptivos. Já aqueles que preferem ficar parados, os 
hiporresponsíveis, parecem descoordenados e evitam o toque, também apresentam desordens proprioceptivas. Ambas as citações convergem para a necessidade de toque, descrita aqui neste trabalho, como o toque compressivo. Utilizando-se de trajes, a terapia por compressão promove a contração muscular que ativa receptores sensoriais localizados próximos às articulações, que propiciam uma melhora nestas respostas citadas.

Os recursos tecnológicos oriundos dos trajes compressivos, são congruentes a um processo terapêutico, no qual podem, ainda, ativar o sistema sensorial proprioceptivo, reduzindo a ação de reflexos patológicos, restaurando as sinergias musculares fisiológicas e exercendo um peso sobre todo o corpo. Todos estes estímulos normalizam a entrada vestíbulo-proprioceptiva aferente, por consequência, propiciando uma boa resposta adaptativa.

Assim, entende-se que o estudo procurou, portanto, levantar conhecimentos quanto à importância dos benefícios e demais implicações relacionadas à utilização desses trajes, visando contribuir com a prática clínica baseada em evidência dentro na intervenção da Terapia Ocupacional.

\section{CONSIDERAÇÕES FINAIS}

O objetivo do presente artigo foi discutir a relevância dos trajes compressivos e sua ação proprioceptiva à luz da Teoria da Integração Sensorial. Nesse percurso foram descritas, inicialmente, as características do TEA, os fundamentos da IS e sistemas sensoriais descritos por Ayres (1972), sequencialmente, descrevemos 0 sistema proprioceptivo, para finalizarmos, enfatizou-se as desordens sensoriais e a ação dos trajes terapêuticos.

Podemos destacar a relevância deste artigo no que concerne a fornecer subsídios teóricos aos profissionais de Terapia Ocupacional que, empiricamente, estão utilizando o recurso em questão, como meio de auxilio no tratamento de crianças com TEA. Muitos são os encaminhamentos médicos, todavia, observou-se a necessidade de um aprofundamento teórico, na ação descrita. A dificuldade no delineamento de pesquisa adotada faz fortalecer este pensamento.

Vale lembrar que a abordagem terapêutica de Integração Sensorial, e seu uso eminentemente clínico, já está amplamente discutido cientificamente. Seus benefícios são claros, quando a terapia é aplicada de maneira adequada. Como já observado, a pratica clínica nos permite perceber, a importância dos trajes, 
combinados com este modelo terapêutico, trazendo benefícios que ultrapassam desde o arcabouço motor ao proprioceptivo propriamente dito.

Temos o entendimento que os objetivos do trabalho foram devidamente alcançados. Entender a importância dos trajes compressivos como propulsores nas melhorias aos indivíduos com TEA nos remete à necessidade de pesquisa prática nos resultados, para uma melhor compreensão destes avanços tecnológicos que sugerem permitir a criação e desenvolvimento de padrões de Integração Sensorial, com favorecimento de alinhamento biomecânico e na estimulação dos movimentos ativos e a promoção de aprendizagem e experiências. A já citada prática clínica fornece subsídios para entender que a proposta mostra-se como potencial plausível na complementação de melhorias em prol do tratamento da criança com TEA, assim como o método terapêutico.

\section{REFERÊNCIAS BIBLIOGRÁFICAS}

AMERICAN PSYCHIATRIC ASSOCIATION. Diagnosticand statistical manual of mental disorders (DSM-5). 5. ed. Washington, DC: American Psychiatric Association, 2013.

AMIGO PANDA. Conjunto ou colete sensorial: saiba o que é e como funciona a roupa proprioceptiva. 25 jun. 2020. Disponível em:

https://blog.amigopanda.com.br/conjunto-ou-colete-sensorial/. Acesso em: 27 nov. 2021.

ANDRADE, Mirela Moreno Almeida de. Análise da influência da abordagem de Integração Sensorial de Ayres na participação escolar de alunos com Transtorno do Espectro Autista. Tese (Doutorado em Educação) - Programa de Pós-Graduação em Educação da Faculdade de Filosofia e Ciências, Universidade Estadual Paulista, Marília, 2020.

AYRES, A. J. Improving academic scoresthrough sensory integration. Journal of Learning Disabilities, v. 5, n. 6, p. 338-343, 1972.

Sensoryl Integration and PraxisTests. Los Angeles: Western Psychological Services, 1989.

BACARO, P. E. F.; MORI, N. N. R. Transtorno do processamento sensorial e deficiências no processo de aprendizagem de alunos com transtornos do espectro do Autismo: uma mensagem para professores. Pesquisa, Sociedade e Desenvolvimento, [s. L.], v. 9, n. 11, p. e62691110314, 2020. Disponível em: https://rsdjournal.org/index.php/rsd/article/view/10314. Acesso em: 19 set. 2021. autista no ensino regular: desafios e possibilidades. Dissertação (Mestrado em 
Planejamento e Análise de Políticas Públicas) - Programa de Pós-graduação em Planejamento e Análise de Políticas Pública da Faculdade de Ciências Humanas, Universidade Estadual Paulista, Franca, 2017. Disponível em:

https://repositorio.unesp.br/bitstream/handle/11449/150651/bianchi_rc_me_fran.pdf? sequence=3. Acessado em: 25 de jul. 2021.

BRITES, Clay. Como ajudar crianças com Autismo a melhorar a interação social. 2016. Disponível em: http://entendendoAutismo.com.br/artigo/como-ajudarcriancas-com-Autismo-a-melhorar-a-interacao-social/. Acesso em: 12 de jul. 2021.

BRITO, Elaine Rodrigues de. A inclusão do autista a partir da educação infantil: um estudo de caso em um pré-escola e em uma escola pública no município de Sinop Mato Grosso. Revista Eventos Pedagógicos, v. 6, n. 2, p. 82-91, jun./jul. 2015.

CAMINHA, Roberta Costa. Investigação de problemas sensoriais em crianças autistas: relações com o grau de severidade do transtorno. $120 \mathrm{f}$. Tese (Doutorado em Psicologia) - Pontifícia Universidade Católica, Rio de janeiro, 2013.

CARDOSO, Nathalia Rodrigues; BLANCO, Marília Bazan. Terapia de Integração Sensorial e o Transtorno do Espectro Autista: uma revisão sistemática de literatura. Revista Conhecimento Online, v. 1, p. 108-125, jan./abr. 2019.

GAMA, Emilia J. F. (Org.). Guia de Abordagem Transdisciplinar na Síndrome de Down (T21). Macéio: IEPSIS, 2018.

GUYTON, A. C.; HALL, J. E. Tratado de Fisiologia Médica. 13 ed. Rio de Janeiro: Editora Campus-Elsevier, 2017

HALL, John E.; HALL, Michael E. Guyton e Hall: Tratato de Fisiologia Médica. 14. ed. São Paulo: GEN Guanabara Koogan, 2021.

LANE, Shelly J. et al. Neural Foundations of Ayres Sensory Integration. Brain Sci, v. 9, n. 7, p. 153, 2019. doi: 10.3390/brainsci9070153.

MARINHO, E. A. R.; MERKLE, V. L. B. Um olhar sobre o Autismo e sua especificação. In: IX CONGRESSO INTERNACIONAL DE EDUCAÇÃO; III ENCONTRO SUL BRASILEIRO DE PSICOPEDAGOGIA, IX-III, Paraná. Anais [...]. 26-29 out. 2009. Disponível em: https://educere.bruc.com.br/cd2009/pdf/1913_1023.pdf. Acesso em: 27 nov. 2021.

MATTOS, Jací Carnicelli. Alterações sensoriais no Transtorno do Espectro Autista (TEA): Implicações no desenvolvimento e na aprendizagem. Rev. Psicopedagogia, v. 26, n. 109, p. $87-95,2019$.

MENDES, Jaqueline Izabebela; COSTA, Juliane Rissardi. Integração Sensorial em crianças com Transtorno do Espectro Autista. Cad. da Esc. de Saúde, Curitiba, v. 17, n. 2, p. 1-3, 2017.

MOLLERI, N. et al. Aspectos relevantes da Integração Sensorial: Organização cerebral, distúrbios e tratamento. Revista Neurociências, v. 6, p. 173-179, 2010. 
MOMO, A.; SILVESTRE, C. Integração Sensorial nos transtornos do espectro do Autismo. In: SCHWARTZMAN, J.; ARAÚJO, C. A. Transtornos do espectro do Autismo. São Paulo: Memnon, 2011. p. 297-313.

OLIVEIRA, A. I. Alves de. Pesquisa e desenvolvimento infantil. Belém: Conhecimento \& Ciência, 2018.

OLIVEIRA, Leonardo, Apostila do curso básico do Protocolo Pediasuit. Rio de Janeiro: Clínica FollowKids, 2017.

PARHAM, L. D. et al. Development of a Fidelity Measure for Research on the Effectiveness of the Ayres Sensory Integration Intervention. American Journal of Occupation Therapy, Albuquerque, v. 65, n. 2, p. 133-142, 2011. Disponível em: http://jdc.jefferson.edu/otfp/24/. Acesso em: 19 jun. 2021.

PAULINO, K. V. T. Autismo. 21f. Trabalho de Conclusão de Curso (Graduação em Psicologia) - Universidade de São Paulo - USP, São Carlos, 2015.

POSAR, Annio; VISCONTI, Paola. Alterações sensoriais em crianças com Transtorno do Espectro do Autismo. J. Pediatr., Rio de Janeiro, v. 94, n. 4, jul./ago. 2018. doi: https://doi.org/10.1016/j.jpedp.2017.11.009.

PRAÇA, Élida Tamara Prata de Oliveira. Uma reflexão acerca da inclusão de aluno autista no ensino regular. 140 f. Dissertação (Mestrado em Educação Matemática) - Instituto de Ciências Exatas, Universidade Federal de Juiz de Fora, Juiz de Fora, 2011.

ROLEY, S. S. et al. Understanding Ayres' Sensory Integration. OT Practice, v. 12, n. 7, set. 2007.

SCHMIDT, C. Temple Grandin e o Autismo: uma análise do filme. Rev. Bras. Ed. Esp., Marília, v. 18, n. 2, p. 179-194, abr./jun. 2012.

SERRANO, P. A Integração Sensorial: no desenvolvimento e aprendizagem da criança. 3. ed. Lisboa: Papa-Letras, 2018.

SILVA, Sandra Francisca da. Atendimento educacional especializado para aluno com Autismo: Desafios e possibilidade. Intl. J. of Knowl. Eng., Florianópolis, v. 1, n. 1, p. 62-88, set. 2012.

SOARES, Thaiane; BRAGA, Evangelista de Matos. Relação da terapia de Holding com a Integração Sensorial no Autismo Infantil. Revista Científica Interdisciplinar, v. 1, n. 2, p. 78-95, out./dez. 2014.

SOUZA, Renata Ferreira de; NUNES, Débora Regina de Paula. Transtornos do processamento sensorial no Autismo: algumas considerações. Revista Educação Especial, Santa Maria, v. 32, p. 1-17, jan./dez. 2019. 
STEVENSON, Ryan A. et al. Multisensory speech perception in autism spectrum disorder: From phoneme to whole-word perception. Autism Res, v. 10, n. 7, p. 12801290, jul. 2017.

WATANABE, B. M. N. et al. Integração Sensorial: déficits sugestivos de disfunções no processamento sensorial e a intervenção da Terapia Ocupacional. 2015. Disponível em: http://atividadeparaeducacaoespecial.com/wpcontent/uploads/2015/10/integra\%C3\%A7\%C3\%A3o-sensorial-e-sistemavestibular.pdf. Acesso em: 27 nov. 2021.

WATKINS, N.; SPARLING, E. The Effectiveness of the Snug Vest on Stereotypic Behaviors in Children Diagnosed With an Autism Spectrum Disorder. Behav Modif., v. 38, n. 3, p. 412-427, maio 2014. 


\title{
INTERVENÇÃO DA TERAPIA OCUPACIONAL COM CRIANÇAS COM TRANSTORNO DO ESPECTRO AUTISTA (TEA) QUE APRESENTAM SELETIVIDADE ALIMENTAR USANDO A ABORDAGEM DE INTEGRAÇÃO SENSORIAL: uma revisão da literatura
}

\author{
Roseane Mesquita da Silva Pantoja ${ }^{1}$ \\ Suane Nascimento de Sousa ${ }^{1}$ \\ Tatyane Mieli Pamplona Porto ${ }^{1}$ \\ Vanessa Rafaelle Brasil de Souza ${ }^{2}$
}

\section{RESUMO}

Esta pesquisa trata-se de um levantamento bibliográfico de abordagem quantiqualitativa. Tem a finalidade de levantar dados sobre a seletividade alimentar em crianças com Transtorno do Espectro Autista (TEA) e analisar estudos sobre a intervenção do Terapeuta Ocupacional em crianças com Transtorno do Espectro Autista que apresentam seletividade alimentar, sob a perspectiva da abordagem da Integração Sensorial. Utilizou-se a técnica de revisão integrativa da literatura. Quanto ao perfil dos artigos encontrados, a maioria é de revisão bibliográfica. Após a análise do conteúdo, observou-se que a maioria dos artigos associou a seletividade alimentar de crianças com TEA a dificuldades do processamento sensorial. Este trabalho aponta que as crianças com TEA apresentam comportamentos tendenciosos na seletividade alimentar e a intervenção precoce do Terapeuta Ocupacional no tratamento contribui para amenizar as questões da seletividade alimentar. Embora tenham sido encontrados alguns artigos, nota-se que este campo necessita de mais pesquisas e esclarecimentos, especialmente no domínio da intervenção na área e com esse público específico.

Palavras-chave: Transtorno de Espectro Autismo. Seletividade alimentar. Integração Sensorial. Terapia. Ocupacional.

\section{INTRODUÇÃO}

Partindo da análise de base literária e sobretudo da vivência de nossa profissão, foi notada a necessidade de realizar um trabalho bibliográfico sobre a intervenção da Terapia Ocupacional com crianças com Transtorno do Espectro Autista (TEA) que apresentam seletividade alimentar, usando a abordagem de Integração Sensorial, de Ayres, o que se nota, na prática, é que muitos profissionais que trabalham com crianças autistas descrevem a seletividade alimentar.

\footnotetext{
${ }^{1}$ Terapeutas Ocupacionais.

${ }^{2}$ Terapeuta Ocupacional/UEPA, Msc. em Psicologia UFPA, Certificação em IS - WPS/USC, Docente do Curso de Certificação Brasileira em Integração Sensorial - Integris/UEPA, Orientadora do trabalho.
} 
Com isto em mente, desejou-se investigar qual a importância das contribuições da prática da Terapia Ocupacional com crianças com TEA que apresentem a seletividade alimentar no que se refere à Integração Sensorial?

Quando se fala em processamento sensorial, este diz respeito à forma como o Sistema Nervoso Central (SNC) gerencia as informações recebidas dos órgãos sensoriais, ou seja, os estímulos visual, auditivo, tátil, gustativo, olfativo, proprioceptivo, vestibular e interoceptivo. O processo inclui a recepção, modulação, integração, discriminação e organização de estímulos sensoriais, tal como as respostas comportamentais adaptativas a estes estímulos (MACHADO et al., 2017).

Quanto ao Autismo, em 1943, o conceito de Autismo infantil foi descrito pela primeira vez pelo o psiquiatra austríaco Leo Kanner, sendo inserido em um transtorno caracterizado por perdas na comunicação, comportamento e interação social (VIEIRA, 2016).

Com o tempo e o progresso de novas pesquisas científicas no campo da psiquiatria infantil, o conceito de Autismo mudou, levando em consideração diferentes etiologias e as características foram inicialmente consideradas como uma síndrome e não mais tratado como um único quadro (ANDRADE et al., 2016).

Isso prova uma nova nomenclatura, Transtorno do Espectro Autista. Desta forma, complementa as características do TEA, a classificação Internacional (CID10-OMS, 1993), acrescentando-se o diagnóstico da síndrome os critérios: "comportamentos sensoriais incomuns e comportamentos motores ou verbais estereotipados."

O TEA é atualmente considerado uma síndrome de comportamento enigmática que possui múltiplas etiologias, combinadas com fatores ambientais e genéticos, apresenta suas características de forma precoce, trata-se de transtorno pervasivo e permanente, não havendo cura, ainda que a intervenção precoce possa alterar o prognóstico e suavizar os sintomas, no qual as dificuldades comprometem o desenvolvimento do indivíduo ao longo da vida (MONTENEGRO et al., 2020).

Ressalta-se que o Transtorno do Espectro Autista (TEA) consiste em dificuldades persistentes de comunicação e nas interações sociais em diferentes contextos, e em padrões de comportamento restritos e repetitivos, interesse ou atividade (ANDRADE et al., 2016).

O Autismo tem origem nos primeiros anos de vida. Em algumas crianças, os sintomas são aparentes logo após o nascimento, no entanto, os sintomas do TEA só 
são consistentemente identificados entre os 12 e 24 meses de idade (LÁZARO; CARON; PONDÉ, 2018). O diagnóstico é definido de acordo com os padrões clínicos, por meio de observações com crianças e entrevistas com os pais ou responsáveis, observações com aplicação de uma ferramenta específica, a maneira ideal de ser feita é por meio de uma equipe interdisciplinar (VIEIRA, 2016).

Ao diagnosticar uma pessoa com TEA, é fundamental e relevante compreender o perfil intelectual e a gravidade do Autismo, entende-se que os déficits de comunicação, interação social e comportamental do autista pode estar enquadrado em diferentes níveis, sendo eles nível 1, 2 e 3, que compreende Autismo leve, moderado e severo (SANTOS; VIEIRA, 2017). É importante que se inicie a intervenção apropriada e de forma precoce, assim, melhor será o prognóstico em termo de desenvolvimento (MONTENEGRO et al., 2020)

O Autismo requer uma série de intervenções e tratamentos. A atuação conjunta de psicólogos, neuropediatra, fisioterapeuta, nutricionista, Terapeuta Ocupacional, fonoaudiólogos, professores e demais profissionais de crianças com Transtorno do Espectro Autista e seus familiares pode melhorar significativamente a qualidade de vida das crianças e seus familiares e fortalecer o contato (BURTET; GODINHO, 2017).

Dentre esses conceitos, reitera sobre a seletividade alimentar que é caracterizada pela recusa e/ou falta de interesse na ingestão dos alimentos, sendo que padrões alimentares muito comuns são: dificuldades da criança em lidar com as texturas, consistências, temperaturas, cores, aparência, cheiros e sabores dos alimentos, apresentação do prato, utensílios utilizados ou até mesmo ter incômodo com o som produzido pela mastigação (MARÍ-BAUSET et al., 2014). Entende-se que todas essas reações têm relação com o processamento sensorial.

O transtorno do processamento sensorial é caracterizado pela dificuldade na percepção e interpretação da qualidade de estímulos sensoriais, sendo eles, visual, tátil, auditiva, vestibular, proprioceptiva, gustativa e/ou olfativa (SOUZA; NUNES, 2019).

Para tornar a discussão mais clara, é importante dizer que a Teoria de Integração Sensorial foi desenvolvida pela Terapeuta Ocupacional Anna Jean Ayres, entre os anos de 1960 e 1970. Segundo Ayres (1972), o funcionamento cerebral e a forma como a informação sensorial é processada tem forte impacto no comportamento adaptativo da criança, defendendo a importância de se entender 
melhor a "organização das sensações para o uso". A Integração Sensorial é um processo neurofisiológico que se refere à capacidade do cérebro organizar e interpretar as informações provenientes dos diferentes sistemas sensoriais, mediante às experiências de aprendizagens anteriores e memórias armazenadas no cérebro. Integração Sensorial é a organização e interpretação das informações que recebemos dos sentidos como toque, cheiro, paladar, visão, audição, vestibular e propriocepção (CORREIA, 2015).

Nesse sentido, as crianças cujos limiares neurológicos são muito altos tendem a ser menos receptivas (isto é, são necessários muitos estímulos para atingir seu limiar, por exemplo, não respondem ao serem chamadas ou demostram não sentir dor). As crianças cujos limiares neurológicos são muito baixos tendem a ser excessivamente receptivas (ou seja, pouco estímulo provoca uma reação, por exemplo, são distraídas ou demonstram irritação a um simples toque/textura/som) (MATTOS, 2019).

A disfunção de Integração Sensorial é determinada pela presença de alteração em detectar, modular, interpretar ou responder ao estímulo sensorial (LÁZARO, 2016). Segundo Green e Ben-Sasson (2010), problemas relacionados à modulação sensorial tendem a interferir de modo direto no paladar, olfato, visão, audição, tato e nos sistemas vestibulares e proprioceptivos, interferindo com o desempenho de Atividades de Vida Diária (AVDs), como a alimentação.

A seletividade alimentar também pode estar ligada a outros fatores, como interesses rígidos e restritos, comportamento muito comum em crianças com TEA (LÁZARO; CARON; PONDÉ, 2008), além de problemas no trato gastrointestinal, dificuldade na motricidade oral e disfunção sensorial.

Para o tratamento de crianças com seletividade alimentar que apresentam disfunções sensoriais, uma das abordagens muito utilizada junto à criança com TEA é a Terapia de Integração Sensorial, abordagem exclusiva da Terapia Ocupacional, a qual tem evidenciado bons resultados na prática clínica (SERRANO, 2016).

Levando em consideração que a alimentação no desenvolvimento de crianças autistas requer especial atenção, consideramos que seria útil realizar uma revisão integrativa da literatura sobre a seletividade alimentar em crianças com TEA, com ênfase em trabalhos que se baseiam na abordagem de IS. Assim, objetivou-se analisar estudos sobre a intervenção do Terapeuta Ocupacional em crianças com 
Transtorno do Espectro Autista que apresentam seletividade alimentar e sua relação com a perspectiva da Integração Sensorial.

Para colaborar com alcance deste artigo foram selecionados os seguintes objetivos específicos: a) identificar quais são as principais demandas suscitadas que seriam válidas para a intervenção do Terapeuta Ocupacional nos casos de seletividade alimentar; b) descrever as possíveis dificuldades citadas nos estudos para a introdução de diferentes alimentos; c) verificar a existência de estudos que discutam a eficácia da abordagem da Integração Sensorial na intervenção do Terapeuta Ocupacional nos casos de seletividade alimentar em criança com TEA.

\section{METODOLOGIA}

Trata-se de revisão integrativa de literatura com análise qualitativa, realizada a partir da busca em periódicos científicos, do ano 2017 até 2021. A parte qualitativa está organizada em categorias de análise a partir dos estudos encontrados.

As bases de dados utilizadas para realizar a revisão integrativa foram: Google Acadêmico, SciELO e LILACS. O processo de busca dos artigos nesta revisão se baseou em combinações das seguintes palavras-chaves: "Autismo", "Transtorno do Espectro Autista", "seletividade alimentar", "processamento sensorial" e "Terapia Ocupacional".

Para serem incluídos na revisão, os estudos deveriam atender os seguintes critérios: estudos com textos completos disponíveis. A seleção dos trabalhos foi realizada diante o estabelecimento de critérios, sendo estes: categoria do trabalho (artigo original); dando preferência para idioma de publicação em português; visto que é melhor a análise de pesquisa, tendo como público alvo indivíduos com TEA, mencionar explicitamente o uso da abordagem de Integração Sensorial. Foram excluídos da revisão os estudos com data de publicação anterior de 2017, que não disponibilizavam o texto completo e que utilizavam outras abordagens de intervenção.

\section{RESULTADOS E DISCUSSÃO}

No Quadro 1 apresenta-se a quantidade referente aos trabalhos acadêmicos nas plataformas Google Acadêmico, SciELO e LILACS, de bases científicas, as coletas de dados quantitativos no que corresponde às descrições de 
estratégias de busca, esses textos podem ser agrupados com base nas características de cada documento.

Quadro 1- Busca de dados nas três plataformas utilizadas

\begin{tabular}{|l|c|c|c|}
\hline \multicolumn{1}{|c|}{ Descritores } & $\begin{array}{c}\text { Google } \\
\text { Acadêmico }\end{array}$ & SCIELO & LILACS \\
\hline Transtorno de Espectro Autismo & 1.300 & 4 & 23 \\
\hline Seletividade Alimentar & 2.500 & 1 & 1 \\
\hline Integração Sensorial & 222 & 2 & 2 \\
\hline Terapia Ocupacional & 110 & 87 & 55 \\
\hline
\end{tabular}

Fonte: Dados da pesquisa.

No Quadro 2 apresenta-se a quantidade de trabalhos selecionados que estão conforme os descritores utilizados no artigo.

Quadro 2 - Quantidade de trabalhos selecionados conforme descritores

\begin{tabular}{|lr|c|c|c|}
\hline \multicolumn{2}{|c|}{ Descritores } & $\begin{array}{c}\text { Google } \\
\text { Acadêmico }\end{array}$ & SCIELO & LILACS \\
\hline $\begin{array}{l}\text { Transtorno de Espectro } \\
\begin{array}{l}\text { Autismo; } \\
\text { Seletividade }\end{array}\end{array}$ Alimentar; \\
$\begin{array}{l}\text { Integração Sensorial; Terapia } \\
\text { Ocupacional. }\end{array}$ & 11 & 2 & 2 \\
\hline
\end{tabular}

Fonte: Dados da pesquisa.

Após as leituras e as análises dos trabalhos selecionados, foi realizada a transcrição dos dados mais relevantes de cada pesquisa, no intuito de identificar os que mais se identificam com o foco de nossa pesquisa. Os trabalhos abaixo (Quadro 3) fazem referência às intervenções da Terapia Ocupacional com crianças com Transtorno do Espectro Autista que apresentam seletividade alimentar, usando a abordagem de Integração Sensorial.

Quadro 3 - Referente aos trabalhos selecionadas para leitura e análise na plataforma de bases de dados Google Acadêmico

\begin{tabular}{|c|c|c|c|}
\hline ORD & TÍTULO & ANO & AUTOR \\
\hline 01 & & 2020 & \\
\hline & $\begin{array}{l}\text { Seletividade alimentar em } \\
\text { crianças com Transtorno do } \\
\text { Espectro Autista (TEA): uma } \\
\text { revisão de literatura }\end{array}$ & & $\begin{array}{llr}\text { GAMA, Bruna } & \text { Tainá } & \text { Brito; } \\
\text { LOBO, Hélida Hyglá } & \text { Montiro; } \\
\text { TRINDADE } & \text { DA } & \text { SILVA, } \\
\text { Andreza } & & \text { Kelly; } \\
\text { MONTENEGRO } & & \text { Karina } \\
\text { Sauders } & & \\
\end{array}$ \\
\hline
\end{tabular}




\begin{tabular}{|c|l|l|l|}
02 & $\begin{array}{l}\text { Seletividade alimentar voltada } \\
\text { para crianças com Transtorno } \\
\text { do Espectro Autista (TEA): uma } \\
\text { revisão de literatura }\end{array}$ & $\begin{array}{l}\text { MOURA, Gisele Viana; SILVA, } \\
\text { Rayana Rodrigues da; } \\
\text { LANDIM, Liejy Agnes dos } \\
\text { Santos Raposo. }\end{array}$ \\
\hline 03 & $\begin{array}{l}\text { Autismo, seletividade alimentar } \\
\text { e transtorno do processamento } \\
\text { sensorial: revisão de literatura. }\end{array}$ & 2020 & $\begin{array}{l}\text { ALMEIDA, Bruna Ferreira de } \\
\text { Paula. }\end{array}$ \\
\hline
\end{tabular}

Fonte: Dados da pesquisa.

Na pesquisa de Gama et al. (2021), se ateve-se a analisar a seletividade alimentar em crianças com Transtorno do Espectro Autista (TEA), a pesquisa foi um levantamento bibliográfico descritivo exploratório, de abordagem quantiqualitativa. Utilizou-se a técnica de revisão narrativa de literatura, com o objetivo de levantar dados sobre a seletividade alimentar em crianças com o Transtorno do Espectro Autista (TEA).

Os autores concluíram que a seletividade alimentar corresponde a um comportamento em que apresenta como principal característica a exclusão de variações de alimentos, entre os quais estes comportamentos ocorrem principalmente durante o processo de transição (fase de adaptação ou insira novos alimentos em sua vida diária), isso pode durar todo o processo de desenvolvimento individual.

Moura, Silva e Landim (2021) desenvolveram uma pesquisa sobre seletividade alimentar voltada para crianças com Transtorno do Espectro Autista (TEA), uma revisão da literatura. Os autores desenvolveram uma pesquisa de revisão bibliográfica, e com o artigo pode-se concluir que a disfunção sensorial pode ser detectada no início do desenvolvimento das crianças com TEA e têm sintomas muito diferentes, com relevantes variações nos sintomas ao uma modulação insuficiente, ou seja, as respostas neurais não são de forma adequada pelo cérebro, pois, quando modulação é adequada, o sistema nervoso responde de forma positiva, gerando respostas satisfatórias.

Almeida (2020) investigou sobre uma revisão de literatura de artigos que tratavam de dificuldades alimentares e alterações sensoriais em crianças com TEA, a pesquisa foi para observar a relação entre esses sintomas. A autora explicou que as alterações sensoriais em crianças com TEA podem levar a problemas nas atividades diárias, incluindo a alimentação. Problemas alimentares 
são descritos como comuns em crianças com TEA e podem interferir na saúde, crescimento e desenvolvimento, além de terem impacto para as famílias e no convívio social.

Ressalta-se que apenas três artigos abordavam sobre o Terapeuta Ocupacional e o tratamento da seletividade alimentar, utilizando a abordagem de Integração Sensorial, o que demonstra que os dados ainda são poucos sobre a prática em si e de como desenvolver métodos, estratégias para minimizar os efeitos da seletividade alimentar em crianças com TEA.

A maioria dos artigos selecionados na plataforma de base Google Acadêmico abrangem estudos de revisão bibliográfica. Porém, apesar de poucos, esses estudos demonstraram que a intervenção precoce do Terapeuta Ocupacional no tratamento dos transtornos do processamento sensorial em crianças com TEA são fundamentais para contribuir e minimizar as consequências da seletividade alimentar.

Com base no Quadro 4, foram selecionados na busca de dados os artigos já com os critérios de inclusão e exclusão, por meio de filtro de aplicação, dentre o período de publicação, de 2017 a 2021. Através dos descritores foram encontrados somente dois artigos, dentre as quais escolhemos apenas um, que mais se aproximou da temática para ser lido e analisado.

Quadro 4 - Referente aos trabalhos selecionadas para leitura e análise na plataforma de bases de dados SCIELO

\begin{tabular}{|c|c|c|c|}
\hline ORD & TÍTULO & ANO & AUTOR \\
\hline 01 & $\begin{array}{l}\text { Escala de Avaliação do } \\
\text { Comportamento Alimentar } \\
\text { no Transtorno do Espectro } \\
\text { Autista: estudo de validação }\end{array}$ & 2019 & $\begin{array}{l}\text { LÁZARO, Cristiane Pinheiro } \\
\text { SIQUARA, } \\
\text { Marcelino; } \\
\text { PONDÉ, Milena Pereira. }\end{array}$ \\
\hline \multirow[b]{2}{*}{02} & Autista: estudo de validação & \multirow[b]{2}{*}{2018} & Dias, e. C. \\
\hline & $\begin{array}{l}\text { Dieta isenta de glúten e } \\
\text { caseína no Transtorno do } \\
\text { Espectro do Autismo: uma } \\
\text { revisão sistemática. }\end{array}$ & & Dias, e. C. \\
\hline 03 & $\begin{array}{l}\text { Muito além dos nutrientes: } \\
\text { experiências e conexões com } \\
\text { crianças autistas a partir do } \\
\text { cozinhar e comer juntos. }\end{array}$ & 2021 & $\begin{array}{l}\text { FRUTUOSO, Maria } \\
\text { Fernanda Petroli; OLIVEIRA, } \\
\text { Bruna Muratti Ferraz de. }\end{array}$ \\
\hline
\end{tabular}

Fonte: Dados da pesquisa. 
Frutuoso e Oliveira (2021) realizou um estudo sobre como ampliar a análise da alimentação de crianças autistas, considerada inadequada pela seletividade alimentar ou pela dificuldade de interação nos momentos das refeições, atribuídas a alterações no processamento sensorial e a dificuldades sociais, comunicativas e cognitivas descritas no transtorno.

As autoras concluíram que o comportamento sensorial atípico foi incorporado como um critério diagnóstico dos transtornos do espectro autista, onde o estudo discute as possíveis disfunções no processamento sensorial de autistas, como causas de alterações comportamentais, incluindo a seletividade alimentar e as tensões durante as refeições.

Quadro 5 - Referente aos trabalhos selecionadas para leitura e análise na plataforma de bases de dados LILACS

\begin{tabular}{|c|c|c|c|}
\hline ORD & \multicolumn{1}{|c|}{ TíTULO } & ANO & AUTOR \\
\hline 01 & $\begin{array}{l}\text { Dieta isenta de glúten e } \\
\text { caseína no Transtorno do }\end{array}$ & 2018 & DIAS, e. C \\
& $\begin{array}{l}\text { Espectro do Autismo: uma } \\
\text { revisão sistemática. }\end{array}$ & \\
\hline
\end{tabular}

Fonte: Dados da pesquisa.

Lázaro, Siquara e Pondé (2019) realizaram um estudo sobre uma avaliação de comportamento alimentar com crianças autistas, o objetivo do estudo foi o de construir os itens e realizar a validade de conteúdo e constructo da Escala de Comportamento Alimentar do Autismo. Os autores concluíram que a escala é projetada para determinar as dimensões do comportamento alimentar alterado, fornece orientações mais específicas relacionadas ao tratamento e também pode ser usada para medir o progresso do tratamento.

Com base na literatura encontrada de Dias (2018), explica-se que é importante considerar o risco de problemas nutricionais nas crianças com TEA, haja vista que é necessária uma intervenção multidisciplinar do Terapeuta Ocupacional e outros profissionais da área, dentre eles um nutricionista, para que a criança receba intervenção adequada no que corresponde à seletividade alimentar.

A partir das informações obtidas do texto consultado de Machado et al. (2017) e Marí-Bauset et al. (2014), se extraíram os aspectos relacionados com a 
Integração Sensorial, onde as experiências sensoriais ajudam no desenvolvimento de respostas adaptativas conforme o ambiente.

Isto é, fornece respostas adequadas, esses trabalhos apontam que a seletividade alimentar inclui três domínios, dentre eles: alta frequência de ingestão única, repertório limitado de alimentos e recusa alimentar, adicionalmente, se identificou que existem lacunas na literatura relacionados com a seletividade alimentar em crianças com TEA, onde os aspectos se enquadram com comportamentais, sensoriais e culturais.

Portanto, os Terapeutas Ocupacionais apresentam relevantes benefícios de suas intervenções para somar com os demais profissionais para contribuir com informações científicas no tratamento mais indicado a cada caso de crianças com TEA que apresentem seletividade alimentar.

\section{CONSIDERAÇÕES FINAIS}

Esta revisão mostrou no resultado as expressões sobre a relação entre problemas alimentares e distúrbios de processamento sensorial, assim como a prevalência de seletividade alimentar em crianças com TEA, embora tenham sido encontrados alguns artigos, nota-se que esse campo necessita de mais pesquisas e esclarecimentos, especialmente no domínio da intervenção na área específica e com esse público específico.

O lócus das pesquisas em sua grande maioria foram para analisar estudos sobre a intervenção do Terapeuta Ocupacional em crianças com Transtorno do Espectro Autista que apresentam seletividade alimentar e sua relação com a perspectiva da Integração Sensorial.

Atendendo, assim, os objetivos do estudo, onde os resultados obtidos mostraram que determinadas crianças com Transtorno do Espectro Autista (TEA) em alguns momentos da sua vida, apresentam ou irão se apresentar um grau de seletividade alimentar ou aversão aos alimentos, ambos relacionados aos distúrbios sensoriais, características dos alimentos, textura, consistência, aparência visual e até mesmo o comportamento das crianças diante das refeições.

Faz-se necessário realizar mais estudos, para a avaliação dos problemas alimentares, apesar das fortes relações entre os quatros assuntos abordados, é preciso considerar as questões sensoriais ao se abordar os problemas alimentares, no que corresponde a crianças com TEA. 
Constatou-se, portanto, que há necessidade de estudos voltados a trazer contribuições para a teoria e prática da Terapia Ocupacional na área de seletividade alimentar. A pesquisa clínica é importante para obtermos melhor entendimento da realidade da seletividade alimentar em crianças com 0 diagnóstico de TEA e quais as contribuições da abordagem de Integração Sensorial.

\section{REFERÊNCIAS BIBLIOGRÁFICAS}

ALMEIDA, Bruna Ferreira de Paula. Autismo, seletividade alimentar e transtorno do processamento sensorial: revisão de literatura. Monografia (Especialização em Transtorno do Espectro do Autismo) - Universidade Federal de Minas Gerais, 2020.

ANDRADE, Aline Abreu et al. Treinamento de Pais e Autismo: Uma Revisão de Literatura. Ciências \& Cognição, v. 21, n.1, p. 07-22, 2016.

AYRES, A. J. Integração Sensorial e distúrbios de aprendizagem. Los Angeles, CA: Western Psychological Services; 1972

GAMA, B. T. B. et al. Seletividade Alimentar Em Crianças Com Transtorno Do Espectro Autista (TEA): uma revisão narrativa da literatura. Revista Artigos.Com, v. 17, p. e3916, 13 jun. 2021.

BURTET, Karine Souza; GODINHO, Lúcia Belina Rech. Envolvimento familiar na clínica do Autismo. Revista Cippus - UnilaSalle, Canoas/RS, v. 7, n. 2, p. 29- 44, nov. 2017.

CORREIA, C. Seletividade Alimentar e Sensibilidade Sensorial em Crianças com Perturbação do Espectro do Autismo. 26 f. Dissertação (Mestrado em Terapia Ocupacional) - Escola Superior de Saúde do Alcoitão, Santa Casa da Misericórdia de Lisboa, Lisboa, abr. 2015.

DIAS, E. C. Dieta isenta de glúten e caseína no Transtorno do Espectro do Autismo: uma revisão sistemática. Revista Cuidarte, Minas Gerais, v. 9, n. 1, p. 1-16, 2018.

FRUTUOSO, Maria Fernanda Petroli; OLIVEIRA, Bruna Muratti Ferraz de. Muito além dos nutrientes: experiências e conexões com crianças autistas a partir do cozinhar e comer juntos. Cad. Saúde Pública, Rio de Janeiro, v. 37, n. 4, p. e00132020, maio 2021.

GREEN, S. A.; BEN-SASSON, A. Anxiety disorders and sensory over-responsivity in children with autism spectrum disorders: is there a causal relationship? $\mathbf{J}$

Autism Dev Disord. v. 40, n. 12, p. 1495-1504, 2010.

LÁZARO, Cristiane Pinheiro. Construção de escala para avaliar o comportamento alimentar de indivíduos com transtorno do espectro do 
autismo (TEA). Tese (Doutorado em Medicina e Saúde Humana) - Escola Bahiana de Medicina e Saúde Pública, Salvador, 2016.

LÁZARO, Cristiane Pinheiro; CARON, Jean; PONDÉ, Milena Pereira. Escalas de avaliação do comportamento alimentar de indivíduos com Transtorno do Espectro Autista. Revista Psicologia: Teoria e Prática. São Paulo, v. 20, n. 3, p. 23-41, set./dez. 2018.

LÁZARO, Cristiane Pinheiro, SIQUARA, Gustavo Marcelino; PONDÉ, Milena Pereira. Escala de Avaliação do Comportamento Alimentar no Transtorno do Espectro Autista: estudo de validação. Jornal Brasileiro de Psiquiatria, v. 68, n. 4, 2019.

MARÍ-BAUSET, S. et al. Food Selectivity in Autism Spectrum Disorders: A Systematic Review. Journal of Child Neurology, v. 29, n. 11, p. 1554-61, nov. 2014.

MACHADO, Ana Carolina Cabral de Paula et al. Processamento Sensorial no Período da Infância em crianças nascidas Pré-termo: Revisão Sistemática. Revista Paulista de Pediatria, v. 35, n. 1, p. 92-101, 2017.

MATTOS, Jací Carnicelli. Alterações sensoriais no Transtorno do Espectro Autista (TEA): implicações no desenvolvimento e na aprendizagem. Rev. psicopedag., São Paulo, v. 36, n. 109, p. 87-95, 2019.

MONTENEGRO, K. S. et al. Desempenho ocupacional de cuidadores de crianças com Transtorno do Espectro Autista (TEA): uma revisão da literatura. Revista Eletrônica Acervo Saúde, n. 56, p. e4033, 13 ago. 2020.

MOURA, G.; SILVA, R. da; LANDIM, L. Seletividade alimentar voltada para crianças com transtorno do espectro autista (TEA): uma revisão da literatura. Revista Arquivos Científicos (IMMES), v. 4, n. 1, p. 14-19, 2021.

ROCHA, G. S. S. et al. Análise da seletividade alimentar de pessoas com Transtorno do Espectro Autista. Revista Eletrônica Acervo Saúde, n. 24, p. e538, 20 jun. 2019.

SANTOS, Regina Kelly dos; VIEIRA, Antônia Maira Emelly Cabral da Silva. Transtorno do Espectro do Autismo (TEA): do reconhecimento à inclusão no âmbito educacional. Universidade em Movimento: Educação, Diversidade e Práticas Inclusivas, v. 3 n. 1, 2017.

SERRANO, Paula Cira de Luque. A criança e a motricidade fina: desenvolvimento, problemas e estratégias. 2. ed. Lisboa: Papa-Letras, 2016.

SOUZA, R. F; NUNES, D. R. P. Transtornos do processamento sensorial no Autismo: algumas considerações. Revista Educação Especial, Santa Maria, v. 32, p. 1-17, 2019. papel da Terapia Ocupacional neste ambiente. 2016. 27f. Trabalho de Conclusão 
de Curso (Graduação em Terapia Ocupacional) - Universidade Federal de Minas Gerais, Belo Horizonte, 2016. 


\title{
EQUOTERAPIA SOBRE A PERSPECTIVA DA INTEGRAÇÃO SENSORIAL:
}

\author{
revisão de literatura
}

\author{
Débora Cristina dos Santos Pereira Tavares ${ }^{1}$ \\ Lenicy de Fátima Pina Ferreira ${ }^{1}$ \\ Raquel Bezerra da Silva ${ }^{1}$ \\ Marcilene Alves Pinheiro
}

\section{RESUMO}

A Integração Sensorial é um processo onde o SNC recebe, registra, organiza as sensações que chegam até o corpo internamente ou do ambiente, e gera respostas adaptativas, cada vez mais complexas. A Equoterapia proporciona movimentos tridimensionais, rítmicos e precisos; exigindo do praticante a participação integral do corpo, regulando tônus muscular, controle postural, entre outros, assim como sensoriais, equilíbrio, propriocepção e vestibular. Portanto, gera benefícios físicos, psicológicos, sociais e educacionais. O objetivo do estudo foi o de levantar literaturas acerca do processamento sensorial na Equoterapia e seus ganhos no desempenho das ocupações cotidianas na vida dos praticantes. A pesquisa caracteriza-se como descritivo, exploratório e retrospectivo. Utilizou-se a revisão integrativa da literatura, com seis etapas. Empregou-se os critérios de inclusão da produção científica: artigos completos, publicados na Biblioteca Virtual em Saúde (BVS), no período 2011 a 2021, na língua portuguesa, com resumo disponível, que explorassem os descritores de busca: "desordens sensoriais", "Equoterapia" e "Integração Sensorial". $\mathrm{Na} 1^{\circ} \stackrel{0}{ }$ varredura, encontrou-se 95 publicações. $\mathrm{Na} 2^{\underline{a}}$ varredura, após leitura na íntegra, utilizando como instrumento o roteiro (Anexo 1), adaptado por Ursi (2005), com resultado de 11 publicações, onde geraram a categoria de análise "TPS e a Equoterapia: inclusão e estratégias de Integração Sensorial para o desempenho ocupacional dos praticantes." Diante dos dados analisados, constatou-se a importância de incentivo à produção e publicação científicas relacionadas à temática, para a contribuição de novos e atuais estudos que relacionem a Equoterapia, Integração Sensorial, TPS no desempenho ocupacional para o aumento do arcabouço teórico e maior contribuição para esse campo profissional.

Palavras-chave: Equoterapia. Integração Sensorial. Desordem Sensorial.

\section{INTRODUÇÃO}

$\mathrm{Na}$ clínica de Terapia Ocupacional vem sendo mais frequente a procura por avaliações de demandas sensoriais. James et al. (2011) refere que 5\% a $16 \%$ da

\footnotetext{
1 Terapeutas Ocupacionais.

${ }^{2}$ Terapeuta Ocupacional/UEPA, Msc. Teoria e Pesquisa do Comportamento/UFPA, Certificação em IS - WPS/USC, Docente do Curso de Certificação Brasileira em Integração Sensorial - Integris/UEPA, Orientadora do trabalho.
} 
população geral de crianças são afetadas por desordens de modulação sensorial, e Chang et al. (2016), em suas pesquisas, constataram que "mais" de 16\% das crianças em idade escolar tem alteração no processamento sensorial, o que pode desencadear déficits cognitivos e comportamentais, trazendo prejuízos no cotidiano das crianças e de suas famílias.

A teoria da Integração Sensorial, originada na década de 1970 pela Terapeuta Ocupacional e Neuropsicóloga $\mathrm{Dr}^{\mathrm{a}}$ Anna Jean Ayres, tem fundamentos na neurobiologia do comportamento, onde se aprofunda sobre o sistema nervoso e os processamentos sensoriais e motores do comportamento humano; as pesquisas neste campo de conhecimento são emergentes e em constante evolução, ainda têmse limitada produção na literatura, hoje esse método terapêutico é registrado como Ayres Sensory Integration e está atrelado a um rol de princípios de fidelidade e prática baseada em evidências (LANE et al., 2019).

Ayres (2005) define a Integração Sensorial como um processo neurológico, onde o SNC recebe, registra e organiza as sensações que chegam até o corpo internamente e/ou do ambiente, de forma com que possa gerar respostas adaptativas, cada vez mais complexas, para o uso eficiente do corpo no ambiente. As informações referentes aos aspectos espaciais e temporais recebidas das modalidades sensoriais, tem ligação direta com as exigências do meio e o tipo de resposta emitida.

O desenvolvimento da práxis é um dos objetivos da Integração Sensorial,
que favorece a capacidade prática de realizar as atividades da vida diária
como: alimentação, vestuário, higiene pessoal, brincar, atividades
escolares, participação social entre outras. Três sistemas sensoriais são
centrais na Teoria de Integração Sensorial: tátil, vestibular e proprioceptivo.
Suas inter-relações começam a se formar antes do nascimento e continuam
a se desenvolver à medida que a pessoa amadurece e interage com seu
ambiente. Embora estes três sistemas sensoriais sejam menos familiares do
que a visão e a audição, eles são importantes para nossa sobrevivência
básica e desenvolvem um papel fundamental no comportamento humano
tanto físico quanto mental. (AYRES, 2005, p. 17).

Seus estudos também levantaram hipóteses onde um número significativo de crianças apresenta algum grau de dificuldades de processar e integrar informações sensoriais, podendo interferir na participação dessas em suas atividades diárias, visto que as habilidades de processamento dos inputs sensoriais dentro do corpo e do meio ambiente é importante para o desempenho ocupacional (AYRES, 2005).

Em pesquisas recentes, tem-se observado que o uso da terminologia de 
"Integração Sensorial" vem sendo substituída por "Processamento Sensorial". Dessa forma, define-se o Processamento Sensorial como função neurofisiológica onde se registra, organiza e interpreta as informações sensoriais captadas pelos sistemas sensoriais. Quando este processamento sensorial é deficitário, ou seja, há inabilidade de reproduzir informação útil diante das experiências sensoriais, manifesta-se um transtorno do processamento sensorial (MOMO; SILVESTRE, 2011).

O Transtorno do Processamento Sensorial (TPS) é considerado um transtorno neurológico, que ocasiona dificuldades na interpretação, no processamento e na percepção da informação sensorial advinda do corpo ou do ambiente via sistemas sensoriais. Os sistemas sensoriais são formados por receptores sensoriais que detectam os estímulos vindos do ambiente e do interior do corpo; estão localizados nos órgãos dos sentidos (pele, ouvido, olhos, língua e fossas nasais) e são constituídos por células nervosas especializadas em traduzir ou converter as mensagens em impulsos elétricos ou nervosos, para serem processados e analisados em áreas cerebrais, emitindo diferentes respostas do organismo (DUNN, 2014).

Segundo Schaaf e Nightlinger (2007), há três tipos de TPS: transtorno da modulação sensorial, transtorno sensório-motor e transtorno da discriminação sensorial. O TPS ocasiona problemas de comportamento e autoestima, já que interfere diretamente na interação social, assim, o fluxo de sensações é desorganizado, consequentemente, o indivíduo perde a capacidade de comportar-se adequadamente aos estímulos, afetando o aprendizado, o desenvolvimento da coordenação motora e da linguagem. Os sintomas das desordens sensoriais ocorrem em um leque de severidade, variando entre os indivíduos e afetando seu cotidiano (DUNN, 2014).

Ressalta-se que as alterações sensoriais de crianças vêm interferindo no desempenho de atividades diárias, como comer, dormir, mudanças nas rotinas de autocuidado e nas atividades fora de casa, como escola, viagens e participação em eventos na comunidade. Assim, as condutas terapêuticas vêm incluindo estratégias específicas de manejo de comportamentos sensoriais para melhorar a qualidade de vida e a participação social (POSAR; VISCONTI, 2018).

Segundo Krishnan (2018), os TPS podem afetar um indivíduo em um único sentido sensorial ou em vários; as dificuldades manifestadas terão relação com 
déficit de atenção, alterações comportamentais e/ou emocionais, dificuldades em planejamento motor e em organização dos movimentos, problemas em desempenhar com eficácia as AVDs e de Vida Prática (autocuidado, lazer, brincar e escola).

Segundo a Associação Mundial da Terapia Ocupacional (AOTA) (2015), o Terapeuta Ocupacional considera que um sujeito saudável é aquele capaz de estar envolvido ativamente no contexto em que está inserido. Nessa perspectiva, a Equoterapia é uma das possibilidades terapêuticas, onde o cavalo e seu ambiente natural oportunizará múltiplas experiências sensoriomotoras a partir da participação ativa, através do engajamento em atividades programadas durante a prática terapêutica.

A Associação Nacional de Equoterapia (ANDE) (2013) define esta prática como o método terapêutico e educacional que utiliza o cavalo dentro de uma abordagem multidisciplinar e interdisciplinar nas áreas de saúde, educação e equitação, buscando o desenvolvimento biopsicossocial de pessoas com deficiência e/ou com necessidades especiais, e emprega o cavalo como agente promotor de ganhos em nível físico e psíquico. Esta atividade exige a participação do corpo inteiro, contribuindo, assim, para o desenvolvimento da força muscular, relaxamento, conscientização do próprio corpo e aperfeiçoamento da coordenação motora e do equilíbrio. A interação com o cavalo, incluindo os primeiros contatos, os cuidados preliminares, o ato de montar e o manuseio final, desenvolvem, ainda, novas formas de socialização, autoconfiança e autoestima (LOPES, 2019).

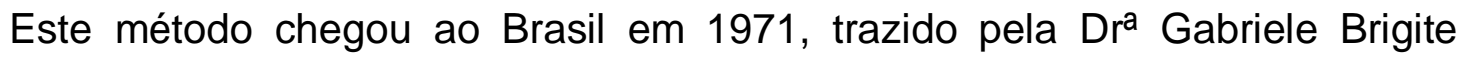
Walter, e vem sendo foco de estudos e aplicado com sucesso desde então (UZUN, 2005). Com a criação da ANDE-BRASIL, em 1989, foi dado um grande impulso à implantação de centros de Equoterapia no país e, de acordo com os dados, atualmente existem mais de 210 centros de Equoterapia, distribuídos nas cinco regiões, formados por equipe multiprofissional (ANDE, 2013).

O Conselho Médico Federal reconheceu o método em 1998 e o Conselho Federal de Fisioterapia e Terapia Ocupacional (COFFITO) dispõe sobre o reconhecimento da Equoterapia como recurso terapêutico da Fisioterapia e Terapia Ocupacional na Resolução no 348, de 27 de março de 2008 (BRASIL, 2008).

Vale ressaltar que o cavalo é naturalmente provido por três tipos de andaduras: passo, trote e galope. Para a abordagem da Equoterapia, o principal tipo 
utilizado é o passo. Estudos têm relacionado semelhanças com o movimento do corpo humano; a andadura do passo é ritmada, compassada e executada em quatro tempos (FONTANA et al., 2010).

Sanches (2010) diz que o cavalo pode proporcionar movimentos tridimensionais, rítmicos e precisos; exigindo do praticante (pessoa que participa do programa) a participação integral do corpo, regulando o tônus muscular, facilitando o desenvolvimento do controle postural, força muscular, coordenação motora, dissociação de cinturas, equilíbrio, propriocepção, autoconfiança e autoestima. Portanto, a base científica do método é o movimento tridimensional do passo do cavalo, este gera benefícios de ordem física, psicológica, social e educacional.

Duarte, Barbosa e Montenegro (2017) abordam sobre a semelhança da deambulação do cavalo com o caminhar humano, tendo apenas $5 \%$ de diferença, o cavalo ao caminhar seu movimento é rítmico e tridimensional devido a deslocar-se para frente, para trás, para os lados, para cima e para baixo, bem semelhante com a ação da pelve humana ao andar. Schmitt (2015) diz que a complexidade do movimento do cavalo é transmitida através da ligação existente do assento do praticante e o dorso do animal, onde o mesmo recebe uma série de estímulos motores sequenciados e simultâneos. O passo é uma andadura mais lenta, em quatro tempos e simétrica, geralmente, é a básica dos programas de Equoterapia.

Durante a prática da Equoterapia, o sistema sensorial também é estimulado, pois quando o praticante está em movimento no cavalo é ativado o sistema proprioceptivo, o vestibular e o tátil. Então, o cavalo está atuando nesses três sistemas que vão contribuir para o desenvolvimento e maturação de todos os sentidos.

Diante de uma sessão de 30 minutos de Equoterapia, estima-se a execução de 1800 a 2200 deslocamentos do praticante, estes inputs são transmitidos pelas vias aferentes para o SNC, onde serão processados e traduzidos como respostas estímulos para a melhoria na postura e consciência corporal (PFEIFER, 2012).

Lôbo (2016) cita que quando o cavalo troca de patas, desloca a cabeça para olhar para os lados, as flexões da coluna, o alongar do pescoço, estimula o praticante a uma mudança em seu comportamento muscular, a fim de gerar ajustes tônicos posturais, estes por ser ritmados causa mobilização ósteo-articular, o que proporciona uma variedade de informações proprioceptivas.

Silveira e Wibilingue (2011) relata que é imposto ao praticante de Equoterapia 
o alinhamento postural a partir dos ajustes tônicos, a estimulação proprioceptiva, tende a melhorar os padrões de movimentos globais, aumentando a estabilidade corporal; a estabilização da cintura escapular dos membros superiores irá torna os movimentos mais seletivos e coordenados. Acredita-se que o movimento tridimensional também estimula o sistema vestibular, que é um dos principais sistemas responsáveis pelas reações de equilíbrio, pois é ele que aciona o sistema musculoesquelético, para que ocorra a contração ou o relaxamento muscular.

Souza e Silva (2015) relembram que as sessões de Equoterapia são realizadas em ambiente amplo, em proximidade com a natureza, o que incentiva a motivação e descontração durante as atividades dirigidas pelo terapeuta, aumentando a disposição para a aprendizagem, já que o SNC através dos inputs multissensoriais, como estímulos táteis, visual, auditivo e olfativo, aumenta suas sinapses em diferentes áreas corticais. Cuervo (2017) enfatiza que durante a Equoterapia as sinapses neurais são ativadas tanto por neurotransmissores como por neuromoduladores, sendo liberado hormônios, tais como serotonina, endorfina, adrenalina, dopamina e noradrenalina, melhorando a atenção, habilidades cognitivas, emocionais e sociais.

Portanto, os Terapeutas Ocupacionais com qualificação na abordagem de Integração Sensorial e treinamento na Equoterapia, são profissionais essenciais dentro do contexto desta prática terapêutica. Dessa forma, o interesse pela temática começou a partir dos questionamentos, da escuta e observação de pacientes e seus familiares, sobre possibilidades terapêuticas, surgindo a motivação e o interesse de buscar conhecimento acerca dos estímulos sensoriais e motores promovidos pelo método da Equoterapia e, assim, relacionar com a teoria e prática de Integração Sensorial de Ayres. Assim como o desejo de atualização e de proporcionar uma prática baseada em evidências, para melhor atendermos possíveis demandas.

Diante do exposto, surgiu a problemática que visava discutir como a Integração Sensorial pode favorecer o processo de modulação das desordens sensoriais através do método da Equoterapia no desempenho cotidiano dos praticantes? E teve como questão problema: quais as possíveis contribuições da Equoterapia para as desordens sensoriais na perspectiva da Integração Sensorial de Ayres e melhoria no desempenho das ocupações cotidianas dos praticantes? Logo, este estudo teve como objetivo geral, levantar literaturas acerca do processamento sensorial na Equoterapia e seus ganhos no desempenho das ocupações cotidianas 
na vida dos praticantes.

\section{METODOLOGIA}

\subsection{Tipo de Estudo}

O estudo caracteriza-se como descritivo, exploratório e retrospectivo. Utilizamos como método de procedimento, a revisão integrativa da literatura, que envolve seis etapas. A revisão integrativa é um método de pesquisa utilizado desde 1980, no âmbito da Prática Baseada em Evidências (PBE), que envolve a sistematização e publicação dos resultados de uma pesquisa bibliográfica em saúde para que possam ser úteis na assistência à saúde, acentuando a importância da pesquisa acadêmica na prática clínica. O principal objetivo da revisão integrativa é a integração entre a pesquisa científica e a prática profissional no âmbito da atuação profissional (MENDES, SILVEIRA; GALVÃO, 2008).

\subsection{Estratégias de Busca}

As buscas ocorreram no período de julho a setembro de 2021 por pesquisadores independentes, seguindo o roteiro de análise adaptado proposto por Ursi e Galvão (2005).

A base eletrônica selecionada (BVS) foi determinada pelo fato de que ela engloba artigos científicos de variadas bases virtuais, como Bireme, LILACS e SciELO.

\subsection{Etapas da Pesquisa}

$\mathrm{Na}$ primeira etapa buscou-se o estabelecimento da questão norteadora de investigação, ou seja, "Quais as possíveis contribuições da Equoterapia para a modulação/redução dasdesordens sensoriais na perspectiva da Integração Sensorial de Ayres e melhoria no desempenho das ocupações cotidianas dos praticantes?".

A segunda etapa se referiu à seleção da amostra, em que foram empregados os seguintes critérios de inclusão da produção científica: artigos completos, publicados na Biblioteca Virtual em Saúde (BVS), no período de 2011 a 2021, na língua portuguesa e/ou inglesa, com resumo disponível, realizados no Brasil, que explorassem as palavras-chaves determinadas: "desordens sensoriais", "Equoterapia" e "Integração Sensorial". 
$\mathrm{Na}$ terceira e quarta etapa foi realizada a caracterização dos estudos e os dados foram sistematizados em quadros. Na quinta etapa procedeu-se a análise temática dos artigos e a discussão dos resultados. Na sexta etapa, referente à interpretação dos resultados, foi incluído informações para que o leitor examine as evidências levantadas e suas implicações quanto ao objeto de pesquisa.

\subsection{Critérios de Elegibilidade}

Quanto à seleção das publicações foi realizada mediante a leitura do título e resumo de cada artigo, a fim de avaliar se os critérios de inclusão estavam contemplados. A leitura inicial resultou em um quantitativo de 11 publicações, com levantamento de pontos relevantes de cada artigo, com o intuito de melhor organizar os principais assuntos abordados no texto para posterior caracterização.

\subsection{Análise e Apresentação dos Resultados}

Em cada um dos artigos foram identificadas unidades de significado relativas à questão norteadora. Posteriormente, cada conjunto de unidades de significado semelhantes gerou um tema para a análise ao qual foi contemplado neste estudo: Transtorno do Processamento Sensorial (TPS) e a Equoterapia: inclusão de estratégias de Integração Sensorial para o desempenho ocupacional dos praticantes.

\section{RESULTADOS}

Do total de artigos analisados na base de dados (BVS), em uma busca inicial, foram encontradas 95 publicações, divididas entre os seguintes descritores do Quadro 1.

Quadro 1 - Quantidade de artigos por descritor (1av varredura)

\begin{tabular}{|c|c|}
\hline Descritor Quantidade de Artigos & Descritor Quantidade de Artigos \\
\hline Desordem Sensorial & 05 \\
\hline Equoterapia & 35 \\
\hline Integração Sensorial & 55 \\
\hline Total & 95 \\
\hline
\end{tabular}

Fonte: Elaboração dos autores. 
Quanto à pequena quantidade de achados referentes ao descritor "desordem sensorial" e onde os mesmos não estavam contemplando o objetivo do presente estudo, o mesmo foi refeito para melhor contemplar o objetivo das pesquisadoras, tornando-se "Transtorno do Processamento Sensorial", resultando em 39 achados deste novo descritor. Mesmo com o acréscimo de um novo descritor, continuou um quantitativo de três descritores e o total de artigos, como especificado a seguir no Quadro 2. 
Quadro 2 - Quantidade de artigos por descritor (ajustes)

\begin{tabular}{|c|c|}
\hline Descritor Quantidade de Artigos & Descritor Quantidade de Artigos \\
\hline Transtorno do Processamento Sensorial & 39 \\
\hline Equoterapia & 35 \\
\hline Integração Sensorial & 56 \\
\hline Total & $\mathbf{1 2 0}$ \\
\hline
\end{tabular}

Fonte: Elaboração dos autores.

Após a leitura de cada resumo, foram selecionados 11 artigos para a análise final (Quadro 3), que contemplaram os critérios de inclusão para este estudo. No que tange aos achados a partir do descritor "Transtorno do Processamento Sensorial", que obteve 39 achados, apenas três foram utilizados; no "Equoterapia", dos 35 achados, cinco foram utilizados, em "Integração Sensorial" obteve-se 56 achados, porém, apenas três foram selecionados. Ao final da segunda varredura, obtiveramse os seguintes resultados:

Quadro 3 - Quantidade de artigos por descritor (2ª varredura)

\begin{tabular}{|c|c|}
\hline Descritor Quantidade de Artigos & Descritor Quantidade de Artigos \\
\hline Equoterapia & 05 \\
\hline Integração Sensorial & 03 \\
\hline Transtorno do Processamento Sensorial & 03 \\
\hline Total & $\mathbf{1 1}$ \\
\hline
\end{tabular}

Fonte: Elaboração dos autores.

Quanto à análise de dados, foi selecionada a unidade temática a partir da leitura dos 11 artigos da segunda varredura, de acordo com o Quadro 4.

Quadro 4 - Unidades temáticas geradas a partir dos descritores pesquisados

\begin{tabular}{|c|c|}
\hline Descritor (es) & Unidade Temática \\
\hline Equoterapia & $\begin{array}{c}\text { TPS e a Equoterapia: inclusão e estratégias } \\
\text { de Integração Sensorial para o desempenho } \\
\text { ocupacional dos praticantes. }\end{array}$ \\
\hline Integração Sensorial & \begin{tabular}{c} 
Transtorno do Processamento Sensorial \\
\hline
\end{tabular}
\end{tabular}

Fonte: Elaboração dos autores.

\section{DISCUSSÃO}

No âmbito da análise temática dos artigos, foi possível ordenar uma categoria de análise, a saber: "TPS e a Equoterapia: inclusão e estratégias de Integração Sensorial para o desempenho ocupacional dos praticantes." 
4.1 TPS e a Equoterapia: inclusão e estratégias de Integração Sensorial para o desempenho ocupacional dos praticantes

Equoterapia é um conceito formulado pela Associação Brasileira de Equoterapia (ANDE) como um método terapêutico e educacional que, através do emprego do cavalo, busca objetivar o desenvolvimento biopsicossocial de pessoas com alguma deficiência, seguindo uma abordagem interdisciplinar (GONÇALVES; LIMA, 2019).

A Equoterapia vai auxiliar na integração social, no comportamento e na efetividade, promovendo inúmeros efeitos benéficos (LANNING et al., 2014), trabalhando em torno da estimulação física, pois, embora o paciente não se exercite, receberá estimulação física por meio do movimento tridimensional proporcionado pela postura do cavalo.

O estado assíncrono dos cavalos fornece estimulação física por meio de movimentos e oscilações, a fim de promover a estimulação sensorial, ativação e regulação nervosa, capaz de disparar, conforme descrito por Barbosa e Muster (2014), eferentes (movimentos) correspondendo a um conjunto de ativações sensoriais, aos quais fornecem muitos benefícios psíquicos, melhora a interação social, concentração, autonomia, autoconfiança e autoestima também conduzem ao equilíbrio e ao exercício (BORGI et al., 2016). Logo, podemos perceber a importância que o movimento do cavalo pode proporcionar aos seus praticantes através do método de Equoterapia.

Ou seja, a Equoterapia também é considerada um recurso para a superação de deficiências sensoriais, cognitivas e comportamentais, permite que os pacientes tenham maiores habilidades sociais e melhorem significativamente no nível de atenção (UZUN, 2005).

Dentre os artigos eleitos nesta revisão, percebe que o público predominante é o infantojuvenil. Ré (2011) descreve que o processo de desenvolvimento humano na infância passa por muitas alterações no aspecto motor, cognitivo, afetivo e social, em decorrência da maturação do sistema nervoso central, o qual recebe influência dos fatores ambientais e biológicos. Assim como na adolescência, fase de mudanças hormonais e alterações biológicas, físicas e funcionais. Esse fato presente na prática da Equoterapia enfatiza as habilidades motoras e cognitivas em constante evolução no referido público.

Paralelo aos benefícios que a Equoterapia pode proporcionar nas alterações 
sensoriais, é de extrema importância relatar que a Integração Sensorial inicia desde a vida intrauterina, quando o SNC do feto sente os movimentos maternos e seguese aperfeiçoando após o nascimento ao longo de toda a infância (KANDEL et al, 2014). A $\mathrm{Dr}^{\mathrm{a}}$ Ayres referia que a criança carrega uma capacidade inata para responder ao meio de forma adaptada, e é durante o desenvolvimento infantil a partir da interação com o meio e com os significados deste que se dará a organização da informação sensorial e a habilidade de responder de forma adaptativa, sendo evidente nas áreas motoras, cognitivas, da linguagem e psicoemocional (SERRANO, 2016).

A capacidade inata enfatizada nos estudos de Ayres, é definida como motivador interno diante de um desafio certo. A criança é ativa como receptora das sensações, ela fará a integração da sensação, a organização da informação, para um futuro plano de ação, reação ou comportamento. Diante de respostas adaptativas, sabe-se que as sensações estão sendo organizadas de maneira eficaz no SNC, possível devido à plasticidade que o cérebro tem e que faz as estruturas cerebrais alcançarem maior maturação (SERRANO, 2016).

Durante a prática de Equoterapia, o SNC recebe uma variedade de inputs sensório-motores, gerando uma situação motivacional e maior disposição para a aprendizagem. Cattaneo e Jonsdottir (2009) observaram melhores respostas no equilíbrio postural diante da utilização de exercícios com estratégias sensoriais do que exercícios aeróbicos e resistivos; isto ocorreu devido à posição de montaria associada a passada do cavalo solicitar constantes reações posturais do praticante (sistema somatossensorial) combinadas com a dissociação das cinturas pélvicas e escapular, retificação de tronco e ajustes tônicos, além de diversificar as inúmeras informações captadas pelo sistema visual, auditivo e enviadas ao sistema vestibular.

Serrano (2016) elucida que essa participação ativa na sessão de Equoterapia, onde SNC do praticante procura oportunidades para o desenvolvimento de novas sinapses através de respostas adaptativas é o que separa a Integração Sensorial da estimulação sensorial.

Segundo Silva e Grubits (1994), a Equoterapia estimula constantemente o mecanismo do controle postural e noções de posição dos vários segmentos corporais no espaço, favorecendo as reações de equilíbrio, através do sistema vestibular. Existem também, de acordo com os autores, as informações proprioceptivas, advindas das regiões articulares, musculares e tendinosas, as quais 
realizam uma reeducação neuromuscular através dos movimentos do cavalo, permitindo, assim, ganhos no alinhamento corporal (cabeça, tronco, quadril), controle das simetrias globais, equilíbrio estático e dinâmico.

Assim como os estímulos já citados, existem os interligados à via auditiva e olfatória que são proporcionados pelas características do ambiente natural onde são realizadas as sessões e também aqueles relacionados à comunicação com a equipe que realiza a intervenção. Portanto, conclui-se que a terapia com cavalos pode ser considerada um recurso capaz de oferecer ao deficiente um estímulo global e motivador (LEITÃO, 2008).

De acordo com o Conselho Regional de Fisioterapia e Terapia Ocupacional da $3^{\circ}$ região (CREFITO 3), correspondente ao estado de São Paulo, a Terapia Ocupacional é uma área da saúde que possui uma ampla formação nas ciências que abordam a saúde, o social, o comportamento, os aspectos psicossociais e ocupacionais. Centrada no cliente, o Terapeuta Ocupacional possui competência para promover saúde e bem-estar através da ocupação.

No método da Equoterapia, um dos objetivos do Terapeuta Ocupacional é proporcionar ao praticante o maior nível de independência e autonomia em suas ocupações por intermédio do cavalo. Segundo AOTA (2015), a estrutura na prática da profissão descreve que as ocupações são caracterizadas como atividades nas quais os indivíduos se engajam diariamente, podendo ser categorizadas como Atividades de Vida Diária (AVDs), Atividades Instrumentais de Vida Diária (AIVDs), educação, trabalho, brincar, lazer, descanso, sono e participação social.

\section{CONSIDERAÇÕES FINAIS}

Pesquisas que avaliam a contribuição da Equoterapia para a Integração Sensorial e no Transtorno do Processamento Sensorial, de modo geral, estão sendo apresentadas sob diferentes perspectivas. Nesse sentido, as investigações multidisciplinares e interdisciplinares com a contribuição científica estão abrindo caminhos que podem levar a pesquisa da prática em Equoterapia à prática da Integração Sensorial e a melhoria no desempenho ocupacional.

A partir desta pesquisa buscou-se uma gama de análises vinculadas à temática com o intuito de proporcionar e fazer um levantamento atualizado sobre a relação entre a Equoterapia, a Integração Sensorial e o Transtorno do Processamento Sensorial para relacionar e problematizar tais possibilidades. 
Porém, no decorrer das pesquisas sobre o tema deparou-se com as dificuldades de encontrar artigos sobre a interface entre a Integração Sensorial, desordens sensoriais e as intervenções com o método da Equoterapia, houve dificuldades na coleta de dados, pois de acordo com os critérios de inclusão, na primeira varredura muitos foram os resultados, contudo, fora do período estipulado (2011 a 2021) e textos não disponíveis. Logo, a busca mais atualizada tornou-se uma dificuldade para coletar mais dados, visto que se constataram poucas produções científicas na interface desejada.

Outra dificuldade encontrada, quanto aos artigos relacionados com a desordem sensorial, além de ser pouquíssimos no período selecionado, a maioria não tinha relação com a temática do artigo. Tanto foi a dificuldade que na primeira varredura, foram quatro achados, entretanto, nenhum foi selecionado, assim como é de conhecimento que esta nomenclatura está em desuso, contribuindo assim para a dificuldade nos achados, na segunda varredura, sendo necessária alteração no descritor, a fim de auxiliar na coleta, mudando de "desordem sensorial" para "Transtorno do Processamento Sensorial", em que 39 artigos foram encontrados e, desses, apenas três foram selecionados para análise, mas, ainda assim, não eram artigos que abordavam especificamente o TPS.

Diante do cenário, é de extrema importância a publicação de mais artigos relacionados à temática, principalmente os de Integração Sensorial e Transtorno do Processamento Sensorial, para o aumento do arcabouço teórico e para maior contribuição do campo profissional prático da Integração Sensorial na Equoterapia, fazendo-se necessário cada vez mais a contribuição de novos e atuais estudos que relacionem a Equoterapia, Integração Sensorial e Transtorno do Processamento Sensorial, assim como analisar as possibilidades da Terapia Ocupacional em contribuir para o engajamento ocupacional satisfatório desses praticantes, que, segundo a Associação Americana de Terapia Ocupacional (AOTA, 2015), proporciona saúde, bem-estar, qualidade de vida, independência e autonomia, o que também demonstra a necessidade de produção de estudos que analisem e comprovem a relevância e os ganhos proporcionados pelo Terapeuta Ocupacional na Equoterapia e a necessidade do mesmo compor a equipe básica.

Faz-se necessário também o aumento das pesquisas científicas que envolvem Terapeutas Ocupacionais como forma de divulgar e evidenciar cientificamente o método com objetivos da referida profissão na Equoterapia ao 
relatarem que os movimentos do cavalo são utilizados com a intenção de promover ganhos motores, cognitivos e no processamento sensorial, de modo a trabalhar em conjunto com os sistemas sensoriais e, consequentemente, obter melhora no desempenho das Atividades de Vida Diárias (AVDs), as quais podem ser atreladas aos cuidados demandados do cavalo, tais como: banho, alimentação e vestuário adequado (equipamentos). Além das AVDs, o Terapeuta Ocupacional está capacitado para desenvolver atividades que contemple todas as outras ocupações humanas. O praticante estará desenvolvendo essas práticas com o cavalo a fim de propiciar uma melhor compreensão dessas atividades dentro das suas vivências como ser humano, igualmente da importância delas.

Mesmo com as dificuldades, ainda assim, acredita-se que esta pesquisa pode contribuir significativamente para a estruturação e divulgação do arcabouço teórico quais as possíveis contribuições da Equoterapia para a modulação/redução das desordens sensoriais, na perspectiva da Integração Sensorial de Ayres, e melhoria no desempenho das ocupações cotidianas dos praticantes, na medida em que frente à escassez de dados, buscou-se refletir e problematizar estratégias e perspectivas que possam auxiliar os praticantes no seu processo de desempenho ocupacional na Equoterapia.

\section{REFERÊNCIAS BIBLIOGRÁFICAS}

AMERICAN OCCUPATIONAL THERAPY ASSOCIATION. Occupational therapy practice framework: Domain and process. 3 ed. American Journal of Occupational Therapy, v. 68, supp. 1, 2014. doi: http://dx.doi.org/10.5014/ajot.2014.682006.

ANDE. ASSOCIAÇÃO NACIONAL DE EQUOTERAPIA. Equoterapia. [s.d.]. Disponível em: http://Equoterapia.org.br/articles/index/articles_list/138/81/0. Acesso em: 27 nov. 2021.

ANDE. Curso básico de Equoterapia. Brasília: Coordenação de Ensino Pesquisa e Extensão - COEPE, 2013.

ARAÚJO, J. F. L. Análise conformacional dos equinos utilizados na Equoterapia do Centro de Reabilitação e Readaptação Doutor Henrique Santillo, Goiânia, Goiás. 2016. 72 f. Dissertação (Mestrado em Ciência Animal) - Universidade Federal de Goiás, Goiânia, 2016.

AYRES, A. J. What's Sensory Integration? An Introduction to the Concept. In: AYRES, A. J. Sensory Integration and the Child: 25th Anniversary Edition. Los Angeles, CA: Western Psychological Services, 2005. 
BARBOSA, O. B; MUNSTER M. A. O efeito de um programa de Equoterapia no desenvolvimento psicomotor de crianças com indicativos de transtorno de déficit de atenção e hiperatividade. Rev. Bras. Educ. Espec., v. 20, n. 1, p. 69-84, 2014. doi: https://doi.org/10.1590/S1413-65382014000100006

BORGI, M. et al. Effectiveness of a standardized equine-assisted therapy program for children with autism spectrum disorder. J Autism Dev Disord, v. 46, n. 1, p. 1-9, 2016. doi: https://doi.org/10.1007/s10803-015-2530-6.

BRASIL. Conselho Federal de Fisioterapia e Terapia Ocupacional. Resolução n. 348, de 27 de março de 2008. Dispõe sobre o reconhecimento da EQUOTERAPIA como recurso terapêutico da Fisioterapia e da Terapia Ocupacional e dá outras providências. Brasília: Diário Oficial da União, 27 mar. 2008.

CATTANEO, D.; JONSDOTTIR, J. Sensory Impairments in quiet standing in subjects with multiple sclerosis. Mult Scler., v. 15, n. 1, p. 59-67, 2009.

CHANG, Y. S. et al. White matter microstructure is associated with auditory and tactile processing in children with and without sensory processing disorder. Front Neuroanat, v. 9, p. 169, 2016.

CUERVO, J. de L. P. Beneficios de la equinoterapia en niños con TEA. Repositorio Abierto de la Universidad de Cantabria, 28 jun. 2017. Disponível em: https://repositorio.unican.es/xmlui/bitstream/handle/10902/11839/PrietaCuervoJazmi naDeLa.pdf?sequence=1\&isAllowed=y. Acesso em: 27 nov. 2021.

DUARTE, E.; BARBOSA, W.; MONTENEGRO, S. Contribuições da Equoterapia para o Desenvolvimento Integral da Criança Autista. Trabalho de Conclusão de Curso (Graduação de Pedagogia) - Universidade Federal de Pernambuco, 2017.

DUNN, W. Sensory profile 2: user's Manual. San Antonio: NCS Pearson, 2014.

FONTANA, R. et al. Therapeutic process and perspectives about the practice of equine-assisted therapy. Revista de Enfermagem Ufpe On Line, [s.L.], v. 4, n. 2, p. 757-763, 2010.

GONÇALVES, L. N.; LIMA, A. C. D. Atuação terapêutica ocupacional na Equoterapia: uma revisão de literatura. Revista Chilena de Terapia Ocupacional, Chile, v. 19, n. 2, p. 11-23, dez. 2019.

JAMES K. et al. Phenotypes with sensory modulation dysfunction. Compr Psychiatry., v. 52, n. 6, p. 715-724, 2011.

KANDEL, E. R. et al. Princípios de neurociências. 5. ed. Porto Alegre: AMGH, 2014.

KRISHNAN, K. N. The SI solution: the definitive family guide to thriving during sensory integratiion dysfunction. Lewiston: Autor, 2018.

LANE, S. J. et al. Neural foundations of Ayres sensory integration. Brain Sciences, v. 9 , n. 7 , p. $1-14,2019$ 
LANNING, B. A. et al. Effects of equine assisted activities on autism spectrum disorder. J Autism Dev Disord, v. 44, n. 8, p. 1897-1907, 2014. doi: https://doi.org/10.1007/s10803-014-2062-5.

LEITÃO, L. G. Sobre a equitação terapêutica: Uma abordagem crítica. Análise Psicológica, v. 1, n. 26, p. 81-100, 2008.

LÔBO, Jakeline Ferreira de Araújo. Análise conformacional dos equinos utilizados na equoterapia do Centro de Reabilitação e Readaptação Doutor Henrique Santillo. Dissertação (Mestrado em Ciência Animal) - Universidade Federal De Goiás, Goiás, 2016.

LOPES, Josiane et al. Efetividade da Equoterapia na marcha de crianças com Paralisia Cerebral: revisão sistemática de ensaios clínicos. Revista Brasileira de Neurologia, Rio de Janeiro, v. 55, n. 1, p. 25-34, jan./mar.2019

MENDES, K. D. S.; SILVEIRA, R. C. C. P.; GALVÃO, C. M. Revisão integrativa: método de pesquisa para a incorporação de evidências na saúde e na enfermagem. Texto Contexto Enfermagem, Florianópolis, v. 17, n. 4, p. 758-764, out./dez. 2008.

MOMO, A.; SILVESTRE, C. Integração Sensorial nos Transtornos do Espectro do Autismo. In: SCHWARTZMAN, J. S.; ARAUJO, C. A. Transtornos do Espectro do Autismo. São Paulo: MEMNON, 2011. p. 297-313.

PFEIFER, L. T. O. Equoterapia: a influência da variação do peso na frequência do passo do cavalo. Ensaios e Ciência: Ciências Biológicas, Agrárias e da Saúde, v. 16, n. 3, p. 39-48, 2012.

POSAR, A.; VISCONTI, P. Anormalidades sensoriais em crianças com Transtorno do Espectro Autista. J Pediatr., Rio de Janeiro, v. 94, n. 4, p. 342-350, jul./ago. 2018. doi: 10.1016/j.jped.2017.08.008.

RÉ, A. H. N. Crescimento, maturação e desenvolvimento na infância e adolescência: Implicações para o esporte. Motricidade, v. 7, n. 3, p. 55-67, 2011.

ROSA, N. F. Manual de avaliação motora. Porto Alegre: Artmed Editora, 2002. $136 p$.

SANCHES, S. M. N. Equoterapia na reabilitação da meningoencefalocele: estudo de caso. Fisioterapia e Pesquisa, v. 17, n. 4, p. 358-361, 2010.

SANGHAVI, R. K. R. Visual-motor integration and learning disabled children. The Indian Journal of Occupational Therapy, v. 37, n. 2, p. 33-38, 2005.

SANTOS, P. Educação Não Formal e Equoterapia: O galope do educador na arena da terapia. Dissertação (Mestrado em Pedagogia) - Centro Universitário Salesiano de São Paulo, Americana, 2012.

SCHAAF, R.; NIGHTLINGER, K. Occupational therapy using a sensory integrative 
approach: a case study of effectiveness. The American Journal of Occupational Therapy, v. 61, p. 239-246, 2007.

SERRANO, P. A Integração Sensorial no desenvolvimento da aprendizagem da criança. Lisboa: Papa Letras, 2016.

SCHMITT, J. F. Terapia assistida por animais e pessoas com transtorno do espectro autista: uma revisão. Tese - Universidade de Tuiuti do Paraná, Curitiba, 2015.

SILVA, C.H; GRUBITS, S. Discussão sobre o efeito positivo da Equoterapia em crianças cegas. PSIC - Revista de Psicologia, v. 5, n. 2, p. 06-13, 1994.

SILVEIRA, Michele M; WIBELINGER, Lia M. Reeducação da Postura com a Equoterapia. Revista Neurociências, Passo Fundo, v. 19, n. 3, p. 519-524, set. 2011.

SOUZA, M. B.; SILVA, P. L. N. Equoterapia no Tratamento do Transtorno do Espectro Autista: A Percepção dos Técnicos. Revista Ciência e Conhecimento, v. 9, n.1, fev. 2015.

URSI, E. S.; GALVÃO, C. M. Prevenção de lesões de pele no perioperatório: revisão integrativa da literatura. Rev Latino-am Enfermagem, v. 14, n. 1, p. 124-131, jan./fev. 2006.

UZUN, A. L. L. Equoterapia: aplicação em distúrbios do equilíbrio. São Paulo: Vetor 2005.

\section{ANEXO 1 -}

INSTRUMENTO PARA COLETA DE DADOS

Adaptado de Ursi (2005)

Quadro 5 - Itens para análise dos artigos coletados

\begin{tabular}{|l|}
\hline Identificação \\
\hline Título do Artigo \\
\hline Título do Periódico \\
\hline Ano de Publicação \\
\hline Características metodológicas do Estudo \\
\hline Objetivo ou questão de investigação \\
\hline Resultados \\
\hline
\end{tabular}

Fonte: Ursi e Galvão (2006). 


\title{
A ABORDAGEM DE INTEGRAÇÃO SENSORIAL NO TRATAMENTO DE CRIANÇAS COM PARALISIA CEREBRAL
}

\author{
Gyselle da Silva Coutinho ${ }^{1}$ \\ Isabelly Nair Barbosa Camelo ${ }^{1}$ \\ Mariane da Silva Miranda ${ }^{1}$ \\ Arla Lobo Fonseca ${ }^{2}$
}

\section{RESUMO}

O presente artigo consiste em uma revisão bibliográfica de natureza básica, com caráter exploratório usando da abordagem qualitativa, tendo como referencial um total de 15 artigos que abordam na íntegra ou parcialmente sobre o tema da pesquisa, buscando enfatizar os efeitos e contribuições do uso da abordagem de Integração Sensorial no tratamento de crianças com diagnóstico de Paralisia Cerebral (PC), que é uma desordem no mecanismo postural, devido a uma anomalia não progressiva do cérebro imaturo, tendo como classificação topográfica: Monoplegia, Diplegia, Hemiplegia, Triplegia e Quadriplegia. A Integração Sensorial (IS) é uma abordagem da Terapia Ocupacional que é responsável por organizar as informações do cérebro, dar significado e responder aos estímulos sensoriais. A Teoria de Integração Sensorial é baseada na neurociência e baseada em pesquisas científicas. O presente estudo buscou analisar os efeitos e contribuições do uso da abordagem de Integração Sensorial no tratamento de crianças com o diagnóstico de Paralisia Cerebral. Sendo selecionados apenas três artigos, sendo um da PubMed e dois do Google Acadêmico, os quais foram lidos integralmente para verificar se abordavam a Integração Sensorial e Paralisia Cerebral. Os estudos pesquisados demonstram resultados significativos na função motora grossa e nos aspectos sensoriais das crianças com PC. Portanto, o presente artigo ressalta a possibilidade de combinação da abordagem de Integração Sensorial com outros métodos de tratamento para a criança com Paralisia Cerebral, favorecendo não apenas estímulos sensoriais como também motores, ofertando, desse modo, uma intervenção mais enriquecida dentro da Terapia Ocupacional.

Palavras-chave: Paralisia Cerebral. Integração Sensorial. Intervenções.

\footnotetext{
${ }^{1}$ Terapeutas Ocupacionais.

${ }^{2}$ Terapeuta Ocupacional. Docente do Curso de Certificação Brasileira em Integração Sensorial Integris/UEPA. Orientadora do trabalho.
} 


\section{INTRODUÇÃO}

Definido por Ayres (1979), o conceito de Integração Sensorial, como usado atualmente, é a habilidade de organizar os estímulos recebidos, filtrar as principais informações necessárias no momento e descartar as que não merecem atenção. Esse processo neurobiológico que organiza as sensações do próprio corpo e externas, permitindo organizar o comportamento e reações adequadas a determinados estímulos sensoriais. A Teoria de Integração Sensorial é baseada na neurociência e baseada em pesquisas científicas.

Magalhães (2008) ressalta que o estudo desenvolvido por Ayres teve um maior direcionamento para os sistemas: tátil, vestibular e proprioceptivo, e suas possíveis contribuições para a aprendizagem escolar de crianças, devido a esses sistemas processarem informações do corpo, diferentemente dos demais, como: visão, audição, olfação e gustação, que processam informações externas ou ambientais. Em 1950, Ayres também desenvolve estudos com crianças com Paralisia Cerebral, e, diante dos resultados obtidos, sugere que os déficits não seriam apenas motores, mas também sensoriais (MAGALHÃES, 2008).

Dunn (2014) define o processamento sensorial como o mecanismo para organizar, dar significado e responder aos estímulos sensoriais, sendo a Integração Sensorial um componente desse processo. Fisher, Murray e Bundy (1993) referemse à inabilidade de realizar de forma adequada o processamento sensorial para responder aos estímulos, como Transtorno do Processamento Sensorial.

As crianças com Transtorno do Processamento Sensorial apresentam dificuldades no planejamento e execução de movimentos, o que comprometerá seu desempenho (FARIAS, 2010). Blanche e Nakasuji (2001) ressaltam as consequências advindas desse déficit, afetando, possivelmente, a coordenação motora, aprendizagem, interação social e com o ambiente em que o indivíduo está inserido, dentre outros.

A Encefalopatia Crônica Não Progressiva da infância (ECNP) ou Paralisia Cerebral (PC), como também é denominada, consiste em uma sequela ou agressão que afeta o Sistema Nervoso Central (SNC) da criança, causando impactos no desenvolvimento motor normal e tônus muscular. Esse transtorno ocorre na infância, exercendo influência no processo de maturação neurológica, ainda no desenvolvimento fetal ou infantil (FARIAS, 2010). 
Conforme o estabelecido pelas Diretrizes Brasileiras de Atenção à Pessoa com Paralisia Cerebral (2013), no Brasil, existe carência de estudos sobre a prevalência e incidência da PC no cenário nacional. Segundo Silva, Romão e Andrade (2019), a incidência da PC em nosso país é em torno de sete em cada mil crianças nascidas vivas, resultando em cerca de 30.000 a 40.000 crianças com PC ao ano. Os números globais são de 2,1 em cada mil nascidos em países desenvolvidos, correspondendo a $74 \%$ dos casos em todo o mundo (LIANG et al., 2021).

A PC é considerada um transtorno sensório-motor, pois as lesões causadas no sistema nervoso podem afetar o sistema neuromotor, interferindo no progresso do movimento e postura. Aliada a falta de independência em competências das atividades de vida diária, como: autocuidado, brincar funcional, alimentação, atividades instrumentais de vida diária e participação social, pode apresentar déficits neuromotores e sensoriais nas competências escolares de escrita, movimentos finos, cognitivos e de percepção visual, limitando a ativa exploração do ambiente (ZANINI; CEMIN, 2009).

Para Silva e Beltrami-Daltrário (2008), a criança com PC tem dificuldades de sensoriais e perceptivas no cotidiano, bem como na habilidade de fornecer uma resposta eficaz para o meio externo. Apresentando distúrbios de postura e movimento devido a essas limitações neuromotoras e sensoriais causadas pela Paralisia Cerebral, que comprometem a habilidade de deambulação e a independência funcional que são tão limitantes quanto as desordens motoras e que dificultam a maior ocupação de uma criança, que é o brincar.

Os principais transtornos do processamento sensorial apresentadas pelas crianças com PC são táteis, vestibulares e proprioceptivas. Há um déficit no processamento para respostas que exigem movimento, incluindo respostas aversivas ao movimento e insegurança gravitacional, medo e respostas inadequadas devido à ausência de experiências gravitacionais, déficits do sistema proprioceptivo com o cérebro, não processando adequadamente as informações relacionadas ao corpo no espaço, a hipossensibilidade ao estímulo proprioceptivo pode causar um tônus muscular baixo alterando a execução dos movimentos e resultar em problemas no desenvolvimento do controle postural, planejamento motor, esquema corporal, coordenação motora global, além de influenciar no brincar funcional, sendo está a maior ocupação na infância. Com isso, faz-se necessário considerar a 
importância das deficiências sensoriais que acompanham as deficiências motoras, lançando mão ao uso dos fundamentos da Integração Sensorial e biomecânica (REIS; COSTA; OLIVEIRA, 2017).

A Terapia Ocupacional pode contribuir através da abordagem de Integração Sensorial intervindo com crianças diagnosticadas com PC e que apresentam desordens no processamento sensorial, promovendo a organização das sensações, com objetivo de favorecer ganhos de habilidades funcionais, desenvolver o controle postural, esquema corporal, equilíbrio e planejamento motor (NEGRISOLLI; BARROS; ROCHA, 2016).

Diante do exposto, esta pesquisa bibliográfica teve como objetivo analisar os efeitos do uso da abordagem de Integração Sensorial no tratamento de crianças com diagnóstico de Paralisia Cerebral.

\section{METODOLOGIA}

A pesquisa apresentada caracteriza-se como revisão bibliográfica de natureza básica, com caráter exploratório, usando da abordagem qualitativa. A qual se desenvolveu nos meses de maio a agosto do ano de 2021, como trabalho de conclusão do curso de Certificação Brasileira em Integração Sensorial, baseada em materiais disponíveis nas bases de dados eletrônicos: PubMed e Google Acadêmico.

Em português, foram usadas como palavras-chave para a pesquisa: "Paralisia Cerebral”, "processamento Sensorial”, em inglês "cerebral palsy", "sensory disorder", "sensory processing". Resultando no total de 15 artigos que abordavam na íntegra ou parcialmente em relação ao tema. Convém destacar que não foi delimitado o período de tempo para pesquisa, tendo em vista a baixa produção científica sobre o tema

Como critérios de inclusão, foram eleitos: artigos e materiais publicados nos idiomas português e inglês, que faziam uso da abordagem de Integração Sensorial nas intervenções com crianças com PC, escritos por terapeutas ocupacionais e que estão disponíveis na íntegra nas bases eletrônicas. Como critérios de exclusão: publicações que não contemplavam o tema, escritos por outros profissionais e que não foram encontrados em bases eletrônicas (Quadro 1).

Após a checagem dos critérios de inclusão, foram excluídos 12 artigos que não se adequavam ao tema. Com isso, foram selecionados apenas três artigos (Quadro 
2), sendo um da PubMed e dois do Google acadêmico, os quais foram lidos integralmente para verificar se abordavam a Integração Sensorial e Paralisia Cerebral. Convêm destacar que não foi estabelecido como critério de inclusão apenas publicações realizadas nos últimos cinco anos, tendo em vista a baixa produção científica sobre 0 tema. 
Quadro 1 - Artigos identificados na busca inicial conforme critérios de inclusão e exclusão

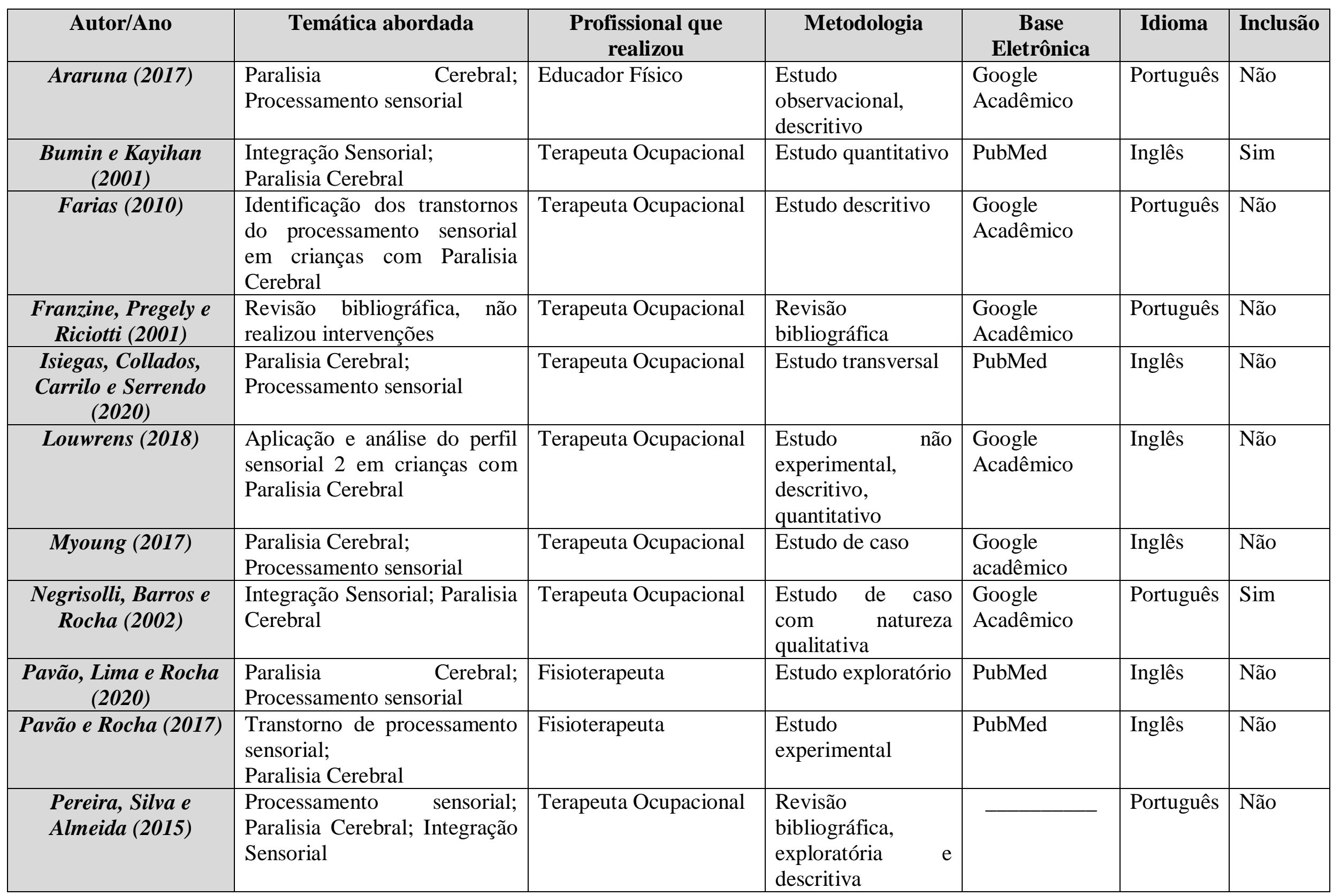




\begin{tabular}{|c|c|c|c|c|c|c|}
\hline $\begin{array}{c}\text { Prakash, } \\
\text { Vaishampayan } \\
(2007) \\
\end{array}$ & $\begin{array}{l}\text { Paralisia Cerebral; } \\
\text { Processamento sensorial }\end{array}$ & Terapeuta Ocupacional & $\begin{array}{l}\text { Estudo } \\
\text { experimental, } \\
\text { qualitativo } \\
\end{array}$ & $\begin{array}{l}\text { Google } \\
\text { Acadêmico }\end{array}$ & Inglês & Não \\
\hline $\begin{array}{c}\text { Reis, Costa e Oliveira } \\
\text { (2017) }\end{array}$ & $\begin{array}{l}\text { Aplicação de avaliações } \\
\text { padronizadas entre elas o } \\
\text { perfil sensorial em crianças } \\
\text { com Paralisia Cerebral }\end{array}$ & Terapeuta Ocupacional & Estudo quantitativo & $\begin{array}{l}\text { Google } \\
\text { Acadêmico }\end{array}$ & Português & Não \\
\hline Shamsoddini (2010) & $\begin{array}{l}\text { Integração Sensorial; Paralisia } \\
\text { Cerebral }\end{array}$ & Terapeuta Ocupacional & Estudo quantitativo & $\begin{array}{l}\text { Google } \\
\text { Acadêmico }\end{array}$ & Inglês & Sim \\
\hline
\end{tabular}

Fonte: Elaborado pelos autores. 


\section{RESULTADOS E DISCUSSÃO}

Para delineamento de pesquisa, conforme a leitura dos textos, foram realizadas extrações das publicações selecionadas, para buscar o entendimento quanto à prática $\mathrm{e}$ resultados apresentados nos estudos, conforme o evidenciado no Quadro 2. 
Quadro 2 - Extração das publicações

\begin{tabular}{|c|c|c|c|c|c|}
\hline TÍTULO & AUTORES & AMOSTRA & $\begin{array}{c}\text { PERÍODO DE } \\
\text { INTERVENÇÃO }\end{array}$ & $\begin{array}{l}\text { ABORDAGEM/ } \\
\text { INTERVENÇÃO }\end{array}$ & RESULTADOS \\
\hline $\begin{array}{lr}1-\text { A Integração } \\
\text { Sensorial r no } \\
\text { tratamento } \\
\text { paralisado cerebral } \\
\text { sob a visão da } \\
\text { Terapia } \\
\text { Ocupacional. }\end{array}$ & $\begin{array}{l}\text {-Fernanda } \\
\text { Katayama } \\
\text { Negrisolli; } \\
\text { - Sabrina Queiróz } \\
\text { Barros; } \\
\text { - Luciana Barbosa } \\
\text { Rocha. }\end{array}$ & $\begin{array}{l}3 \text { crianças com PC } \\
\text { grave. } \\
\text { Criança A, } 12 \text { anos, } \\
\text { PC quadriplégica } \\
\text { espástica. } \\
\text { Criança B, } 7 \text { anos, } \\
\text { PC extrapiramidal } \\
\text { distônica. Criança } \\
\text { C, } 7 \text { anos, PC } \\
\text { quadriplégica } \\
\text { espástica. }\end{array}$ & $\begin{array}{l}\text { Foram atendidas } \\
\text { durante } 3 \text { meses, duas } \\
\text { vezes na semana. }\end{array}$ & $\begin{array}{l}\text { Integração Sensorial associada } \\
\text { ao tratamento neuroevolutivo - } \\
\text { conceito bobath. } \\
\text { Durante os atendimentos foram } \\
\text { aplicadas diferentes atividades } \\
\text { com os recursos disponíveis na } \\
\text { Integração Sensorial. } \\
\text { Conforme a demanda de cada } \\
\text { criança. }\end{array}$ & $\begin{array}{l}\text { Foi registrado pelas } \\
\text { autoras que a } \\
\text { aplicação das duas } \\
\text { abordagens } \\
\text { demonstrara ganhos } \\
\text { na graduação de } \\
\text { tônus muscular, } \\
\text { maior aceitação ao } \\
\text { contato com certas } \\
\text { texturas e a evolução } \\
\text { no controle de } \\
\text { cervical e tronco. }\end{array}$ \\
\hline 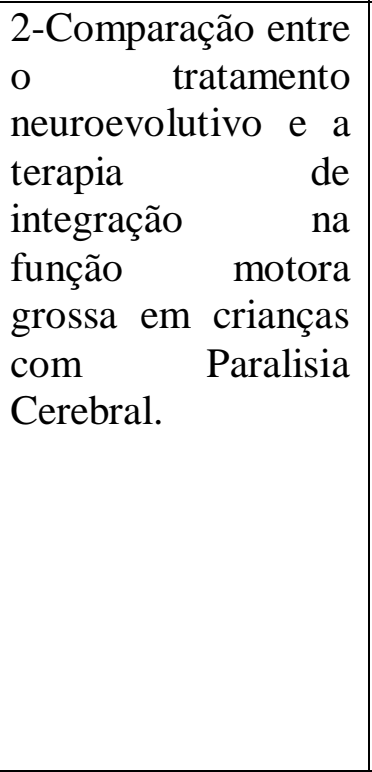 & $\begin{array}{l}\text {-Alireza } \\
\text { Shamsoddini. }\end{array}$ & $\begin{array}{l}22 \text { crianças com PC } \\
\text { espástica } \\
\text { diplegia, } \\
\text { tetraplegia), de } 2 \text { a } 6 \\
\text { anos. } \\
\text { Grupo 1: } 5 \text { crianças } \\
\text { com diplegia e } 6 \\
\text { crianças } \quad \text { com } \\
\text { tetraplegia. } \\
\text { Grupo 2: } 6 \text { crianças } \\
\text { com diplegia e } 5 \\
\text { com tetraplegia. }\end{array}$ & $\begin{array}{l}\text { Durante } 3 \text { meses, com } \\
3 \text { sessões de uma hora } \\
\text { por semana. }\end{array}$ & 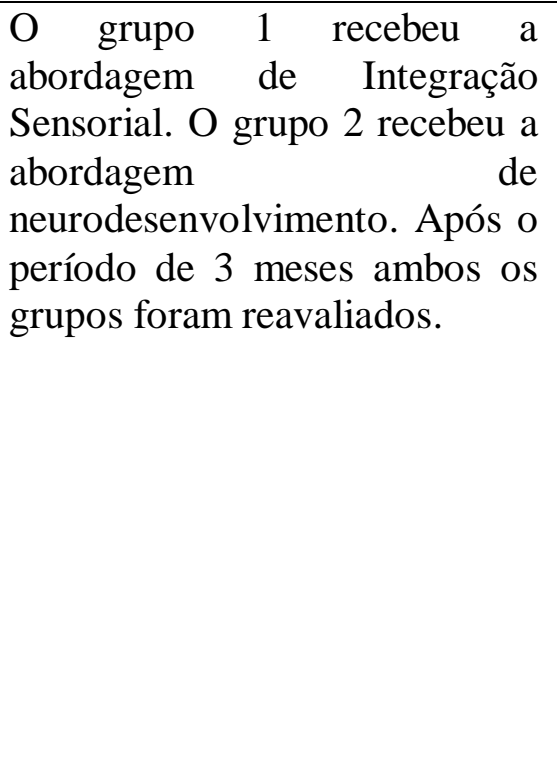 & 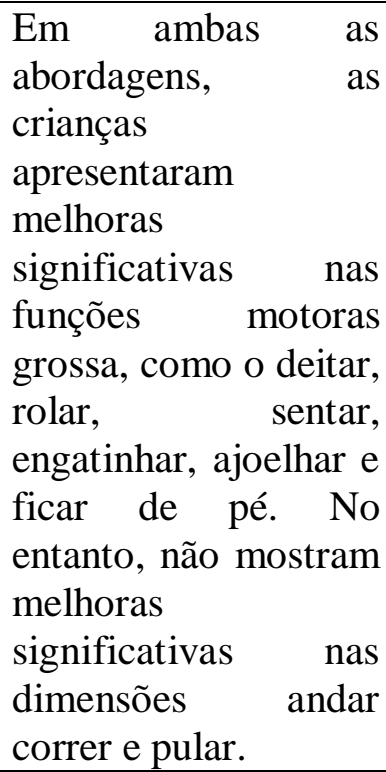 \\
\hline
\end{tabular}




\begin{tabular}{|c|c|c|c|c|c|}
\hline $\begin{array}{lr}3 \text { - Eficácia de } & \text { dois } \\
\text { programas } & \\
\text { diferentes } & \text { de } \\
\text { Integração } & \\
\text { Sensorial } & \text { para } \\
\text { crianças r com } \\
\text { Paralisia } & \text { Cerebral } \\
\text { diplégica espástica }\end{array}$ & $\begin{array}{l}\text { - Gonca Bumin; } \\
\text { •Hulya Kayihan }\end{array}$ & $\begin{array}{l}\text { 41 crianças com PC } \\
\text { diplégica espástica } \\
\text { que foram divididas } \\
\text { aleatoriamente em } \\
\text { três grupos. Grupo } 1 \\
\text { - Atividade } \\
\text { individual } \\
\text { crianças). } \\
\text { Grupo } 2 \text { - Atividade } \\
\text { em grupo } \\
\text { crianças). Grupo } 3- \\
\text { programa domiciliar } \\
\text { (9 crianças). }\end{array}$ & $\begin{array}{lrr}\text { Os programas } & \text { foram } \\
\text { aplicados } & \text { por } & 1,5 \\
\text { horas, } 3 & \text { dias } & \text { por } \\
\text { semana, durante } & 3 \\
\text { meses. } & & \\
\end{array}$ & $\begin{array}{l}\text { Foram realizadas atividades } \\
\text { baseadas no conceito de } \\
\text { Integração Sensorial tanto nas } \\
\text { intervenções individuais para o } \\
\text { primeiro grupo, como no } \\
\text { segundo grupo onde as } \\
\text { crianças foram agrupadas em } \\
\text { quatro subgrupos e realizadas } \\
\text { intervenções com abordagem } \\
\text { grupal, o terceiro grupo foi } \\
\text { selecionado para controle } \\
\text { sendo designado apenas para o } \\
\text { programa domiciliar, todas as } \\
\text { crianças foram avaliadas } \\
\text { individualmente e aplicado o } \\
\text { teste para avaliar problemas de } \\
\text { Integração Sensorial e teste de } \\
\text { capacidade física. }\end{array}$ & $\begin{array}{l}\text { Os resultados dessa } \\
\text { pesquisa revelaram } \\
\text { que os tratamentos } \\
\text { individualizados e em } \\
\text { grupo mostraram se } \\
\text { eficazes em crianças } \\
\text { com PC Diplégia. } \\
\text { Entretanto não } \\
\text { mostrou eficácia no } \\
\text { grupo de programa } \\
\text { domiciliar (Grupo 3). }\end{array}$ \\
\hline
\end{tabular}

Fonte: Elaborado pelos autores. 
Nos artigos, os autores realizaram intervenções com as crianças durante três meses, sendo de duas ou três vezes na semana, com tempo de sessão variando entre 45 minutos à 90 minutos.

E, para iniciar as intervenções, realizaram questionários padronizados com os pais/responsáveis, com o objetivo de avaliar as demandas motoras e sensoriais presentes.

No estudo de Negrisolli, Barros e Rocha (2002) usaram-se de forma associada as abordagens de Integração Sensorial e tratamento neuroevolutivo conceito bobath. No estudo de Shamsoddini (2010), as pesquisadoras dividiram a amostra em dois grupos, na qual um grupo recebeu a abordagem de Integração Sensorial e o outro grupo recebeu a abordagem de neurodesenvolvimento. No estudo de Bumin e Kayihan (2001), as crianças receberam intervenção de Integração Sensorial, algumas de forma individualizadas, outras com atividades em grupo e 9 crianças receberam apenas acompanhamento domiciliar.

Nos estudos de Negrisolli, Barros e Rocha (2002), Shamsoddini (2010) e Bumin e Kayihan (2001), os pesquisadores evidenciaram resultados significativos na função motora grossa e nos aspectos sensoriais das crianças com PC, ao serem submetidas a abordagem de Integração Sensorial, mesmo quando usada de forma isolada, associada a outras abordagens, com atividades individualizadas ou em grupo.

\section{CONSIDERAÇÕES FINAIS}

Durante a realização desta pesquisa observou-se a dificuldade para encontrar estudos científicos que abordassem a intervenção da Terapia de Integração Sensorial em crianças com Paralisia Cerebral, tanto no âmbito nacional quanto no internacional.

Desse modo, percebe-se a necessidade de abordar no meio científico a atuação da Terapia Ocupacional utilizando esta abordagem, enfatizando o cuidado com as desordens sensoriais apresentadas por esse público, oferecendo estímulos vestibulares, proprioceptivos e táteis, integrando e organizando-os de forma a favorecer a sua consciência corporal e espacial, assim, aumenta-se o controle de seus movimentos voluntários, favorecendo a sua capacidade funcional, diminuindo movimentos involuntários, aumentando a capacidade de atenção e concentração, 
oferecendo um melhor desenvolvimento perceptivo-motor, habilidade funcional e desenvolvimento da aprendizagem ao paciente.

Ressalta-se a possibilidade de combinação da abordagem de Integração Sensorial com outros métodos de tratamento para a criança com Paralisia Cerebral, favorecendo não apenas estímulos sensoriais como também motores, ofertando, desse modo, uma intervenção mais enriquecida dentro da Terapia Ocupacional, além da importância de novos estudos que abordem o tema proposto.

\section{REFERÊNCIAS BIBLIOGRÁFICAS}

AYRES, J.A. Sensory integration and the child. Los Angeles: Western Psychological Services, 1979.

BRASIL. Ministério da Saúde. Secretaria de Atenção à Saúde. Departamento de Ações Programáticas Estratégicas. Diretrizes de atenção à pessoa com Paralisia Cerebral. Brasília: Ministério da Saúde, 2013.

BLANCHE, E. I.; NAKASUJI, B. Sensory integration in the child with cerebral palsy. In: ROLEY, S.S.; BLANCHE, E.I.; SCHAAF, R. C. Sensory integration with diverse populations. San Antonio, TX: Therapy Skill Buiders, 2001. p. 345-364.

BUMIN, G.; KAYIHAN H. Eficácia de dois programas diferentes de Integração Sensorial para crianças com Paralisia Cerebral diplégica espástica. Incapacidade e Reabilitação, v. 23, n. 9, p. 394-399, jun. 2001. doi: 10.1080/09638280010008843.

BUMIN, G.; KAYIHAN, H. Effectiveness of two different sensory-integration programmes for children with spastic diplegic cerebral palsy. Disability and Rehabilitation, v. 23, n. 9, p. 394-399, 2001.

FARIAS, F. C. Paralisia Cerebral e transtorno do processamento sensorial.

Pernambuco: Universidade Federal de Pernambuco-UFPE, 2010.

FISHER, A. G.; MURRAY, E. A.; BUNDY. A.C. Sensory Integration: theory and practice. Philadelphia: Davis, 1993.

LAKATOS, Eva Maria; MARCONI, Marina de Andrade. Fundamentos de metodologia científica. 5. ed. São Paulo: Atlas, 2003.

LIANG X. et al. Effectiveness of exercise interventions for children withcerebral palsy: A systematic review and meta-analysis ofrandomized controlled trials. J Rehabil Med, [s. L.]., v. 53, p. 18-22, 2021.

MAGALHÃES, L. C. Integração Sensorial: uma abordagem específica da Terapia Ocupacional. In: DRUMMOND, A. F; REZENDE, M. B. Intervenções da Terapia Ocupacional. Belo Horizonte: UFMG, 2008. 44-69. 
NEGRISOLLI, F. K.; BARROS, S. Q.; ROCHA, L. B. A Integração Sensorial no tratamento do paralisado cerebral sob a visão da Terapia Ocupacional. Multitemas, v. 26, abr. 2002. Disponível em:

https://www.multitemas.ucdb.br/multitemas/article/view/827/802. Acesso em: 27 nov. 2021.

REIS, D. T. L.; COSTA, R. M. da; OLIVEIRA, L. V. L. de. et al. Repercussões dos Transtornos de Processamento Sensorial nas habilidades funcionais de crianças com Paralisia Cerebral. Rev. Interinst. Bras. Ter. Ocup., Rio de Janeiro, v. 1, n. 3, p. 318-331, 2017.

SANTOS, Natália Silva Carvalho dos et al. Perfil epidemiológico dos pacientes com Paralisia Cerebral atendidos na clínica de fisioterapia da Universidade São Judas Tadeu. Revista Brasileira De Ciências Biomédicas, v. 2, n. 1, p. 1-7, 2021.

SHAMSODDINI, A. Comparação entre o efeito do tratamento neurodesenvolvimental e da Terapia de Integração Sensorial na função motora grossa em crianças com Paralisia Cerebral. Iranian Journal of Child Neurology, v. 4, n. 1, p. 31-38, 2010. doi: https://doi.org/10.22037/ijcn.v4i1.1723.

SILVA, M. S.; BELTRAMI-DALTRÁRIO, S. M. B. Paralisia Cerebral: desempenho funcional após treinamento da marcha em esteira. Fisioterapia em Movimento, $v$. 21, n. 3, p. 109-115, 2008.

SILVA, Gabriela Gomes da; ROMÃO, Josilene; ANDRADE, Erci Gaspar da Silva. Paralisia Cerebral e o impacto do diagnóstico para a família. REIcEn - Revista de Iniciação Científica e Extensão, v. 2, n. 1, p. 4-10, 2019.

ZANINI, G.; CEMIN N. Paralisia Cerebral: causas e prevalências. Rev Fisio do Mov, v. 22, n. 3, p. 375-381, 2009. 


\title{
OS IMPACTOS DA HIPER-RESPONSIVIDADE TÁTIL NO DESENVOLVIMENTO DE CRIANÇAS COM TRANSTORNO DO ESPECTRO AUTISTA
}

\author{
Brenda Monteiro Maia ${ }^{1}$ \\ Tatiane Costa dos Santos ${ }^{1}$ \\ Samara de Araújo Costa ${ }^{2}$
}

\section{RESUMO}

A Disfunção de Integração Sensorial (DIS) tem alta prevalência em crianças com Transtorno do Espectro Autista (TEA). Algumas delas apresentam alterações de processamento sensorial relacionadas à modulação e demonstram hiperresponsividade tátil, que tem impacto direto nas Atividades de Vida Diária (AVDs), interação social, coordenação motora global e fina, brincar e personalidade da criança. O presente estudo objetivou investigar os impactos da hiper-responsividade tátil no desenvolvimento de crianças com TEA. A metodologia trata-se de uma revisão bibliográfica realizada nas bases de dados PubMed (US National Library of Medicine), SciELO (ScientificElectronic Library of Medicine) e BVS (Biblioteca Virtual em Saúde), incluindo artigos entre os anos 2007 e 2021. Foram encontrados 281 artigos com a busca, usando os descritores nas bases de dados, e, destes, apenas sete artigos abordavam a temática proposta para a discussão. Conclui-se que crianças com TEA que apresentam hiper-responsividade tátil podem ter dificuldades com aceitação do toque social, ansiedade, dificuldades de aprendizagem, entre outras, que geram impactos no desenvolvimento. Foi visto também a escassez de estudos com a temática abordada.

Palavras-chave: Transtorno do Espectro Autista. Integração Sensorial. Terapia Ocupacional. Tátil.

\section{INTRODUÇÃO}

O Transtorno do Espectro Autista (TEA) é um transtorno de natureza social e cognitiva, caracterizado por déficits persistentes na comunicação, no comportamento e nas interações sociais. Tais déficits causam prejuízos importantes em diversas áreas do funcionamento, como atividades de vida diária, ambiente escolar, social e cognitivo. Alguns desses sinais podem ser vistos ainda na primeira infância, como a falha no uso da linguagem, dificuldade em manter contato visual, rígida adesão a rotinas etc. (SCHLIEMANN; ALVES; DUARTE, 2020).

\footnotetext{
${ }^{1}$ Terapeutas Ocupacionais.

${ }^{2}$ Terapeuta Ocupacional, Mestre em Ciências da Reabilitação pela UFMG. Certificação em IS WPS/USC, Docente do Curso de Certificação Brasileira em Integração Sensorial - Integris/UEPA, Orientadora do trabalho.
} 
Segundo Ayres (1979), a Integração Sensorial (IS) é a capacidade inata para organizar e interpretar as sensações do próprio corpo e do ambiente e responder apropriadamente, de forma a permitir ao ser humano participar de atividades e ocupações exercidas no dia a dia. A autora afirma que através da IS o cérebro organiza as informações sensoriais em busca de uma resposta adaptativa, visando a organização das sensações do próprio corpo e do ambiente para que haja um uso eficiente. Assim, nos permite agir ou responder à situação que estamos vivendo de forma intencional/significativa (conhecido como resposta adaptativa) (SERRANO, 2018).

As alterações sensoriais são muito frequentes no TEA, mas muitas vezes passam despercebidas pelas dificuldades de comunicação desses indivíduos. $O$ DSM-5 (Manual Diagnóstico e Estatístico de Transtornos Mentais, 5a edição) definiu alguns critérios que incluem o aumento ou redução da reatividade à entrada sensorial ou o interesse incomum por aspectos sensoriais do ambiente. Alguns exemplos citados no DSM-5 são: fascínio visual por luzes, fixação por objetos que rodam, aversão a sons ou texturas específicos, sensibilidade a cheiros, toque excessivos de objetos e aparente indiferença a temperaturas e dor (American Psychiatric Association, 2014).

A Disfunção de Integração Sensorial (DIS) tem sido notada com frequência em crianças com TEA e foi inserida como critério para diagnóstico médico no DSM-5. Estima-se que 40 a $90 \%$ das crianças com TEA apresentam DIS, trazendo prejuízos para o desenvolvimento da criança, bem como para a rotina de seus familiares (MENDES; COSTA, 2017).

Os transtornos de modulação sensorial são caracterizados por dificuldades em regular o grau, intensidade e natureza das respostas aos estímulos sensoriais, sendo classificados como hiporresponsividade ou hiperrresponsividade à sensação. A criança hiporresponsiva apresenta respostas pobres e lentas aos estímulos ao passo que as hiper-responsivas sentem os estímulos de forma mais rápida, mais intensa ou durante mais tempo, que crianças com modulação normal (SERRANO, 2018).

O sistema tátil é fundamental para o desenvolvimento da noção corporal. É através do toque que recebemos informações e desenvolvemos nosso esquema corporal, criando a noção dos limites corporais e das partes que compõem o nosso corpo. O sistema tátil tem ainda receptores que são 
responsáveis por nos avisar quando estamos em perigo e estimula a reação de defesa (SOARES; BRAGA, 2014).

Algumas crianças com TEA demonstram alterações de processamento sensorial relacionadas à modulação e tendem a apresentar hiper-responsividade tátil, ou seja, um limiar neurológico baixo aos estímulos táteis. Desse modo, respondem de forma mais intensa, automática e exagerada a esse input e podem reagir com comportamentos defensivos de recusa, ansiedade e nervosismo perante determinadas texturas (SOUZA; NUNES, 2019).

Segundo Serrano (2018), a hiper-responsividade tátil em crianças com TEA pode impactar diretamente a interação social, alimentação, coordenação motora global, coordenação motora fina, controle postural, Atividades de Vida Diária (AVDs), brincar, comportamento e personalidade. O tato é um sistema que está relacionado com as nossas emoções, cada sensação de toque está associada a um significado emocional. Considerando a crescente prevalência de crianças com TEA, o tema foi escolhido em prol da disseminação de conhecimento, que visa esclarecer os impactos da hiper-responsividade tátil nessas crianças.

\section{METODOLOGIA}

\subsection{Tipo de pesquisa}

Trata-se de uma revisão bibliográfica, com o objetivo de entender os impactos da hiper-responsividade tátil no desenvolvimento de crianças com Transtorno do Espectro Autista (TEA).

A revisão bibliográfica é uma revisão das pesquisas e das discussões de outros autores sobre o tema que será abordado, é a contribuição das teorias de outros autores para a pesquisa. O levantamento de literatura é a localização e a obtenção de documentos para avaliar a disponibilidade de material que subsidiará o tema do trabalho de pesquisa (GONÇALVES, 2021).

Os artigos foram identificados pelo levantamento bibliográfico nas bases de dados: PubMed (US National Library of Medicine), SciELO (ScientificElectronic Library ofMedicine) e BVS (Biblioteca Virtual em Saúde), utilizando os descritores combinados em português e inglês: "Transtorno do Espectro Autista", "Integração Sensorial", "Terapia Ocupacional", "tátil”; “Autism Spectrum Disorder", "Sensory integration", "sensory processing", "táctile". 
Como critério de inclusão para este estudo, foram considerados artigos em inglês e português que abordassem o tema, com ano de publicação superior a 2007. Foram excluídas teses, trabalhos de conclusão de curso, estudos com animais ou que não disponibilizavam suas versões na íntegra, além de artigos nos anos inferiores ao proposto no trabalho.

\section{RESULTADO E DISCUSSÃO}

Inicialmente, foi realizada busca sobre a abordagem de Integração Sensorial no Transtorno do Espectro Autista, tendo como objetivo identificar os impactos que a hiper-responsividade tátil em crianças com TEA. Foram considerados os títulos e os resumos dos artigos para a seleção ampla de possíveis trabalhos de interesse.

O levantamento bibliográfico amplo localizou 281 artigos usando os descritores nas bases de dados citadas. Foram excluídos 255 artigos por título e duplicidade, resultando em 26 artigos relevantes aos descritores do estudo. Após a leitura dos resumos, foram excluídos 16 artigos, sendo então selecionados 10 artigos para leitura na íntegra. Destes artigos, três foram excluídos por não abordar o tema, resultando em sete artigos que abordavam a temática proposta. O fluxograma abaixo representa os passos do processo de seleção dos artigos que foram abordados na discussão do presente estudo. 
Figura 1 - Achados Bibliográficos

Pubmed
167
Scielo $=36$
BVS $=78$

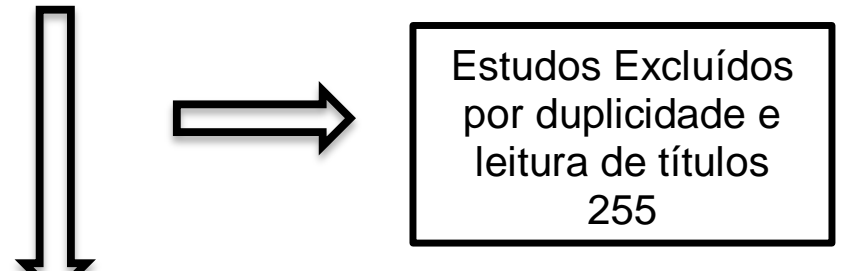

Estudos selecionados para

leitura do resumo (26)

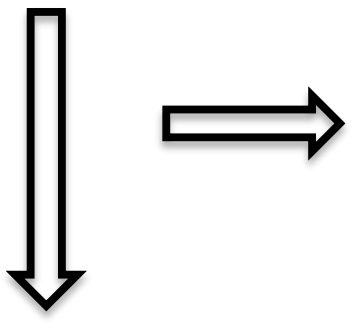

Estudos excluídos após a leitura do resumo (16)

Estudos avaliados na integra (10)
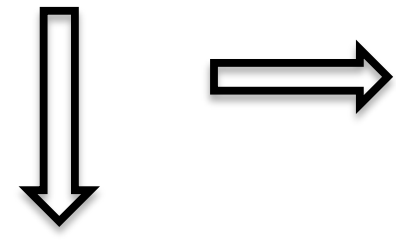

Estudos excluídos por não abordar o tema (03)

Estudos incluídos na revisão (07)

Fonte: Elaborado pelos autores.

O Transtorno do Espectro Autista (TEA) é um transtorno do neurodesenvolvimento com alta prevalência, caracterizado por déficits sociais e comportamentos repetitivos estereotipados (APA, 2013). Além dessas características básicas do Autismo, Posar e Visconti (2018), em sua pesquisa, relatam que aproximadamente $95 \%$ dos indivíduos com TEA exibem alterações sensoriais, com $60 \%$ exibindo sensibilidade tátil alterada. 
Cascio, Moore e Mcglone (2018) enfatizam que a maioria das pesquisas do Transtorno do Espectro Autista tem se concentrado em mecanismos e circuitos específicos do cérebro, com pouca atenção às contribuições potenciais do SNP para os fenótipos do TEA. Os autores descrevem como o toque social no desenvolvimento é altamente importante para a formação de apego seguro, desenvolvimento cognitivo, linguístico e recompensa social.

Para Voos, Pelphrey e Kaiser (2013) existem poucas pesquisas sobre os mecanismos por trás das alterações táteis associadas ao TEA em comparação com a pesquisa sobre os principais sintomas do Autismo. No entanto, ressaltam que essas alterações táteis podem contribuir para alguns dos sintomas principais. Por exemplo, a hipersensibilidade de neurônios periféricos pode colaborar para evitar o toque social, um fenótipo comportamental comum em indivíduos com TEA.

Riquelme, Hatem e Montoya (2016) realizaram um estudo de sensibilidade ao toque em indivíduos com TEA, que trouxe como resultados que crianças com hiper-responsividade tátil apresentam dificuldades nos comportamentos sociais que envolvem o toque interpessoal.

Schaffler, Middleton e Abdus-Saboor (2019), em sua revisão, sugerem que a hiper-responsividade tátil pode levar a comportamentos sociais inadequados, dificuldade na aceitação ao toque físico, e pode contribuir para outros sintomas no TEA, como ansiedade, hiperexcitação, déficits de sono, déficits de atenção, comportamentos estereotipados e dificuldades de aprendizagem, que interferem na participação social.

Essa ansiedade e hiperexcitação podem gerar reações como intensa agitação e agressão dirigida a outros ou a si mesmo. De acordo com Leekam et al. (2007), esses comportamentos de angústia são bem presentes em crianças com TEA de baixo funcionamento, que não conseguem relatar seu desconforto. Isso interfere na participação social, pois a criança apresenta dificuldades na interação com outros indivíduos.

Para Posar e Visconti (2018), crianças com hiper-responsividade tátil podem apresentar comportamentos diferentes: algumas ficam muito ativas, negativas, impulsivas ou agressivas e outras afastam-se ou evitam sensações. As respostas mais intensas acontecem quando a sensação é inesperada. Algumas reagem mal a texturas diferentes, andam na ponta dos pés para 
diminuir o contato com o chão, não gostam de areia da praia, apresentam seletividade alimentar com preferência por certas texturas, resistem a escovar os dentes e podem reagir mal a certas texturas da roupa, a cortar o cabelo e as unhas.

Brown e Dunn (2010), em seu estudo, indicam que a percepção da sensibilidade tátil alterada em crianças com TEA pode ser atribuível a uma disfunção no processamento do toque afetivo, e não a uma detecção prejudicada de estímulos táteis. Prejuízos sensoriais podem influenciar a participação de crianças com TEA nas atividades diárias, no ambiente escolar e familiar, além de comportamentos exacerbados ou retraídos, e devem ser levados em conta para uma intervenção terapêutica.

\section{CONCLUSÃO}

Conclui-se que crianças com TEA que apresentam hiper-responsividade tátil podem apresentar comportamentos sociais inadequados, dificuldades na aceitação ao toque social, no brincar funcional, alimentação, coordenação motora global, coordenação motora fina, contribuindo com sintomas secundários. A ansiedade, hiperexcitação, déficits de sono, déficits de atenção e comportamentos estereotipados podem impactar diretamente a interação social, Atividades de Vida Diária (AVDs), personalidade e aprendizagem dessas crianças.

Visto os impactos que a hiper-responsividade tátil traz no desenvolvimento infantil em crianças com TEA, questiona-se se com a intervenção precoce as crianças podem apresentar maiores ganhos no desenvolvimento infantil e em suas ocupações, o que lhes proporcionaria uma melhor experiência quando iniciam a vida escolar e social, evitando o aparecimento de problemas secundários. Crianças que falham em tarefas que a maioria dos pares realiza de forma automática, estão em risco de desenvolver problemas, como a baixa autoestima.

Durante a construção deste estudo, percebeu-se a escassez de artigos que descrevam detalhadamente os impactos da hiper-responsividade tátil no desenvolvimento infantil em crianças com TEA. É necessário compreender os impactos das alterações sensoriais para as crianças, para, assim, iniciar a 
intervenção com abordagens específicas e favorecer ao máximo o desenvolvimento das mesmas.

\section{REFERÊNCIAS BIBLIOGRÁFICAS}

AMERICAN PSYCHIATRIC ASSOCIATION. DSM-5: Manual diagnóstico e Estatístico de Transtornos Mentais. Tradução de Maria Inês Corrêa Nascimento. 5. ed. Porto Alegre: Artmed, 2014. 992 p.

AYRES, A. J. Sensory Integration and The Child. Los Angeles: WPS, 1979.

BROWN, N. B.; DUNN, W. Relationship Between Context and Sensory Processing in Children With Autism. American Journal of Occupational Therapy, v. 64, n. 3, p. 474-483, maio 2010.

BROWN, Anahita; TSE, Tamara; FORTUNE, Tracy. Defining sensory modulation: a review of the concept and a contemporary definition for application by occupational therapists. Scand J Occup Ther, v. 26, n. 7, p. 515-523, 2019. doi: 10.1080/11038128.2018.1509370.

CASCIO, Carissa J; MOORE, David; MCGLONE, Francis. Social touch and human development. Dev Cogn Neurosci, n. 35, p. 05-11, fev. 2019.

GONÇALVES, Jonas Rodrigo. Manual de Artigo de Revisão de Literatura. 3. ed. Brasília: Instituto Processus, 2021. 105 p.

LEEKAM, S. R. et al. Describing the sensory abnormalities of children and adults with autism. J AutismDevDisord, n. 37, p. 894-910, 2007.

MENDES, J. I.; COSTA, J. R. Integração Sensorial em crianças com Transtorno do Espectro Autista. Cad. da Esc. de Saúde, Curitiba, v. 17, n. 2, p. 01-03, 2017.

POSAR, Annio; VISCONTI, Paola. Sensory abnormalities in children with autism spectrum disorder. J. Pediatr., Rio de Janeiro, v. 94, n. 4, jul./ago. 2018.

RIQUELME, I.; HATEM, S. M.; MONTOYA, P. Abnormal Pressure Pain, Touch Sensitivity, Proprioception, and Manual Dexterity in Children with Autism Spectrum Disorders. Neural Plasticity, p. 1-9, 2016.

SCHAFFLER, Melanie D.; MIDDLETON, Leah J.; ABDUS-SABOOR, Ishmail. Mechanisms of Tactile Sensory Phenotypes in Autism: Current Understanding and Future Directions for Research. Curr Psychiatry Rep, v. 21, n. 12, p. 134, 05 dez. 2019.

SCHLIEMANN, A.; ALVES, M. L. T.; DUARTE, E. Educação física inclusiva e Autismo: perspectivas de pais, alunos, professores e seus desafios. Revista Brasileira de Educação Física e Esporte, [s. L.], v. 34, n. esp., p. 77-86, 2020. 
SERRANO, P. A. Integração Sensorial no desenvolvimento e aprendizagem da criança. 3. ed. [s.L.]: Papa Letras; 2018.

SOARES, T.; BRAGA.S.E.M. Relação da terapia de holding com a Integração Sensorial no Autismo infantil. Revista Científica Interdisciplinar, v. 1, n. 2, out./dez. 2014.

SOUZA, Renata Ferreira de; NUNES, Débora Regina de Paula. Transtornos do processamento sensorial no Autismo: algumas considerações. Revista de Educação Especial, v. 32, 2019.

STEFFEN, F. et al. Diagnóstico precoce de Autismo: uma revisão literária. Revista Saúde Multidisciplinar, v. 6, n. 2, 2020.

VOOS, Avery C.; PELPHREY, Kevin A.; KAISER, Martha D. Autistic traits are associated with diminished neural response to affective touch. Social Cognitive and Affective Neuroscience, v. 8, n. 4, p. 378-386, abr. 2013. 


\title{
MAPEAMENTO DE RESULTADOS EM INTERVENÇÕES BASEADASNA INTEGRAÇÃO SENSORIAL EM FUNÇÕES NEUROLÓGICAS RELACIONADAS AO EQUILÍBRIO E À LINGUAGEM
}

\author{
Anne Caroline Cesar Ribeiro ${ }^{1}$ \\ Elizabeth S. F. S. Farias ${ }^{1}$ \\ Maria L. P. dos Santos ${ }^{1}$ \\ Patrícia X. Mente ${ }^{1}$ \\ Vanessa M. Perin ${ }^{1}$ \\ Marcelo Marques Cardoso²
}

\section{RESUMO}

Os resultados das intervenções que integram esse sistema, por meio do equilíbrio e/ou linguagem, ainda não estão suficientemente esclarecidos. Assim, objetiva-se mapear os achados e os efeitos da Integração Sensorial em funções neurológicas, como o equilíbrio e a linguagem. $O$ presente levantamento foi realizado baseado na proposta de Arksey e O'Malley, contidas nas orientações da Metodologia Joanna Briggs Institute (JBI). A pergunta de pesquisa aplicada foi: Quais os efeitos da Integração Sensorial sobre o Sistema Vestibular e/ou a Linguagem independentemente da manifestação clínica estuda? Os descritores de busca foram definidos a partir das palavras-chave: Integração Sensorial, equilíbrio e Linguagem. Esses termos, em Inglês, foram aplicados nas plataformas científicas de buscas de dados: Cochrane Library, Portal BVS, PubMed, Scopus e Web Of Science. O programa on-line Rayyan foi utilizado como gerenciador das etapas de identificação, seleção, elegibilidade e inclusão dos artigos relevantes para o presente estudo, segundo os critérios definidos para os últimos dez anos, cujo conteúdo estivesse integralmente disponível em inglês, espanhol e/ou português. Dos artigos incluídos, foram retirados os metadados de interesse para gerar as inferências dos resultados. Do montante de 1.022 publicações identificadas, nove foram incluídas. Nenhuma delas estava em plataforma nacional, cujo maior interesse das propostas focavam na linguagem e com desfechos favoráveis, na maioria deles. Conclui-se que as intervenções que utilizam a Integração Sensorial a partir de variáveis relacionadas à linguagem e/ou equilíbrio manifestam desfechos promissores, apesar da baixa evidência entre as publicações disponíveis.

Palavras-chave: Integração Sensorial. Equilíbrio. Linguagem. Intervenções.

Práticas.

\section{INTRODUÇÃO}

\footnotetext{
${ }^{1}$ Terapeutas Ocupacionais.

${ }^{2}$ Terapeuta Ocupacional pela Universidade do Estado do Pará (UEPA, 2001-2005), Doutor pelo Programa de Pós-Graduação em Neurociências e Biologia Celular (PPGNeuroBC), Docente da FFTO - ICS - UFPA. Docente do Curso de Certificação Brasileira em Integração Sensorial Integris/UEPA. Orientador do trabalho.
} 
Em termos abrangentes, a Integração Sensorial reconhece que processos intrínsecos ao indivíduo registram, modulam e permitem a discriminação de informações ambientais recebidas pelos diferentes receptores sensoriais do corpo e são capazes de gerar respostas que podem modificar aspectos comportamentais desse indivíduo, após o devido processamento central (LANE et al., 2019). Aqui, merecem destaque os sistemas sensitivos genuinamente classificados como especiais (GANDOLFI et al., 2014). Em outras palavras, os estudos originais de Ayres acreditavam que o desenvolvimento pleno dessas funções neurológicas favorece a participação ocupacional dos indivíduos (MILLER et al., 2009).

Subsequentemente, outros estudos vêm validando os trabalhos de Ayres. De modo clássico, as intervenções baseadas na Integração Sensorial tiveram uma boa receptividade para demonstrar resultados promissores em quadros relacionados ao transtorno no desenvolvimento, em particular, o Espectro Autista (KILROY; AZIZZADEH; CERMAK, 2019; SCHAAF et al., 2018). Mais recentemente, as teorias de Ayres aplicados em outros contextos também manifestam resultados importantes. Em situações de prematuridade, os nascidos pré-termos podem manifestar atraso no desenvolvimento em função da imaturidade do sistema nervoso. Estudos controlados nessa clientela apresentam evidências que a prática baseada na Integração Sensorial de Ayres traz potenciais benefícios a aspectos cognitivos, motores e de linguagem expressados no desenvolvimento da amostra pesquisada (LECUONA et al., 2017).

De modo igualmente inovador, que demostra a extensão de possibilidades da Integração Sensorial. Pacientes com Esclerose Múltipla podem ter o sistema vestibular acometido pela evolução da doença. Em um recente ensaio clínico randomizado, adultos com Esclerose Múltipla receberam procedimentos baseados na Integração Sensorial durante o treinamento funcional de equilíbrio, os resultados apurados demonstram melhoras nesse componente de desempenho (GANDOLFI et al., 2014). Esse mesmo grupo de pesquisa, em um momento anterior, também testou preceitos de Integração Sensorial coadjuvantemente a dispositivos robóticos no ajuste postural e equilíbrio. Os achados sugerem que a intervenção concomitante das duas opções terapêuticas melhora a estabilidade corporal dos sujeitos (GANDOLFI et al., 2014). Apesar desses estudos não mencionarem as teorias de Ayres, a fundamentação dos trabalhos se relaciona a ela. Em conjunto, esses estudos evidenciam potencialidades e benefícios da Integração Sensorial em 
diferentes populações e acometimentos à saúde. Isso parece um importante passo e avanço dos estudos originais de Ayres, cujos postulados da teoria emergiram da observação do desenvolvimento de aspectos motores e da linguagem (vias de saídas) em crianças, em função da integração funcional satisfatória de vias de entrada sensorial do corpo, em particular: vestibular, auditivo, visual e proprioceptivo (VILLAGE, 2012). Sabidamente, alterações nessas vias podem comprometer a participação social e o pleno exercício de ocupações.

Contextualiza essa afirmativa o conhecimento que sentidos de desenvolvimento primário (vestibular e proprioceptivo) proporcionam a base que permite a maturação de elementos sensoriais mais complexos e tardios, como os sistemas visual e auditivo (SU; PARHAM, 2014). Percebe-se, portanto, a expressão da hierarquia neurofuncional que fundamenta 0 entendimento neurobiológico teorizado por Ayres para a Integração Sensorial. Isso pode ser sinalizado ao ser fazer um breve levantamento sobre a temática na literatura para obter a percepção que, na época de Ayres, a atualização de preceitos clínicos e neurocientíficos, que sustentam a sua teoria, eram rapidamente incorporadas à fundamentação da Integração Sensorial (MILLER et al., 2009). Aos poucos, essa notação pode se tornar um problema por, recentemente, não estar acontecendo na mesma proporção que antes, apesar da crescente produção nas Neurociências e Neurologia.

Buscando minimizar esta situação, colaborar com a produção de conhecimento na área e partindo de um dos vários princípios defendidos por Ayres, baseado na influência relevante que o sistema vestibular tem sobre as funções cerebrais e comportamentais (LANE et al., 2019). Os resultados das intervenções que integram esse sistema, por meio do equilíbrio, aos efeitos neurológicos obtidos ainda não estão suficientemente esclarecidos, em particular, aqueles ligados à linguagem. Sendo assim, o objetivo do presente estudo foi mapear os achados e os efeitos da Integração Sensorial a partir e/ou sobre funções neurológicas, como o equilíbrio e a linguagem.

\section{MÉTODO}

O presente levantamento foi realizado baseado na proposta de Arksey e O'Malley (2005), contidas nas orientações da Metodologia Joanna Briggs Institute (JBI) (PETERS et al., 2020).

A pergunta de pesquisa foi elaborada atendendo o acrônimo PCC (Paciente/ 
População/Problema, Conceito e Contexto), definida: Qual a influência da Integração Sensorial sobre o Sistema Vestibular e/ou a Linguagem independentemente da manifestação clínica estuda? Os detalhes foram encaminhados da seguinte forma:

P - Pessoa com qualquer manifestação clínica relacionada ao desenvolvimento ou adquirida;

C - Integração Sensorial $x$ Equilíbrio $x$ Linguagem;

C - Resposta do tratamento proposto ao atraso/ transtorno/ déficit no desenvolvimento(Equilíbrio $x$ Linguagem).

\subsection{Estratégia de Busca}

As buscas foram realizadas entre julho e agosto de 2021 por pesquisadores independentes em atenção à recomendação Preferred Reporting Items for Systematic reviews and Meta-Analyses extension for Scoping Reviews (PRISMA$\mathrm{ScR})$.

As plataformas científicas pesquisadas foram: Cochrane Library, Scopus, PubMed, Portal BVS e Web Of Science. Os termos de buscas foram consultados nos Descritores em Ciências da Saúde (DeCS) e no Medical Subject Headings (MeSH), em Inglês, na janela temporal de busca delimitada janeiro de 2011 a julho de 2021. A Tabela 1 resume os detalhes das estratégias de buscas.

Tabela 1 - Estratégias de Buscas

\begin{tabular}{|c|c|c|}
\hline \multirow[t]{2}{*}{ PLATAFORMAS } & \multicolumn{2}{|c|}{$\begin{array}{c}\text { ESTRATEGIAS: } \\
\text { Busca 1: \#1 AND \#2 - (B1). } \\
\text { Busca 2: \#1 AND \#3 - (B2). }\end{array}$} \\
\hline & TERMOS X BOOLEANOS & $\begin{array}{l}(\mathrm{B} 1+\mathrm{B} 2) \& \\
\text { FILTROS. }\end{array}$ \\
\hline Cochrane Library. & $\begin{array}{l}\text { \#1. Ayres OR "Sensory Integration". } \\
\text { AND }\end{array}$ & $\begin{array}{l}\text { Title, Abstract, } \\
\text { Keyword. }\end{array}$ \\
\hline Portal BVS. & \#2. Vestibule, Labyrinth OR & $\begin{array}{l}\text { Tituln Resiımn } \\
\text { Assunto. }\end{array}$ \\
\hline $\begin{array}{l}\text { PubMed } \\
\text { (MEDLINE). }\end{array}$ & $\begin{array}{l}\text { "Vestibular System" OR"Postural } \\
\text { Balance" OR Proprioception. }\end{array}$ & Title, Abstract. \\
\hline $\begin{array}{l}\text { Scopus } \\
\text { (Elsevier). }\end{array}$ & $\begin{array}{l}\text { AND } \\
\text { \#3. "Communication Barrier*" OR }\end{array}$ & $\begin{array}{l}\text { Title, Abstract, } \\
\text { Keyword. }\end{array}$ \\
\hline $\begin{array}{l}\text { Web Of Science } \\
\text { (SciELO). }\end{array}$ & $\begin{array}{l}\text { "Language Development" OR "Child } \\
\text { Language" OR "Rehabilitation } \\
\text { of Speech" OR "Language Disorder" }\end{array}$ & Tópicos. \\
\hline
\end{tabular}

Legenda: Busca 1 (B1); e Busca 2 (B2).

Fonte: Elaborado pelos autores. 


\subsection{Critérios de Elegibilidade}

Os critérios de elegibilidade incluíram: artigos originais, experimentais, clínicos randomizados ou não, textos de revisão de qualquer natureza e publicações cinzentas, estudos realizados com qualquer população e independentemente da faixa etária, sendo a Integração Sensorial a principal intervenção terapêutica ou secundária, cuja publicação estivesse em língua inglesa, espanhola e/ou em portuguesa. Paralelamente, foram excluídos os estudos realizados com modelos animal e, da mesma forma, artigos baseados em protocolos de estudo e similares, além de publicações cujo desenho metodológico dos procedimentos não se consegue extrair as linhas gerais da Integração Sensorial, por mais que estivesse citado em qualquer parte do texto.

\subsection{Triagem das fontes de Evidências}

A triagem dos artigos foi estabelecida pelas buscas nas plataformas científicas. Os resultados da identificação foram exportados em extensão compatível com o programa on-line Rayyan (OUZZANI et al., 2016), usado para auxiliar na retirada dos títulos duplicados e análise da seleção de títulos relevantes. Aos artigos remanescentes, foram aplicados os critérios de elegibilidade. A finalização desse processo ocorreu pela aquisição dos artigos disponíveis e a análise completa deles para confirmar a inclusão e posterior extração dos metadados.

As divergências entre os pesquisadores independentes foram resolvidas pelo pesquisador titular, que arbitrou sobre a decisão final em qualquer das etapas realizadas.

\subsection{Extração dos Metadados}

Dos artigos incluídos foram obtidas as informações que consolidaram 0 objetivo principal do estudo e que ajudassem a responder à pergunta de pesquisa desenhada, dos quais foram ordenados os seguintes metadados, além da autoria/ano: (1) Tipo de Estudo; (2) Objetivo; e (3) Principal Resultado.

\subsection{Análise e Apresentação de Resultados}

A análise dos resultados foi estabelecida por categoria individualizada dos metadados tabulados, focando-se na frequência das ocorrências e na geração de inferências sobre os achados. Os desfechos foram analisados a partir da descrição 
encontrada nos artigos incluídos. Essas informações foram ordenadas em um quadro específico, de forma descritiva. Ao final, esses achados foram aglutinados para compor um esquema visual para a exposição dos resultados aqui inferidos.

\section{RESULTADOS}

A busca identificou o total de 1022 artigos (Figura 1). Após a delimitação dos últimos 10 anos, foram retirados 531 artigos que estavam fora da janela temporal de interesse, restando 591 publicações, das quais 41 eram homônimas, com a mesma autoria e 293 artigos não foram considerados relevantes para a pergunta de pesquisa (Figura 1). A aplicação dos demais critérios de elegibilidade permitiu a inclusão de nove artigos para a extração dos metadados no presente levantamento, dos 21 elegíveis (Figura 1).

Figura 1 - Parcial do Fluxograma PRISMA-ScR - Processamento em andamento

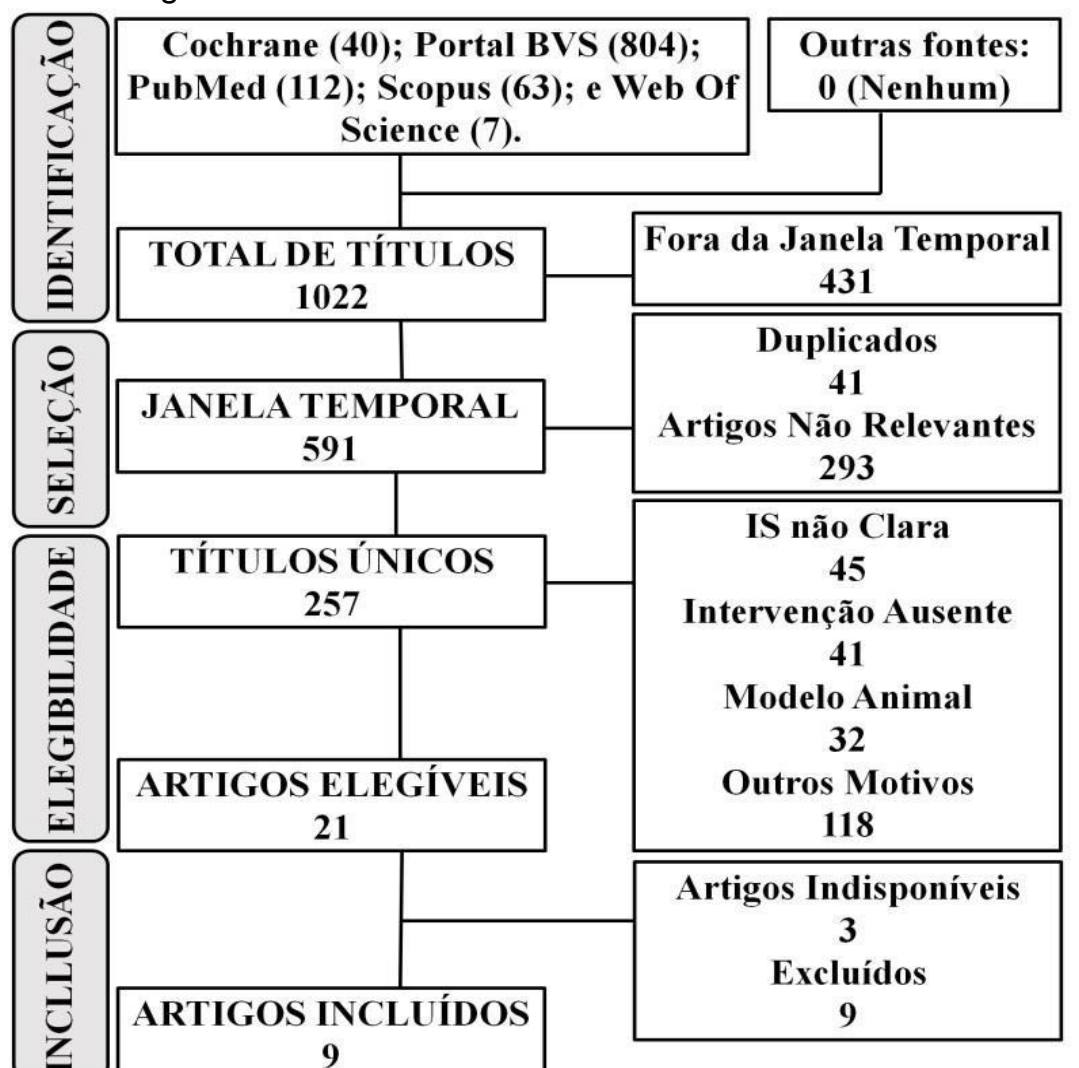

Fonte: Elaborado pelos autores.

Dos artigos incluídos, todos foram publicados em revistas internacionais, nos quais não foram encontrados grupos nacionais ou a participação de brasileiros na equipe de pesquisa. Isto sugere baixo interesse da produção nacional ligada à linguagem e/ou ao equilíbrio a partir da Integração Sensorial (Quadro 1). 
Quadro 1 - Autorias e Publicações - Notação Geral

\begin{tabular}{|c|c|c|}
\hline \# Ordem. Autoria/ Ano. & Revista (journal). & Publicação. \\
\hline $\begin{array}{l}\text { \#1. (DOUMAS; MCKENNA; MURPHY, } \\
\text { 2016). }\end{array}$ & $\begin{array}{l}\text { Journal of autism and } \\
\text { developmental disorders. }\end{array}$ & Inter. \\
\hline $\begin{array}{l}\text { \#2. (ECHEVERRIA-PALACIO; } \\
\text { USCATEGUI- } \\
\text { DACCARETT; TALERO-GUTIÉRREZ, } \\
\text { 2018). }\end{array}$ & $\begin{array}{l}\text { Revista de la Facultad de } \\
\text { Medicina (Bogotá). }\end{array}$ & Inter. \\
\hline \#3. (GANDOLFI et al., 2014). & $\begin{array}{l}\text { Frontiers in human } \\
\text { neuroscience. }\end{array}$ & Inter. \\
\hline \#4. (LECUONA et al., 2017). & $\begin{array}{l}\text { The South African } \\
\text { Medical Journal. }\end{array}$ & Inter. \\
\hline $\begin{array}{l}\text { \#5. (MASON; GOLDSTEIN; SCHWADE, } \\
\text { 2019). }\end{array}$ & $\begin{array}{l}\text { Journal of Experimental } \\
\text { Child Psychology. }\end{array}$ & Inter. \\
\hline \#6. (NICOLA; WATTER, 2016). & $\begin{array}{l}\text { Child: care, health and } \\
\text { development. }\end{array}$ & Inter. \\
\hline \#7. (SCHAAF et al., 2018). & $\begin{array}{l}\text { American Journal of } \\
\text { Occupational Therapy. }\end{array}$ & Inter. \\
\hline \#8. (STEVENSON et al., 2014). & $\begin{array}{l}\text { The Journal of } \\
\text { Neuroscience. }\end{array}$ & Inter. \\
\hline \#9. (XU; YAO; LIU, 2019). & Psychiatria Danubina. & Inter. \\
\hline
\end{tabular}

Legenda: Internacional (Inter).

Fonte: Elaborado pelos autores.

Pela análise dos metadados, a maior quantidade de estudos foi considerada experimental pela autoria, em uma quantidade de três artigos, os quais demonstravam a aplicação da Integração Sensorial em várias situações e grupos diversos de indivíduos, com o intuito de analisar e observar esta forma de intervenção e a possibilidade de sua replicação em outros contextos (Figura 2).

Figura 2 - Metadados e inferências dos artigos incluídos

INTEGRAÇÃO SENSORIAL $x$ EQUILÍBRIO x LINGUAGEM. Artigos Incluídos

\section{Desenhos dos Estudos.}

Estudo Experimental $(\mathrm{n}=3)$; Revisão da Literatura $(\mathrm{n}=2)$; Ensaio Clínico Randomizado $(\mathrm{n}=1)$; Revisão Sistemática $(\mathrm{n}=1)$; Estudo de Coorte $(\mathrm{n}=1)$; Breve Comunicação $(\mathrm{n}=1)$.

\section{Análise dos Objetivos. \\ INTEGRAÇÃO SENSORIAL:}

Linguagem (\#2, \#4, \#5, \#6, \#7 e \#8); Equilíbrio (\#1 e \#3); e Ambos (\#9)

\section{Foco/Variável.}

Controle Postural (\#1); Linguagem (\#2, \#5 e \#6); Marcha (\#3); Prematuridade (\#4); AVDs (\#7); Processamento Multissensorial (\#8); e Qualidade de Vida (\#9).

Achados Apurados.

Positivos (\#1, \#3, \#4, \#6, \#8 e \#9); Indiferentes (n=0); Negativos (n\#7); Não Cabe (\#2 e \#5). 
Legenda: \# Ordem dos artigos incluídos (Tabela 1); e Não Cabe - aplicados a revisões que não apresentamdesfechos a partir de uma pergunta de pesquisa.

Fonte: Elaborado pelos autores.

Em contraponto, foi encontrado um único estudo de ensaio clínico randomizado, caracterizado por sua natureza intervencionista e prospectiva, na qual os indivíduos observados possuem características parecidas, mas são submetidos a intervenções diferenciadas com o intuito de observar e avaliar os resultados (Figura 2). Outros estudos encontrados foram categorizados como: coorte e revisão sistemática, com qualidade metodológica consistente (Figura 2). Isso sugere a busca e a execução de pesquisas qualificadas na área.

O último metadado apurado demonstra que a maioria dos resultados dos estudos incluídos foram benéficos aos participantes (Figura 2). Disso, pode-se dizer que os estudos que empregaram a Integração Sensorial montados em objetivos relacionados à linguagem têm resultados promissores apresentados pelos instrumentos de avaliação aplicados nas pesquisas (Figura 2).

\section{DISCUSSÃO}

\subsection{Principal resultado}

Segundo os dados apurados nos resultados do presente artigo, pode-se observar que a influência da Integração Sensorial na linguagem é positiva. Sendo assim, no levantamento de estudos publicados nos últimos 10 anos sobre a relação da Integração Sensorial sobre a linguagem e/ou equilíbrio é notado predomínio de publicações de grupos internacionais, cujos estudos, em sua maioria, foram classificados como experimentais, com poucas publicações a partir de ensaios clínicos randomizados, e os objetivos foram focados fortemente mais na linguagem do que no equilíbrio. Esses artigos utilizaram diversas ferramentas de avaliação, ea linguagem foi a mais destacada, cujos desfechos foram relatados como favoráveis aos pacientes. Assim, na última década, percebe-se que as publicações a partir da Integração Sensorial relacionadas à linguagem foram aquelas com maior interesse pelos profissionais da área, assim, a qualidade metodológica dos estudos deve continuar recebendo incentivo para se aproximar mais das melhores evidências, como as produzidas a partir de ensaios clínicos randomizados. 


\subsection{Achados secundários}

Durante a execução do presente levantamento, foi notada a ausência de profissionais brasileiros produzindo e publicando sobre a Integração Sensorial, com foco no equilíbrio e/ou linguagem, pelo menos. Assim, hipoteticamente, essa falta de grupos de pesquisa nacionais trabalhando no tema aqui sugerido pode ser explicada pelo interesse maior daqueles que adquirem a certificação pela intervenção prática na clínica, mais que pela atuação acadêmica. Isso é uma constatação não só no Brasil, que o Terapeuta Ocupacional tem pouco alinhamento e participação em sociedades científicas (ZEMKE, 2019). Nacionalmente, além do exposto, a hipótese levantada é corroborada pela literatura, à medida que se percebe, os grupos que formam o corpo de conhecimento ligado à Integração Sensorial trabalham mais ligados na prática da teoria do que na produção literária (CAMARATA; MILLER; WALLACE, 2020).

Focando-se no achado que a maior quantidade de publicações sobre Integração Sensorial está associada à linguagem em relação aos estudos que abordam como tema a Integração Sensorial e equilíbrio. Acredita-se que, provavelmente, um dos motivos disso estar ocorrendo é o fato das avaliações voltadas para o equilíbrio serem extensas e muitas vezes complexas, fazendo com que haja dificuldades em mensurar e quantificar o grau de melhora do paciente. De acordo com publicações anteriores, são raros os estudos destacando as dificuldades de aprendizagem devido às bases vestibulares, por variados motivos, como a dificuldade da criança para relatar os sintomas e suas efetivações, que estão acontecendo durante a realização dos testes e, consequentemente, a reação dos responsáveis perante tal situação, realçando a importância e emergência da construção de novos métodos avaliativos e práticos, em prol do manejo terapêutico com maior assertividade (BARBOSA; MALT, 2007).

Sobre isso, a partir da perspectiva voltada para a realidade acadêmica brasileira, é de extrema importância a investigação das contribuições científicas no campo de conhecimento, que tem sido recorrente nesse contexto (REGALADO, 2010). Além da hipótese anterior, a pouca quantidade de conteúdo específicos ao tema pode ter sofrido influencia pela crescente restrição orçamentária, a qual vem interpelando a área de ciência e tecnologia (GIBNEY, 2015) - isso passa a ser uma outra questão a se levar em consideração. Desta forma, a presente hipótese surge como uma provável limitante à produção cientifica nacional (SIDONE; HADDAD; 
MENA-CHALCO, 2016), incluindo na Terapia Ocupacional, em particular na Integração Sensorial.

Outro achado a destacar se refere aos desfechos positivos na maioria dos estudos. Contudo, é de fácil observação que nem todos tiveram a precisão de utilizar ferramentas avaliativas necessárias para inferências adequadas. Ou, pelo menos, nem todos tiveram a precisão para utilizar ferramentas avaliativas adequadas para as inferências alcançadas. O motivo para tal pode envolver a pouca oferta de ferramentas avaliativas precisas e de qualidade, bem como uso de capital para a obtenção, avaliações não validadas na comunidade cientifica, utilizadas apenas para grupo interno, domínios de difícil utilização, ou até mesmo má aplicação do instrutor. Estudos apontam algumas avaliações, como TERDAF, Tinnitus Handcap Inventory, Early Language Milestone Scale (ELM) e Reynell Developmental Language Scale (RDLS), para a avaliação da linguagem, o que nos leva a questionar a existência de ferramentas que são mais precisas pra avaliar a linguagem do que outras habilidades e, principalmente, em português (GOULART; CHIARI, 2007). Outro questionamento pertinente é o motivo da linguagem ser objetivo de terapeutas ocupacionais, obtendo dados tangíveis durante observação clínica, ou por possuir ferramentas avaliativas, observação da capacidade comunicativa da criança.

Assim, foram expostos argumentos que ajudam no esclarecimento de motivos pelos quais a maioria dos estudos, cujos objetivos estavam focados na linguagem, aconteceram, principalmente, por se acreditar que esta variável tende a ter mais opções de instrumentos de acompanhamento evolutivo das intervenções trabalhadas, associadamente à Integração Sensorial. Isso corrobora com a percepção recente que entende a linguagem como mecanismo comunicativo que favorece a observação/proximidade entre terapeuta e paciente (SILVA et al., 2017).

Durante a execução do presente estudo, foram identificadas duas grandes limitações, a primeira delas destaca a língua. Todas as publicações incluídas estavam em inglês, à luz técnica, isso evidencia a busca da internacionalização das produções científicas (CINTRA; SILVA; FURNIVAL, 2020) e, por outro lado, também pode sinalizar a influência de pensamentos dos poucos grupos internacionais sobre as produções locais, tal qual como jávem sendo sinalizado em outras áreas de conhecimento da Terapia Ocupacional (HAMMELL, 2011). Em última análise, isso pode dificultar o desenvolvimento de uma identidade regionalizada. Outra limitação está no perfil nacional. Pelo menos, para os temas relacionados à 
linguagem e/ou ao equilíbrio, não foram encontradas a participação de brasileiros entre as publicações incluídas, isto sugere o baixo interesse dos pesquisadores pelos tópicos e abre a possibilidade de se fazer um novo levantamento para mapear quais são as áreas de interesse dos profissionais certificados em Integração Sensorial.

\section{CONCLUSÃO}

Nos últimos 10 anos, o presente estudo evidenciou que a maioria das publicações incluídas teve a linguagem como o principal objeto da pesquisa e, secundariamente, o equilíbrio. Paralelamente, infere-se uma ampla relação com desfechos positivos do tratamento proposto baseado na Integração Sensorial. Assim, conclui-se que as intervenções, fundamentadas no monitoramento do desenvolvimento da linguagem e/ou do equilíbrio, manifestam resultados promissores quando trabalhadas pela Integração Sensorial, apesar da baixa contundência das evidências encontradas. Mesmo assim, pelo reduzido número de tópicos relacionados ao equilíbrio, mais estudos devem ser fomentados nesta linha para definir o peso real de estratégias que usam essa abordagem na Integração Sensorial.

\section{REFERÊNCIAS BIBLIOGRÁFICAS}

BARBOSA, Katia; MALT, Samar Mohamad El Avaliação do equilíbrio estático e dinâmico em crianças de $1^{\text {a }}$ série do ensino fundamental com e sem dificuldades escolares. 77 f. 2007. Trabalho de Conclusão de Curso (Graduação em Fonoaudiologia) - Pontifícia Universidade Católica de São Paulo, São Paulo, 2007.

CAMARATA, Stephen; MILLER, Lucy Jane; WALLACE, Mark T. Evaluating Sensory Integration/Sensory Processing Treatment: Issues and Analysis. Front. Integr. Neurosci., 26 nov. 2020. doi: https://doi.org/10.3389/fnint.2020.556660.

CINTRA, Paulo Roberto; SILVA, Marco Donizete Paulino da; FURNIVAL, Ariadne Chloe. Uso do inglês como estratégia de internacionalização da produção científica em Ciências Sociais Aplicadas: estudo de caso na SciELO Brasil. Em Questão, [s. L.], v. 26, n. 1, p. 17-41, 2020. doi: https://doi.org/10.19132/1808-5245261.17-41.

DOUMAS, Michail; MCKENNA, Roisin; MURPHY, Blain. Postural Control Deficits in Autism Spectrum Disorder: The Role of Sensory Integration. Journal of Autism and Developmental Disorders, United States, v. 46, n. 3, p. 853-861, 2016. doi: https://doi.org/10.1007/s10803-015-2621-4 
ECHEVERRÍA-PALACIO, Carlos Mario; USCÁTEGUI-DACCARETT, Angélica; TALERO-GUTIÉRREZ, Claudia. Integración auditiva, visual y propioceptiva como sustratodel desarrollo del lenguaje. Revista de la Facultad de Medicina, [s. L.], v. 66 , n. 3, p. 469-475, 2018. doi: https://doi.org/10.15446/revfacmed.v66n3.60490.

GANDOLFI, M. et al. Sensory integration balance training in patients with multiple sclerosis:a randomized, controlled trial. Multiple sclerosis (Houndmills, Basingstoke, England), [s. L.], v. 21, n. 11, p. 1453-1462, 2015. doi: https://doi.org/10.1177/1352458514562438.

GANDOLFI, Marialuisa et al. Robot-assisted vs. sensory integration training in treating gaitand balance dysfunctions in patients with multiple sclerosis: A randomized controlled trial. Frontiers in Human Neuroscience, [s. L.], v. 8, 2014. doi: https://doi.org/10.3389/fnhum.2014.00318.

GIBNEY, Elizabeth. Brazilian science paralysed by economic slump. Nature, [s. L.], v. 526,n. 7571, p. 16-17, 2015. doi: https://doi.org/10.1038/526016a.

GOULART, Bárbara Niegia Garcia de; CHIARI, Brasília Maria. Testes de rastreamento $x$ testes de diagnóstico: atualidades no contexto da atuação fonoaudiológica. Pró-Fono Revistade Atualização Científica, [s. L.], v. 19, n. 2, p. 223-232, 2007. doi: https://doi.org/10.1590/S0104-56872007000200011

HAMMELL, Karen Whalley. Resisting Theoretical Imperialism in the Disciplines of Occupational Science and Occupational Therapy. British Journal of Occupational Therapy, [s. L.], v. 74, n. 1, p. 27-33, 2011. doi: https://doi.org/10.4276/030802211X12947686093602.

KILROY, Emily; AZIZ-ZADEH, Lisa; CERMAK, Sharon. Ayres theories of autism and sensory integration revisited: What contemporary neuroscience has to say. Brain Sciences, [s.L.], v. 9, n. 3, 2019. doi: https://doi.org/10.3390/brainsci9030068.

LANE, Shelly J. et al. Neural foundations of ayres sensory integration®. Brain Sciences, [s.L], v. 9, n. 7, p. 1-14, 2019. doi: https://doi.org/10.3390/brainsci9070153

LECUONA, E. et al. Sensory integration intervention and the development of the premature infant: a controlled trial. The South African Medical Journal, v. 107, n. 11, 2017.

MASON, Gina M.; GOLDSTEIN, Michael H.; SCHWADE, Jennifer A. The role of multisensory development in early language learning. Journal of Experimental Child Psychology, v. 183, p. 48-64, jul. 2019.

MILLER, Lucy J. et al. Perspectives on sensory processing disorder: A call for translationalresearch. Frontiers in Integrative Neuroscience, [s. L.], v. 3, n. SEP, p. 1-12, 2009. doi: https://doi.org/10.3389/neuro.07.022.2009.

NICOLA, K; WATTER, P. Visual-motor integration performance in children with severespecific language impairment. Child: Care Health Dev, Australia., v. 42, n. 5, 
p. 742-749, 2016. doi: https://dx.doi.org/10.1111/cch.12365.

OUZZANI, Mourad et al. Rayyan-a web and mobile app for systematic reviews.

SystematicReviews, [s. I.], v. 5, n. 1, 2016. doi: https://doi.org/10.1186/s13643-0160384-4.

PETERS, Micah D.J. et al. Updated methodological guidance for the conduct of scoping reviews. JBI Evidence Synthesis, [s. L.], v. 18, n. 10, 2020. doi: https://doi.org/10.11124/JBIES-20-00167.

REGALADO, A. Brazilian Science: Riding a Gusher. Science, [s. L.], v. 330, n. 6009, p.1306-1312, 2010. doi: https://doi.org/10.1126/science.330.6009.1306.

SCHAAF, Roseann C et al. Efficacy of Occupational Therapy Using Ayres Sensory Integration ${ }^{\circledR}$ : A Systematic Review. Am J Occup Ther, Philadelphia, v. 72, n. 1, p. 7201190010p1-7201190010p10, 2018. doi:

https://dx.doi.org/10.5014/ajot.2018.028431.

SECTION ON COMPLEMENTARY AND INTEGRATIVE MEDICINE et al. Sensory integration therapies for children with developmental and behavioral disorders.

Pediatrics, v. 129, n. 6, p. 1186-1189, jun. 2012.

SIDONE, Otávio José Guerci; HADDAD, Eduardo Amaral; MENA-CHALCO, Jesús Pascual. A ciência nas regiões brasileiras: evolução da produção e das redes de colaboraçãocientífica. Transinformação, [s. L.], v. 28, n. 1, p. 15-32, 2016. doi: https://doi.org/10.1590/2318-08892016002800002.

SILVA, Carmen Lucianna Miranda e et al. Characterization of the communication resources used by patients in palliative care - an integrative review. Revista CEFAC, [s. L.], v. 19, n. 6,p. 879-888, 2017. doi: https://doi.org/10.1590/19820216201719613816.

STEVENSON, Ryan A et al. Multisensory temporal integration in autism spectrum disorders.J Neurosci, Nashville, v. 34, n. 3, p. 691-697, 2014. doi:

https://dx.doi.org/10.1523/JNEUROSCI.3615-13.2014.

SU, Chia Ting; PARHAM, L. Diane. Validity of sensory systems as distinct constructs. American Journal of Occupational Therapy, [s. L.], v. 68, n. 5, p. 546-554, 2014. doi: https://doi.org/10.5014/ajot.2014.012518.

XU, Wenxin; YAO, Jiwei; LIU, Wenyao. Intervention Effect of Sensory Integration Trainingon the Behaviors and Quality of Life of Children with Autism. Psychiatria Danubina, v. 31, n. 3, p. 340-346, 2019.

ZEMKE, Ruth. OS, OT and Me: Personal reminiscences inspired by the 2017 Occupational Science Europe conference. Journal of Occupational Science, [s. L.], v. 26, n. 2, p. 156-164, 2019.doi: https://doi.org/10.1080/14427591.2019.1588359. 


\title{
RELAÇÃO ENTRE INTEGRAÇÃO SENSORIAL E O BRINCAR EM CRIANÇAS COM TEA
}

\author{
Tatiane Lima Menezes Barreto ${ }^{1}$ \\ Nayara Couto de Carvalho ${ }^{1}$ \\ Michele de Sena Cruz ${ }^{1}$ \\ Alexsarah de Souza Monteiro ${ }^{1}$ \\ Daniele da Costa Soares ${ }^{1}$ \\ Ana Amélia Cardoso ${ }^{2}$
}

\section{RESUMO}

O objetivo deste trabalho foi realizar uma revisão narrativa de literatura sobre estudos que descrevam o impacto dos transtornos de processamento sensorial no brincar das crianças com Transtorno do Espectro Autista (TEA). Foi realizada busca nas bases de dados Pubmed, LILACS e SciELO, usando os descritores "autismo" AND ("sensoryintegration" OR "sensoryprocessing") AND "play", em inglês e português. Foram selecionados quatro artigos e foi possível observar os impactos que crianças com Autismo enfrentam no desenvolvimento de atividades cotidianas e como a Integração Sensorial desses indivíduos se organiza de forma diferente. Além disso, constatou-se que crianças com TEA demonstram diferenças qualitativas na maneira como brincam, apresentando, assim, dificuldades com a interação social e com o envolvimento em brincadeiras - seja sozinha, seja com colegas. Dessa forma, a partir dessas análises, foi possível sugerir que a Terapia da Integração Sensorial é uma abordagem de intervenção da Terapia Ocupacional que pode ter efeitos positivos no desenvolvimento da aprendizagem desses indivíduos. No entanto, ainda são necessárias maiores investigações no que tange à relação dessa terapia com o brincar das crianças com TEA.

Palavras-chave: Autismo. Brincar. Integração Sensorial.

\section{INTRODUÇÃO}

A Terapia Ocupacional tem como base que a aprendizagem se dá através do pegar, manipular, sentir, construir, diferenciar, ou seja, explorar e dar função para o objeto e o ambiente (SOUZA et al., 2018). O principal objetivo do Terapeuta Ocupacional é promover a independência e a qualidade de vida do indivíduo, por isso, este profissional utiliza métodos e técnicas que atuam no desenvolvimento global do ser humano (SOUZA et al., 2018).

\footnotetext{
${ }^{1}$ Terapeutas Ocupacionais.

${ }^{2}$ Terapeuta Ocupacional. Doutora em Ciências da Reabilitação. Professora Adjunta da Universidade Federal de Minas Gerais (UFMG). Docente do Curso de Certificação Brasileira em Integração Sensorial - Integris/UEPA, Orientadora do trabalho.
} 
Os terapeutas ocupacionais defendem a importância do brincar (REILLY, 1974). Brincar é uma das principais ocupações da infância e as restrições nas oportunidades de brincar podem privar a criança de um contexto de desenvolvimento necessário e de experiências de infância significativas e importantes (AMERICAN OCCUPATIONAL THERAPY ASSOCIATION, 2008).

Muitos autores, bem como a Academia Americana de Pediatria, reconheceram publicamente a importância da brincadeira para a saúde e o aprendizado (BROWN, 2009; ELKIND, 2007; GINSBURG, 2007; PELLEGRINI, 2009). Brincar também é agradável e pode fornecer um tipo de "enriquecimento ambiental" que influencia o funcionamento neurológico, pois altera as trajetórias de desenvolvimento de maneira positiva.

A criança tem como atividade própria o brincar, que é considerado uma área de desempenho ocupacional, que se refere à capacidade de realizar tarefas ocupacionais de maneira satisfatória e apropriada para o estágio de desenvolvimento do indivíduo (SEGAVA; CAVALCANTI, 2011).

Quando a criança apresenta algum atraso/transtorno do desenvolvimento e não é estimulada precocemente, poderá demostrar limitações nas habilidades funcionais, ou seja, banho independente, alimentação, autocuidado, interagir com outra criança, entre outros (SOUZA et al., 2018).

O Transtorno do Espectro Autista (TEA) é um transtorno do desenvolvimento de etiologia desconhecida. A prevalência foi recentemente relatada como $1 \mathrm{em}$ cada 50 crianças nos Estados Unidos (BLUMBERG et al., 2013). As características primárias do TEA incluem dificuldades com a interação social, a comunicação e os comportamentos restritos e repetitivos.

As crianças com diagnóstico de TEA, muitas vezes, apresentam comprometimentos significativos no seu repertório do brincar, apresentando dificuldades na forma de lidar com o brinquedo, com o outro e com o ambiente que a cerca. Conforme afirma Rezende (2008), crianças com Autismo tendem a realizar ações repetitivas, manipulação estereotipada, com menor uso do simbólico no faz de conta com o objeto ou brinquedo.

Essas dificuldades, muitas vezes, estão relacionadas aos transtornos do processamento sensorial ou déficit na capacidade de processar as informações sensoriais, que levam a comportamentos diferentes do esperado. Conforme afirmam Posar e Visconti (2018), as alterações sensoriais são muito frequentes e se 
caracterizam pelo aumento ou pela redução da reatividade ao estímulo sensorial ou pelo interesse incomum por determinados aspectos sensoriais do ambiente.

De acordo com Whitman (2015), os sentidos nos deixam em alerta para eventos que possam acontecer em nosso ambiente, orientando e influenciando o comportamento, as emoções e o pensamento. Na vida intrauterina, os bebês estão isolados pelo útero, tendo um ambiente sensorial rico, porém, razoavelmente organizado. Já no período pós-natal, este ambiente sensorial se torna caótico, mas bebês apresentam mecanismos protetores que os ajudam a se adaptar a esse turbilhão de estímulos.

Em crianças com TEA, esses mecanismos se apresentam desorganizados, 0 mundo sensorial permanece confuso e assustador, sendo muitas vezes percebido como muito luminoso, ruidoso, áspero, doloroso e intenso.

\begin{abstract}
A sintomatologia associada com o Autismo apresenta um quadro de anormalidades sensoriais, motoras e cognitivas; que enfrentam sérios desafios, enquanto tentam se adaptar aos seus ambientes; que tem deficiência em recurso de enfrentamento, e que compensam suas limitações desenvolvendo formas incomuns de regular suas emoções e controlar os aspectos físicos e sociais do ambiente à sua volta. (WHITMAN, 2015, p. 56).
\end{abstract}

Diante desse contexto, a intervenção baseada na abordagem de Integração Sensorial constitui uma alternativa para tentar organizar esses estímulos sensoriais, fazendo com que a criança consiga selecionar as informações relevantes para assim conseguir agir de acordo com a demanda do ambiente.

Integração Sensorial é essa habilidade para organizar os estímulos sensoriais, selecionar as informações importantes, que merecem atenção ou exigem algum tipo de resposta, e ignorar o que não é relevante no momento; enfim, habilidade para organizar e interpretar os estímulos para agir de acordo com a situação. (MAGALHÃES, 2008, p. 46).

Quando esse processo neurológico não ocorre de maneira adequada, a criança não consegue dar uma resposta adaptativa esperada para determinada situação, fato esse que define o Transtorno do Processamento Sensorial ou Disfunção de Integração Sensorial. As falhas em algumas etapas do processamento sensorial interferem com a habilidade do indivíduo para perceber e memorizar as informações, interpretá-las e/ou organizá-las, levando a respostas inadequadas ou comportamentos ineficientes (GRACIANI; MOMO; SILVESTRE, 2012).

Para Whitman (2015), essa desorganização gera incapacidade na modulação e/ou discriminação da informação sensorial, inibindo ainda mais a presença de uma 
resposta eficaz e ativando o mecanismo de luta e fuga, comportamentos estes que impedem a ação coordenada e estratégica.

Nesse sentido, observa-se que a criança se desenvolve pela sua interação com o ambiente que a cerca, mas a efetividade desse processo vai depender de sua capacidade para captar, integrar e usar as informações sensoriais do seu corpo e do ambiente. Assim, a criança típica é motivada a agir por conseguir extrair do seu meio os estímulos provocadores da ação, no entanto, a criança com TEA pode não captar esses estímulos ou não saber como reagir a eles, ficando, assim, privada das melhores oportunidades de desenvolvimento. Para Andrade (2020), a disfunção de Integração Sensorial pode impactar no desempenho e participação inadequados nas suas ocupações, sejam elas as atividades de vida diária, atividades instrumentais de vida diária, descanso e sono, brincar, lazer, educação e participação social.

A intervenção de Integração Sensorial de Ayres objetiva influenciar no processamento das informações sensoriais, de modo a promover mudança na capacidade da resposta adaptativa e no comportamento funcional, considerando a importância dessa intervenção, perante as demandas do brincar e nas demandas ocupacionais de crianças com TEA.

O presente artigo teve por objetivo realizar uma revisão narrativa de literatura sobre estudos que descrevam o impacto dos transtornos de processamento sensorial no brincar das crianças com TEA.

\section{METODOLOGIA}

A busca dos artigos para a realização desta revisão da literatura foi feita nas plataformas LILACS, SciELO e PubMed no mês de agosto de 2021, sem restrição de ano. Foram utilizados os seguintes descritores na língua inglesa e portuguesa: "autismo" AND "sensoryintegration" OR "sensoryprocessing" AND "play".

Como critérios de inclusão foram considerados estudos na língua portuguesa e inglesa, que avaliaram o impacto dos transtornos de processamento sensorial no brincar de crianças com TEA. Foram excluídos estudos em outros idiomas que não sejam português e inglês, revisões de literatura e relatos de caso. Com base nos títulos e resumos das publicações, foram selecionados para a leitura completa aqueles que se encaixaram nos critérios de inclusão. Na Figura 1 está representado o fluxograma completo da seleção dos artigos. 
Figura 1 - Fluxograma de seleção dos artigos

Número de relatos identificados no banco de dados de buscas $n=$ 05 (PubMed $n=5$, Scielo $n=0$, Lilacs $n=0$ )

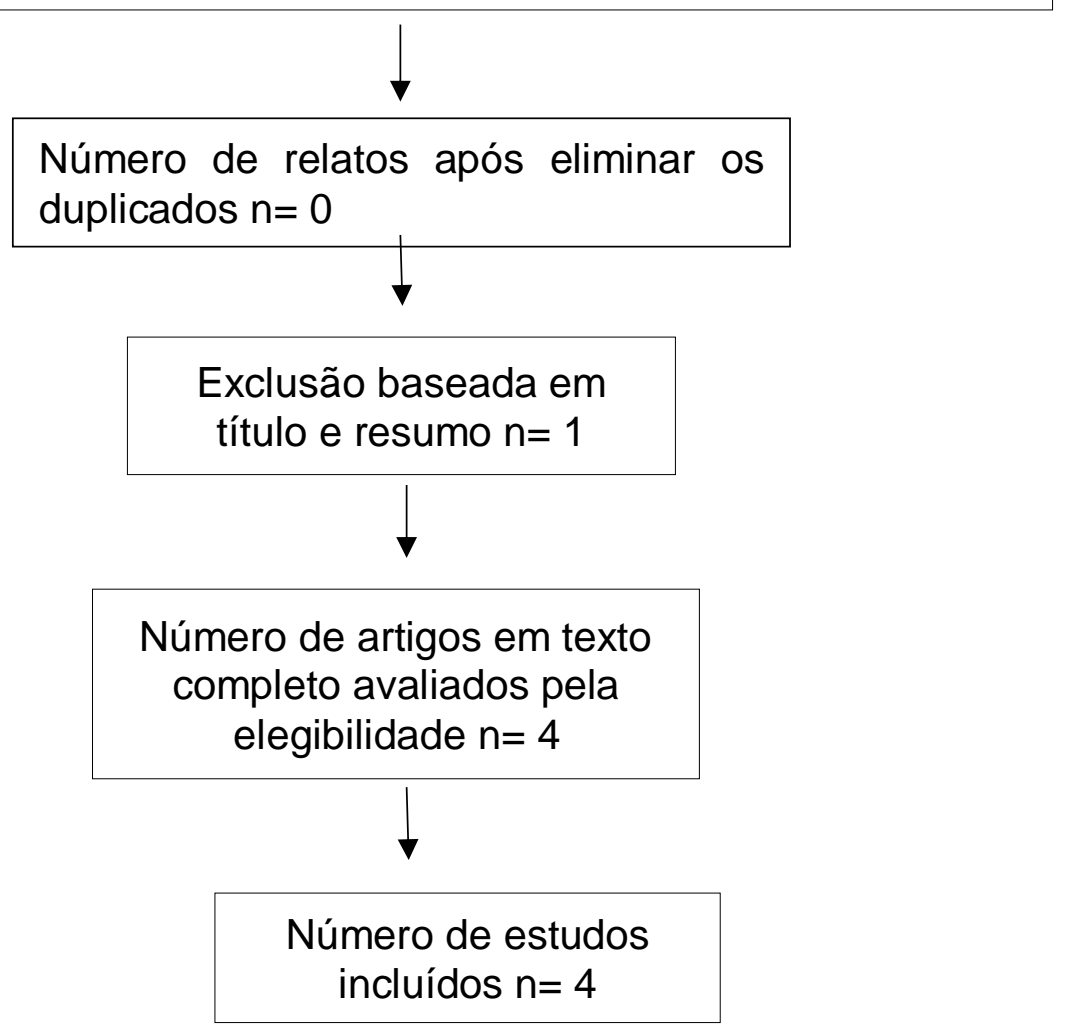

Fonte: Elaborado pelos autores.

\section{RESULTADOS E DISCUSSÃO}

Foram encontradas cinco referências nas bases de dados eletrônicas, dos quais foi eliminado um artigo de acordo com os critérios de exclusão. Ao final, quatro artigos foram incluídos nesta revisão de literatura. Todos os artigos incluídos abordam o impacto dos transtornos de processamento sensorial no brincar de crianças com TEA. 
Quadro 1 - Artigos que abordam o impacto dos transtornos de processamento sensorial no brincar de crianças com TEA

\begin{tabular}{|c|c|c|c|}
\hline Nome do artigo & Objetivos & Procedimentos & Resultados \\
\hline $\begin{array}{l}\text { Influence of Ideational Praxis on } \\
\text { the Development of Play and } \\
\text { Adaptive Behavior of Children } \\
\text { whit Autism Spectrum Disorder: } \\
\text { A Comparative Analysis }\end{array}$ & $\begin{array}{l}\text { Avaliar as habilidades de } \\
\text { ideação de crianças com } \\
\text { TEA; Analisar possíveis } \\
\text { relações com o } \\
\text { desenvolvimento do brincar } \\
\text { e comportamentos } \\
\text { adaptativos. }\end{array}$ & $\begin{array}{l}\text { Amostra do estudo: crianças com } \\
\text { desenvolvimento típico (DT); } \\
\text { crianças com diagnóstico de TEA; } \\
\text { ambos entre } 4 \text { e } 6 \text { anos. } \\
\text { Avaliações utilizadas: teste de Práxis } \\
\text { Ideacional, Escala de Brincadeiras } \\
\text { pré-escolares de Knox Revisada e o } \\
\text { Adaptive Behavior. }\end{array}$ & $\begin{array}{l}\text { Todas as pontuações em } \\
\text { todas as medidas do grupo } \\
\text { DT foram significativamente } \\
\text { mais altas do que as crianças } \\
\text { com TEA. }\end{array}$ \\
\hline $\begin{array}{l}\text { A Preliminary Investigation of } \\
\text { the Relationship Between } \\
\text { Sensory Processing and Social } \\
\text { Play in Autism Spectrum } \\
\text { Disorder }\end{array}$ & $\begin{array}{l}\text { Concluir uma investigação } \\
\text { preliminar da relação entre } \\
\text { os tipos de funções } \\
\text { sensoriais } \quad \text { (modulação, } \\
\text { discriminação, percepção e } \\
\text { práxis) e o brincar social em } \\
\text { uma amostra de crianças } \\
\text { com TEA. }\end{array}$ & $\begin{array}{l}\text { Idade dos participantes: variando de } \\
2 \text { anos e } 2 \text { meses a } 13 \text { anos e } 6 \\
\text { meses, com média de idade de } 7 \\
\text { anos e } 2 \text { meses. } \\
\text { Avaliações utilizadas: SPM e SPM-P } \\
\text { (ambas as ferramentas examinam o } \\
\text { processamento sensorial, a práxis e } \\
\text { a participação social). }\end{array}$ & $\begin{array}{l}\text { Forneceu evidências entre as } \\
\text { funções sensoriais e o brincar } \\
\text { social em combinação com a } \\
\text { práxis. Apresentou dois } \\
\text { pontos fortes: primeiro, o fato } \\
\text { de concluir com uma grande } \\
\text { amostra de crianças com TEA. } \\
\text { Em segundo, foi o primeiro } \\
\text { estudo a examinar os déficits } \\
\text { de processamento sensorial } \\
\text { em conjunto, incluindo } \\
\text { dispraxia e baixo desempenho } \\
\text { lúdico em crianças com TEA. }\end{array}$ \\
\hline $\begin{array}{l}\text { Sensory processing abilities } \\
\text { and their relation to participation } \\
\text { in leisure activities among } \\
\text { children with high-functioning } \\
\text { autism spectrum disorder } \\
\text { (HFASD) }\end{array}$ & $\begin{array}{l}\text { Elaborar o conhecimento } \\
\text { sobre as características } \\
\text { específicas do } \\
\text { processamento sensorial de } \\
\text { crianças com } \\
\text { HFASD e sua relação com } \\
\text { os padrões de participação } \\
\text { em atividades de lazer. }\end{array}$ & $\begin{array}{l}\text { Participantes: } 50 \text { crianças com } \\
\text { idades entre } 6-11 \text { anos. } \\
25 \text { crianças com HFASD (17 } \\
\text { meninos e } 8 \text { meninas); } \\
25 \text { crianças com desenvolvimento } \\
\text { típico ( } 18 \text { meninos e } 7 \text { meninas). } \\
\text { Todas as crianças frequentavam } \\
\text { aulas de educação regular, } \\
\text { nasceram a termo e com QI de pelo } \\
\text { menos } 70 .\end{array}$ & $\begin{array}{l}\text { Descreveu que quanto mais } \\
\text { severo o comprometimento do } \\
\text { processamento sensorial, } \\
\text { mais limitadas foram a } \\
\text { diversidade e a intensidade da } \\
\text { participação em atividades de } \\
\text { lazer. Destacou a relevância } \\
\text { de se referir aos impactos do } \\
\text { processamento sensorial } \\
\text { atípico também na }\end{array}$ \\
\hline
\end{tabular}




\begin{tabular}{|c|c|c|c|}
\hline & & & participação no lazer diário. \\
\hline $\begin{array}{l}\text { Developmental dyspraxia and } \\
\text { the play skills of children with } \\
\text { Autismo }\end{array}$ & $\begin{array}{l}\text { Investigar o impacto da } \\
\text { dispraxia } \\
\text { desenvolvimento do } \\
\text { habilidades lúdicas de } \\
\text { crianças com Transtorno do } \\
\text { Espectro do Autismo (TEA). }\end{array}$ & $\begin{array}{l}\text { Participantes: } 32 \text { crianças } \\
\text { desordem do espectro do } \\
\text { Autismo (ASD). } \\
\text { Foram avaliadas usando dois } \\
\text { subtestes dos testes de Integração } \\
\text { Sensorial e práxis. } \\
\text { As habilidades de brincar e lazer } \\
\text { foram medidas com as escalas de } \\
\text { comportamento adaptativo Vineland } \\
\text { (2 } 2^{\text {a }} \text { edição). }\end{array}$ & $\begin{array}{l}\text { Crianças com TEA } \\
\text { demonstraram disfunção da } \\
\text { práxis imitativa, na geração } \\
\text { de ideias e na participação } \\
\text { no brincar e atividades de } \\
\text { lazer apropriados para idade. }\end{array}$ \\
\hline
\end{tabular}


Segundo o DSM 5, o Transtorno do Espectro Autista é caracterizado pelo déficit na interação e comunicação social, padrões estereotipados e repetitivos de comportamentos e esses sintomas tendem a aparecer no período da infância (AMERICAN PSYCHIATRIC ASSOCIATION, 2013). Essas características afetam a capacidade da criança de se envolver com bom desempenho em ocupações significativas, algumas evidências propõem que déficits associados na prática e nas habilidades lúdicas do mesmo modo podem reduzir a participação da criança e intensificar os déficits persistentes observados nas interações sociais (BODISON, 2015).

No TEA é comum existir dificuldade no processamento sensorial com estimativa de 90-95\%, ou seja, existe um déficit na recepção, organização e processamento de informações sensoriais pelo sistema nervoso central que prejudica resposta motora, comportamental, aprendizagem, entre outros, e, por sua vez, influenciam na participação das atividades de vida diária (RANDELL et al., 2019).

Com relação ao brincar, esses estudos sugerem que em todas as categorias de brincadeiras, crianças com TEA demonstram diferenças qualitativas na maneira como brincam. A pesquisa também apoiou a noção de que indivíduos com Transtorno do Espectro Autista têm dificuldade específica com o brincar social, com a geração de ideias flexíveis e novas para brincar e com o envolvimento em brincar com e sem colegas, com espontaneidade e prazer (CRAIG; BARON-COHEN, 1999; JORDAN, 2003; BUNDY, 2007).

Os terapeutas ocupacionais podem considerar esses déficits dentro de uma estrutura de dispraxia (AYRES, 1979). A dispraxia também foi documentada repetidamente em indivíduos com TEA e alguns pesquisadores sugeriram que 0 planejamento motor é um problema primário para esses indivíduos (DOWELL; MAHONE; MOSTOFSKY, 2009).

Vale ressaltar que de acordo com Ayres, a dispraxia é uma disfunção de Integração Sensorial que interfere com a habilidade de ideação, planejamento e execução de tarefas motoras não habituais. E tem como base as desordens nos sistemas sensoriais: tátil, vestibular, proprioceptivo (AYRES; CERMAK, 1979).

Crianças com TEA também demonstram consistentemente uma variedade de dificuldades adicionais de processamento sensorial. Esses déficits de processamento sensorial agora são considerados parte dos critérios diagnósticos 
para TEA, dentro da categoria de comportamentos repetitivos e restritos (AMERICAN PSYCHIATRIC ASSOCIATION, 2013). A Teoria de Integração Sensorial de Ayres sugere uma relação entre práxis e brincar (AYRES, 1979). Brincadeiras sociais, em particular, podem exigir fortes habilidades de práxis para crianças com TEA, porque elas devem negociar mudanças rápidas nos esquemas de brincadeira e a introdução de novas ideias de brincadeira de outras pessoas. Portanto, a práxis pode ser conceituada como a habilidade de criar, estruturar e executar ações que não são do cotidiano da pessoa (SERRANO, 2016).

Bodison (2015) propôs que os problemas com a imitação e a conceituação de novas maneiras de interagir com objetos e materiais podem afetar significativamente o desenvolvimento de habilidades lúdicas em crianças com TEA e essas dificuldades de práxis influenciariam a capacidade da criança de compartilhar brincadeiras imaginativas ou fazer amigos, além de alterar substancialmente a capacidade da criança de desenvolver e compreender relacionamentos, cuja descrição abarca as características centrais do transtorno.

Hochhauser e Engel-Yeger (2010) descreveram que quanto maior o comprometimento do processamento sensorial, mais limitada se apresentou a intensidade e a diversidade da participação em atividades de lazer.

De acordo com os resultados de Bodison (2015, p. 4):

\begin{abstract}
Nossos resultados indicam que pontuações baixas nos testes de práxis imitativa e domínio de ideias e planejamento se correlacional significativamente com a capacidade das crianças da amostra dos estudos de participar de atividades de lazer e brincadeiras relacionadas a idade.Com base no resultado, proponho que os problemas com a imitação e a conceituação de novas maneiras de interagir com objetos e materiais podem afetar significativamente o desenvolvimento de habilidades lúdicas em crianças com TEA.
\end{abstract}

A Terapia de Integração Sensorial tem como objetivo promover estímulos de qualidade e em quantidade adequada para que a criança melhore o seu desempenho nas atividades do dia a dia, ou seja, a Integração Sensorial de Ayres (ISA) tem como finalidade favorecer uma resposta adaptativa e funcional para a participação efetiva nos ambientes frequentados (ROLEY et al., 2007).

\title{
4 CONSIDERAÇÕES FINAIS
}

Ficou evidente que as informações sensoriais provenientes do ambiente são necessárias para o desenvolvimento, já que aprimoram padrões comportamentais e 
beneficiam aquisições de habilidades e capacidades. Deste modo, um programa de atividades sensoriais pode simular situações com sensações que favoreçam a emissão de comportamentos coerentes e hábeis que influenciarão a aprendizagem e o desenvolvimento.

O tratamento utilizando a abordagem de Integração Sensorial tem como fundamento o conceito da neuroplasticidade, ou seja, que o sistema nervoso modifica sua resposta de acordo com a sua experiência. Essa concepção é embasada por pesquisas neurocientíficas que evidenciam que a aprendizagem é um processo constante de organização e conexões neuronais que são equivalentes ao resultado de experiências e que moldam as funções cerebrais e comportamentais (LANE et al., 2019).

Com isso, percebeu-se a importância da Terapia de Integração Sensorial na influência de demandas do brincar. No entanto, verificou-se a necessidade de mais estudos que abordem a investigação da relação da Terapia de Integração Sensorial e sua influência no brincar das crianças com TEA, pois no decorrer desta pesquisa poucos estudos foram encontrados com o enfoque nesta relação.

\section{REFERÊNCIAS BIBILIOGRÁFICAS}

AMERICAN OCCUPATIONAL THERAPY ASSOCIATION. Ocupacional Estrutura da prática terapêutica: Domínio e processo. American Journal of Occupational Therapy, v. 62, p. 625-683. 2008.

AMERICAN PSYCHIATRIC ASSOCIATION. Diagnóstico e estatístico manual de transtornos mentais. 5. ed. Washington, DC: Autor, 2013.

AOTA - Associação Americana de Terapia Ocupacional. AOTA's declaração da sociedade sobre o jogo. American Journal of Occupational Therapy, v. 62, p. 707708. 2008.

ASSOCIAÇÃO PSIQUIÁTRICA AMERICANA. DSM-V: Manual Diagnóstico e Estatístico de Transtornos Mentais. 5. ed. Porto Alegre: ARTMed. 2014.

AYRES, A. J. Sensory Integration and the child. Los Angeles: Western Psychological Services, 1979.

AYRES, A. J.; CERMAK, S. A. Ayres Dispraxia Monografh. 25. ed. California: Pediatric Therapy. 1974.

BLUMBERG, S. J. et al. Mudanças na prevalência de Transtorno do Espectro do Autismo relatado pelos pais em crianças em idade escolar nos Estados Unidos: 
2007 a 2011-2012. Relatórios de Estatísticas Nacionais de Saúde, v. 65, p. 1-12, 2013.

BODISON, Stefanie C. Development aldys praxia and the play skills of children with autism. American Journal of Occupational Therapy, v. 69, n. 5, p. 6905185060p16905185060p6, 2015.

BROWN, S. Brincar: como ele molda o cérebro, abre a imaginação, e revigora a alma. Nova York: Penguin Books. 2009.

BUNDY, A. C. et al. Como vai disfunção do processamento sensorial afeta o jogo? American Journal of Occupational Therapy, v. 61, p. 201-208. 2007.

CRAIG, J.; BARON-COHEN, S. Criatividade e imaginação no Autismo e na síndrome de Asperger. Journal of Autismand Developmental Disorders, v. 29, p. 319-326. 1999.

DOWELL, L. R; MAHONE, E. M.; MOSTOFSKY, S. H. Associações entre conhecimento postural e habilidade motora básica com dispraxia no Autismo: Implicação para anormalidades na conectividade distribuída e aprendizagem motora. Neuropsicologia, v. 23, p. 563-570, 2009.

ELKIND, D. O poder do jogo. Cambridge, MA: De Capo, 2007.

GINSBURG, K. R. Comitê da Academia Americana de Pediatria on Communications. American Academy of Pediatrics Committee on Psychosocial Aspects of Child and Family Health. A importância da brincadeira na promoção do desenvolvimento infantil saudável e na manutenção de laços fortes entre pais e filhos. Pediatria, v. 119, p. 182-191, 2007.

GRACIANI, Zodja; MOMO, Aline Rodrigues Bueno; SILVESTRE, Claudia.

Atividades Sensoriais: na clínica, na escola, em casa. São Paulo: Memnon Edições Científicas, 2012.

HOCHHAUSER, M.; ENGEL-YEGER, B. Sensory processing abilities and. Their relation to participation in leisure activities among children with high-functioning autism espectro disorder (HFASD). Research in Autism Spectrum Disorders, v. 4, p. 746-754, 2010.

JORDAN, R. Brincadeiras sociais e transtornos do espectro autista: A perspectiva da teoria, implicações e abordagens educacionais. Autismo, v. 7, p. 347-360, 2003. doi: 10.1177 / 1362361303007004002.

KUHANECK, Heather Miller; BRITNER, Preston A. A Preliminary Investigation of the Relationship Between Sensory Processing and Social Play in Autism Spectrum Disorder. OTJR: Ocupation, Participationand Health, v. 33, n. 3, 2013.

LANE, Shelly J. et al. Neural Foundations of Ayres Sensory Integration $\AA$. Brainsciences, v. 9, n. 7, p. 153, 2019. 
MAGALHÃES, Lívia de Castro. Integração Sensorial: Uma Abordagem Específica de Terapia Ocupacional. In: DRUMMOND, Adriana de França; REZENDE, Márcia Bastos. Intervenções da Terapia Ocupacional. Belo Horizonte, MG: Editora UFMG, 2008.

PELLEGRINI, A. O papel do jogo no desenvolvimento humano. Oxford, Inglaterra: Oxford University Press, 2009.

POSAR, Anio; VISCONTI, Paola. Sensory abnormalities in children with autism spectrum disorder. Jornal de Pediatria, Rio de Janeiro, v. 94, p. 342-350, 2018.

RANDELL, Elizabeth et al. Sensory integration therapy versus usual care for sensory processing difficulties in autism spectrum disorder in children: study protocol for a pragmatic randomized controlled trial. Trials, v. 20, n. 1, p. 1-11, 2019.

REILLY, M. Jogue como um aprendizado exploratório. Thousand Oaks, CA: Publicações SAGE, 1974.

REZENDE, Márcia Bastos. O Brincar e a Intervenção da Terapia Ocupacional. In: DRUMMOND, Adriana de França; REZENDE, Márcia Bastos. Intervenções da Terapia Ocupacional. Belo Horizonte, MG: Editora UFMG, 2008.

ROLEY, Susanne Smith et al. Understanding Ayres' sensory integration. OT Practice, v. 12, n. 7, 2007.

SCHAAF, R. C.; MAILLOUX, Z. Clinician's Guide for Implementing Ayres Sensory Integration: Promoting Participation for Children With Autism. United States: AOTA Press, 2015.

SEGAVA, N. B.; CAVALCANTI, A. Análise do desempenho ocupacional de crianças e adolescentes com anemia falciforme. Rev. Ter. Ocup. Univ., São Paulo, v. 22, n. 3, p. 279-288, set./dez. 2011.

SERRANO, Paula. A Integração Sensorial no desenvolvimento e aprendizagem da criança. Portugal: Papa-Letras, 2016.

SOUZA, D. et al. A importância da Terapia Ocupacional da estimulação precoce em crianças com Síndrome de Down. Revista da Faculdade União Goyazes, Trindade, v. 12, n. 1, jan./jul. 2018.

TEJADA, Sergio Serrada et al. Influence of Ideational Praxis on the Developmentof Play and Adaptive Behavior of Children whith Autism Spectrum Disorder: A Comparative Analysis. Int. J. Environ. Res. Public Health, v. 18, 2021.

WHITMAN, Thomas L. O Autismo e Suas Características. In: 0

Desenvolvimento do Autismo: social, cognitivo, linguístico, sensório-motor e suas perspectivas biológicas. São Paulo, SP: M. Books, 2015. p. 55-101. 


\title{
A ESCRITA SOB O OLHAR DA TEORIA DE INTEGRAÇÃO SENSORIAL DE AYRES
}

\author{
Alice Vicentin Nieton ${ }^{1}$ \\ Maria Socorro Aquino Silva ${ }^{1}$ \\ Neuza Soraya Teixeira Coelho Fontes ${ }^{1}$ \\ Kellen Nunes de Souza Borges ${ }^{1}$ \\ Rafael Luiz Morais da Silva ${ }^{2}$
}

\section{RESUMO}

A dificuldade em escrita tem despertado um olhar mais investigativo em relação às causas e tratamentos com evidência científica, o que tem ampliado o papel da Terapia Ocupacional em processos de avaliação e intervenção. Desta forma, a Terapia Ocupacional assume, através da Integração Sensorial, abordagem para obtenção de aquisição de pré-requisitos no âmbito sensorial para o desenvolvimento da escrita. Neste contexto, o presente trabalho tem por objetivo discutir quanto à contribuição do processamento sensorial para o desempenho ocupacional da escrita manual na infância. Metodologicamente, trata-se de uma pesquisa de revisão bibliográfica, em que foram utilizadas pesquisas sobre o tema, selecionadas nas bases de dados da DECs, SciELO, PubMed, LILACS e MEDLINE. Os resultados revelam a importância de avaliações apropriadas relativas ao desempenho da função motora fina, sensorial e perceptiva da criança e a aplicabilidade da ciência da Integração Sensorial como potencializador eficaz para promover a funcionalidade da escrita, vista como a base que alicerça o desempenho motor, perceptivo, cognitivo e social.

Palavras-chave: Terapia Ocupacional. Escrita. Integração Sensorial.

\section{INTRODUÇÃO}

A escrita manual alfabética é uma forma simbólica de comunicação humana com a finalidade de propagar informações. É uma atividade e/ou ocupação complexa, que exige não somente o desenvolvimento neuromuscular, como o bom funcionamento de componentes cognitivos, perceptivos e de linguagem, sendo um resultado do desenvolvimento neuropsicomotor que vem se aprimorando desde a concepção.

O desenvolvimento infantil consiste numa sequência progressiva de transformações que aumentam em complexidade no decorrer do crescimento,

\footnotetext{
${ }^{1}$ Terapeutas Ocupacionais.

${ }^{2}$ Graduado em Terapia Ocupacional pela Universidade do Estado do Pará. Doutorado em Ciências da Reabilitação - UNINOVE-SP (2018). Docente do Curso de Certificação Brasileira em Integração Sensorial - Integris/UEPA, Orientador do trabalho.
} 
assim, faz-se necessário que a criança enfrente as diferentes fases que integram seu desenvolvimento e preparam o caminho para a escrita.

As experiências motoras e sensoriais na primeira infância promovem a formação de conexões sinápticas e de redes neuronais que provocam o processo de desenvolvimento. É na infância que a criança desenvolve grande parte das habilidades percepto-cognitivas e motoras que the proporcionam maior eficiência na realização das atividades (SANTOS; DANTAS; OLIVEIRA, 2004).

Embora haja uma sequência de desenvolvimento esperada, o processo depende da individualidade de cada criança, de forma que experiências diversificadas aumentam a aquisição de habilidades necessárias para o desenvolvimento das etapas seguintes. Nesse contexto, as habilidades psicomotoras são fundamentais para a aprendizagem da escrita. Segundo Rosa Neto (2002), os elementos básicos da motricidade incluem: motricidade fina, motricidade global, equilíbrio, esquema corporal, organização espacial, organização temporal e lateralidade. Atentando-nos à relevância da motricidade fina, o autor ressalta a sequência de funcionamento, a qual envolve o alcance manual do objeto seguido do agarre (preensão) e manipulação, obtendo como resultado a tríade objeto-olho-mão.

A eficácia da escrita está ligada à integração das habilidades motoras às funções percepto-cognitivas, assim, podemos inferir que, quando há alguma alteração no processo de desenvolvimento neuropsicomotor, poderão ocorrer problemas no desempenho da escrita e nos padrões de preensão. Segundo Schneck e Henderson (1990), é possível classificar a preensão do lápis em três padrões de acordo com o desenvolvimento neuropsicomotor: imatura, transicional e madura, não sendo necessariamente um processo linear, dependendo das experiências individuais, consolidando-se até aproximadamente aos sete anos de idade.

O Terapeuta Ocupacional é um dos profissionais que intervém com o intuito de melhorar o desempenho da escrita, lançando mão de técnicas e atividades específicas de acordo com a individualidade de cada criança, nesse ínterim, a abordagem de Integração Sensorial de Ayres auxilia a prática deste profissional ao considerar as questões sensoriais e de práxis. O conceito de Integração Sensorial, desenvolvido por Jean Ayres, é compreendido como influenciador do comportamento e de aprendizagens complexas, sendo definido como um processo 
neurológico que favorece a organização e interpretação das informações sensoriais para que possamos responder de forma adaptativa às demandas ambientais (SERRANO, 2016).

Diante desse breve contexto, o objetivo do presente trabalho é discutir quanto à contribuição do processamento sensorial para o desempenho ocupacional da escrita manual na infância. Além desta introdução, da seção metodológica e das considerações finais, o presente trabalho está organizado da seguinte forma: iniciase discutindo o processamento sensorial no desenvolvimento da escrita seguido dos resultados e discussões.

\subsection{Processamento Sensorial no Desenvolvimento da Escrita}

A mão está envolvida em inúmeras atividades cotidianas, sendo sua completa função atingida através de estímulos aferentes e eferentes, atuando por feedback tátil e respostas musculares. Assim, podemos considerar a escrita a tarefa mais complexa da função manual (ALMEIDA, 2016).

$\mathrm{Na}$ literatura não há um consenso a respeito da estratégia mais eficaz no tratamento das dificuldades de escrita na infância, existem diversas abordagens que abrangem aprendizagem motora, estratégias perceptivo-motoras, cognitivocomportamentais e integrativas sensoriais (FEDER; ANNETTE; ANNE, 2000), sendo esta última o cerne deste trabalho.

As intervenções de Integração Sensorial parecem beneficiar nas dificuldades de planejamento motor, enfatizam os sistemas tátil e vestibular, pois acredita-se que auxiliam capacidade de focar nas tarefas (SMITH, 2002).

O processamento sensorial é inato do desenvolvimento humano e é base para desenvolvimento dos outros sistemas, ou seja, motor, cognitivo, perceptivo, afetivo e social. Nesse contexto, Ayres (1972) destaca que a Integração Sensorial seria o processo neurológico que organiza as sensações do próprio corpo e do meio ambiente e torna possível a utilização do corpo de forma eficaz no ambiente. Ainda, de acordo com a autora, quando há um comprometimento do processamento sensorial de uma criança, ele resulta em problemas sociais, emocionais, motores e/ou funcionais, e que todas as habilidades da criança, inclusive as acadêmicas, tem sua origem em uma base sensório motora.

Ayres (1972) descreveu o funcionamento neurocomportamental e a influência dos aspectos sensoriais e motores na aprendizagem. Seu intuito era detectar 
relações entre as sensações corporais, os mecanismos cerebrais e a aprendizagem, a fim de delinear uma teoria que associasse esses conhecimentos. No início da década de 1970, Ayres propôs uma abordagem terapêutica ocupacional de natureza avaliativa e interventiva, denominada Terapia de Integração Sensorial. Além da descrição do processo adaptativo, Ayres (1972) tratou dos déficits da Integração Sensorial, compreendidos como a inabilidade do sistema nervoso central em modular, discriminar, organizar e coordenar as sensações adequadamente (LANE et al., 2000).

Este modelo foi, posteriormente, aprimorado por Miller et al. (2007) que, com vistas a enfatizar o desempenho ocupacional do indivíduo, em detrimento dos mecanismos neurobiológicos, propuseram o termo Transtornos do Processamento Sensorial (TPS) (MOMO; SILVESTRE, 2011).

Essa forma de categorização, denominada "Proposta Nosológica", subdivide os TPS em três grandes grupos: os Transtornos Motores de Base Sensorial (TMBS), os Transtornos de Discriminação Sensorial (TDS) e os Transtornos de Modulação Sensorial (TMS). Os TMBS caracterizam-se pela dificuldade que o indivíduo apresenta em utilizar o corpo de forma eficiente no ambiente. São identificados dois subtipos de TMBS, o transtorno postural e a dispraxia. O primeiro caracteriza-se pela dificuldade em manter o alinhamento postural, em decorrência de tônus postural baixo e reações pobres de equilíbrio e postura. O segundo é definido por déficits em planejar e executar atos motores novos ou séries de ações motoras (AYRES, 1972; MILLER et al., 2007; CAMINHA, 2008; MAGALHÃES, 2008).

Prejuízos dessa natureza podem culminar no desempenho motor pobre, descoordenado, impactando a coordenação motora grossa e/ou fina, assim como a oral. Os TDS caracterizam-se por déficits em perceber e interpretar a qualidade de estímulos de natureza visual, tátil, auditiva, vestibular, proprioceptiva, gustativa e/ou olfativa (CAMINHA, 2008; LAMBERTUCCI, 2013; GOMES et al., 2014).

Essa condição interfere na capacidade de detectar diferenças e semelhanças entre estímulos, assim como distinguir suas qualidades temporais e espaciais. A imprecisão na discriminação tátil interfere, por exemplo, na capacidade de reconhecer objetos pelo tato, o que impossibilitaria encontrar uma moeda dentro de uma bolsa, sem o auxílio da visão. Prejuízos na discriminação visual, por sua vez, podem interferir na capacidade de diferenciar letras parecidas, como "d, b, p e q" (LANE et al., 2000; CAMINHA, 2008; MAGALHÃES, 2008). 
A dificuldade em graduar a força necessária para pegar em um lápis com o propósito de escrever é um indício de uma discriminação proprioceptiva deficitária. Por fim, os Transtornos de Modulação Sensorial dizem respeito à dificuldade do sistema nervoso central em regular, de maneira gradual e adaptada ao ambiente, a intensidade, duração e frequência da resposta aos estímulos sensoriais. Nesse grupo estão contemplados três subtipos de alterações sensoriais: a hiper-resposta, a hiporesposta e a procura sensorial (MILLER et al., 2007; CAMINHA, 2008; MAGALHÃES, 2008; MOMO; SILVESTRE, 2011).

Os indivíduos hiper-responsivos apresentam baixo limiar aos estímulos sensoriais. Assim, tendem a se orientar ou responder de forma mais intensa, automática e exagerada ao input relacionado a um ou mais sistemas sensoriais. Como resultado, podem reagir expressando comportamentos defensivos de recusa, ansiedade e nervosismo perante determinadas texturas, sabores, odores, ruídos, movimentos e estímulos visuais (BARANEK et al., 1997; MAGALHÃES, 2008; CAMINHA; LAMPREIA, 2012; OMAIRI, 2013; SCHAAF; LANE, 2014).

Em relação aos padrões de hiporesposta, verifica-se uma diminuição das respostas frente a diversos estímulos ou respostas lentificadas. Nessa situação, pode-se dizer que o limiar de resposta ao estímulo sensorial é alto fazendo com que o indivíduo pareça insensível à dor, movimentos, sons, odores, sabores ou estímulos visuais (CAMINHA; LAMPREIA, 2012).

De outro modo, ele aparenta ter uma consciência limitada da informação sensorial, falhando em exibir comportamentos exploratórios. Esses sintomas se manifestam em comportamentos apáticos, lentos, isolados, passivos e com pouco engajamento para iniciar e manter as relações sociais (MOMO; SILVESTRE, 2011).

Normalmente, as crianças que apresentam esse perfil preferem brincadeiras solitárias ou não brincam com frequência (MILLER et al., 2007). A busca sensorial é definida como a procura por estímulos intensos, com maior duração e frequência. Indivíduos com esse perfil tendem a ser excessivamente ativos em termos motores, já que estão em constante procura por estímulos fortes. Dessa maneira, tendem a se engajar em brincadeiras mais dinâmicas, envolvendo quedas, colisões, sons altos e movimentos rápidos. Em termos sociais são tipicamente rotulados de impulsivos, intrusivos ou fisicamente brutos (CAMINHA, 2008; MAGALHÃES, 2008; MOMO; SILVESTRE, 2011). 


\section{METODOLOGIA}

\subsection{Tipo de Estudo}

Trata-se de uma análise bibliográfica, ancorada na sistematização de dados secundários e públicos, seguida de exame qualitativo. Analisa-se contribuições de artigos sobre o tema da escrita manual em três principais bases de dados: SciELO, PubMed, LILACS e MEDLINE. Utilizou-se como recorte temporal a última década de publicação. Foram recortadas pesquisas que tivessem como objeto de estudo a infância, abordando aspectos sensório-motores da escrita manual.

Os dados analisados permitiram a constituição de um quadro temático com os principais elementos analisados (Referência, Objetivo, Público alvo/participantes, Protocolos Utilizados, Tipo de Estudo e Principais Resultados). Os principais autores encontrados e que serviram para a base desta pesquisa foram: Álvares et al. (2021); Nascimento; Bitencourt; Fleig (2021); Fernandes (2020); Ardengue et al. (2019); Iwamizu; Dantas (2018); Beltrame et al. (2017); Coppede; Okuda; Capellini (2012); Souza; Cardoso, et al. (2020); Teixeira (2009); Nascimento; Bitencourt; Rodrigues (2011); Magalhães; Nascimento; Rezende (2004).

\subsection{Seleções dos Estudos}

\subsubsection{Critérios de inclusão}

Em princípio, foi realizada a pesquisa de descritores na plataforma DECs, sendo identificados os descritores que mais se adequavam ao estudo do presente artigo. Foram selecionados os seguintes descritores que foram pesquisados de forma conjugada: "escrita manual Terapia Ocupacional", "escrita manual desenvolvimento infantil" e "transtorno das habilidades motoras". Buscamos pelo termo "Integração Sensorial", no entanto, observamos que este não é considerado um descritor na plataforma DeCs, sendo encontrado como descritor apenas na língua inglesa.

Foram selecionados estudos na língua portuguesa, publicados nos últimos dez anos nas plataformas indexadas SciELO, PubMed, LILACS e MEDLINE, sendo pesquisas correlatas com a infância, abordando aspectos sensório-motores da escrita manual, sendo organizados por ordem cronológica. 


\subsubsection{Critérios de exclusão}

Foram excluídos artigos que não estivessem na língua portuguesa, com publicação que excedem dez anos e com temática não correlata com a infância ou com os aspectos sensório-motores da escrita.

\section{RESULTADOS}

Identificamos que entre os 11 estudos analisados, quatro deles reforçam a importância de avaliações apropriadas relativas aos pré-requisitos necessários ao desempenho da escrita. Os outros sete trabalhos encontrados buscam compreender como algumas questões relacionadas à escrita podem influenciar no seu desempenho, sendo feita uma associação entre aspectos motores amplos, cognitivos, perceptivos e sensoriais. Dentre eles, dois estudos foram direcionados ao Transtorno do Espectro Autista (TEA), os quais averiguaram fatores como lateralidade, destreza manual, interação social, percepções sensoriais e desordens motoras.

Os estudos analisados reforçam a importância de avaliações apropriadas relativas ao desempenho da função motora fina, sensorial e perceptiva da criança, a fim de obter um diagnóstico e tratamento precoce, prevenindo desordens no âmbito da competência da escrita. 
Quadro 1 - Síntese dos trabalhos encontrados.

\begin{tabular}{|c|c|c|c|c|c|}
\hline Referência & Objetivo & $\begin{array}{l}\text { Público alvo/ } \\
\text { participantes }\end{array}$ & $\begin{array}{l}\text { Protocolos } \\
\text { Utilizados }\end{array}$ & Tipo de Estudo & $\begin{array}{l}\text { Principais } \\
\text { Resultados }\end{array}$ \\
\hline
\end{tabular}




\begin{tabular}{|c|c|c|c|c|c|}
\hline & & & $\begin{array}{l}\text { Integration Tests - } \\
\text { SCSIT / Teste de } \\
\text { Gubbay de } \\
\text { Proficiência Motora } \\
\text { / The Purdue } \\
\text { Perceptual-Motor } \\
\text { Survey / Visual } \\
\text { Motor Integration } \\
\text { Test - VMl. }\end{array}$ & & \\
\hline Rodrigues (2011) & $\begin{array}{c}\text { Investigar as } \\
\text { propriedades } \\
\text { psicométricas e a } \\
\text { utilidade clínica do } \\
\text { instrumento } \\
\text { ACOORDEM para } \\
\text { detecção do TDC. }\end{array}$ & $\begin{array}{c}181 \text { crianças de } 7 \text { e } 8 \\
\text { anos. }\end{array}$ & $\begin{array}{l}\text { Developmental } \\
\text { Coordination. } \\
\text { Disorder } \\
\text { Questionnaire } \\
\text { (DCDQ-Brasil) / } \\
\text { teste de Raven / } \\
\text { ACOORDEM/ } \\
\text { Movement } \\
\text { Assessment }\end{array}$ & Estudo de caso. & $\begin{array}{c}\text { Os resultados } \\
\text { apontam o bom } \\
\text { potencial da } \\
\text { ACOORDEM para } \\
\text { detectar o TDC e } \\
\text { caracterizar o } \\
\text { desempenho motor } \\
\text { em crianças de } 7 \text { e } \\
8 .\end{array}$ \\
\hline
\end{tabular}




\begin{tabular}{|c|c|c|c|c|c|}
\hline & & & $\begin{array}{c}\text { Battery for Children } \\
\text { (MABC-II). }\end{array}$ & & \\
\hline $\begin{array}{l}\text { Coppede; Okuda; } \\
\text { Capellini (2012) }\end{array}$ & $\begin{array}{c}\text { Caracterizar e } \\
\text { comparar o } \\
\text { desempenho da } \\
\text { função motora fina, } \\
\text { sensorial e } \\
\text { perceptiva e a } \\
\text { qualidade da } \\
\text { escrita entre } \\
\text { escolares com } \\
\text { dificuldades de } \\
\text { aprendizagem e } \\
\text { escolares com bom } \\
\text { desempenho } \\
\text { acadêmico. }\end{array}$ & $\begin{array}{c}192 \text { crianças de na } \\
\text { faixa etária de } 7 \text { a } 11 \\
\text { anos, de ambos os } \\
\text { gêneros, da } 1^{\circ} \text { a } 4^{\circ} \\
\text { série de escolas } \\
\text { públicas municipais. }\end{array}$ & $\begin{array}{l}\text { Teste de Mann- } \\
\text { Whitney / Escala } \\
\text { de Disgrafia. }\end{array}$ & $\begin{array}{l}\text { Pesquisa com } \\
\text { amostragem. }\end{array}$ & $\begin{array}{c}\text { Os resultados } \\
\text { apresentados neste } \\
\text { estudo sugerem } \\
\text { que } \\
\text { aspectos } \\
\text { qualitativos das } \\
\text { habilidades } \\
\text { motoras finas, } \\
\text { sensoriais e } \\
\text { perceptivas } \\
\text { refletem a } \\
\text { integridade } \\
\text { e a maturidade do } \\
\text { sistema nervoso } \\
\text { central e podem, } \\
\text { provavelmente, } \\
\text { exercer um } \\
\text { importante papel } \\
\text { no diagnóstico } \\
\text { precoce de } \\
\text { desordens do } \\
\text { desenvolvimento e } \\
\text { consequentemente } \\
\text { prevenir desordens } \\
\text { acadêmicas como } \\
\text { o desempenho na } \\
\text { escrita, por } \\
\text { exemplo. }\end{array}$ \\
\hline $\begin{array}{l}\text { Beltrame et al. } \\
(2017)\end{array}$ & $\begin{array}{lr}\text { Investigar } & \text { a } \\
\text { prevalência } & \text { do }\end{array}$ & $\begin{array}{l}787 \text { crianças entre } 7 \text { a } \\
10 \text { anos. }\end{array}$ & $\begin{array}{l}\text { Movemente } \\
\text { Assessmente }\end{array}$ & $\begin{array}{l}\text { Análise de dados } \\
\text { secundários. }\end{array}$ & $\begin{array}{l}\text { A prevalência do } \\
\text { TDC, bem como a }\end{array}$ \\
\hline
\end{tabular}




\begin{tabular}{|c|c|c|c|c|c|}
\hline & TDC. & & $\begin{array}{l}\text { Battery for Children } \\
\text { Second } \quad \text { Edition } \\
\text { (MABC-2). }\end{array}$ & & $\begin{array}{lr}\text { diferença } & \text { entre } \\
\text { sexos } & \text { foi } \\
\text { considerada } & \\
\text { semelhante } & \text { às } \\
\text { evidencias } & \\
\text { internacionais. } & \\
\end{array}$ \\
\hline $\begin{array}{c}\text { Iwamizu; Dantas } \\
(2018)\end{array}$ & $\begin{array}{c}\text { Tradução e } \\
\text { adaptação } \\
\text { transcultural do } \\
\text { Eaarly Years } \\
\text { Movement Skills } \\
\text { Checklist. }\end{array}$ & $\begin{array}{l}38 \text { professores de } 4 \\
\text { escolas municipais. }\end{array}$ & $\begin{array}{l}\text { Tradução e } \\
\text { adaptação } \\
\text { transcultural do } \\
\text { Eaarly Years } \\
\text { Movement Skills } \\
\text { Checklist. }\end{array}$ & $\begin{array}{l}\text { Tradução e } \\
\text { adaptação. }\end{array}$ & $\begin{array}{l}\text { Produção da lista } \\
\text { de checagem das } \\
\text { habilidades } \\
\text { motoras na } \\
\text { primeira infância. }\end{array}$ \\
\hline $\begin{array}{l}\text { Ardengue et al. } \\
\qquad(2019)\end{array}$ & $\begin{array}{c}\text { Analisar se a } \\
\text { competência } \\
\text { motora e a } \\
\text { qualidade da } \\
\text { escrita podem ser } \\
\text { diferentes entre } \\
\text { crianças de ambos } \\
\text { os sexos, com } \\
\text { diferentes níveis de } \\
\text { força e que se } \\
\text { encontram no } \\
\text { processo de } \\
\text { aprendizagem da } \\
\text { escrita. }\end{array}$ & $\begin{array}{c}61 \text { crianças entre } 5 \text { a } \\
7 \text { anos. }\end{array}$ & $\begin{array}{l}\text { Bruininks- } \\
\text { Oseretsky Test of } \\
\text { Motor Proficiency } \\
\text { Second Edition } \\
\text { (BOT-2). }\end{array}$ & $\begin{array}{l}\text { Pesquisa com } \\
\text { amostragem. }\end{array}$ & $\begin{array}{c}\text { Os resultados } \\
\text { sugerem que em } \\
\text { crianças em } \\
\text { aprendizagem da } \\
\text { escrita a Força de } \\
\text { Preensão Manual } \\
\text { (FPM) parece } \\
\text { impactar a } \\
\text { Competência } \\
\text { Motora (CM), } \\
\text { favorecendo os } \\
\text { meninos com alta } \\
\text { força, porém a } \\
\text { Qualidade da } \\
\text { Escrita (QE) parece } \\
\text { não ser } \\
\text { influenciada pela } \\
\text { força, } \\
\text { independente do } \\
\text { sexo. }\end{array}$ \\
\hline
\end{tabular}




\begin{tabular}{|c|c|c|c|c|c|}
\hline $\begin{array}{l}\text { Cardoso et al. } \\
\quad(2020)\end{array}$ & $\begin{array}{c}\text { Examinar as } \\
\text { habilidades de } \\
\text { integração } \\
\text { visomotora e } \\
\text { destreza manual. }\end{array}$ & 22 crianças com TDC. & $\begin{array}{l}\text { Developmental } \\
\text { Coordination } \\
\text { Disorder } \\
\text { Questionaires } \\
\text { (DCDQ- Brasil) / } \\
\text { Movemente } \\
\text { Assessmente } \\
\text { Battery for Children } \\
\text { Second Edition ( } \\
\text { MABC-2)/ Test of } \\
\text { Visuak- Motor } \\
\text { Integration (VMI). }\end{array}$ & $\begin{array}{l}\text { Ensaio clínico } \\
\text { randomizado. }\end{array}$ & $\begin{array}{l}\text { É necessário o uso } \\
\text { combinado de } \\
\text { testes para } \\
\text { avaliação de } \\
\text { crianças com TDC, } \\
\text { a fim de detectar } \\
\text { suas possíveis } \\
\text { dificuldades na } \\
\text { integração } \\
\text { visomotora e } \\
\text { destreza manual e } \\
\text { suas implicações } \\
\text { no desempenho de } \\
\text { tarefas funcionais. }\end{array}$ \\
\hline Fernandes (2020) & $\begin{array}{c}\text { Analisar a } \\
\text { lateralidade e a } \\
\text { destreza manual } \\
\text { em crianças com } \\
\text { TEA. }\end{array}$ & 8 crianças. & $\begin{array}{c}\text { Instrumento 9-HPT, } \\
\text { que avalia a } \\
\text { destreza manual / } \\
\text { Inventário da } \\
\text { dominância lateral } \\
\text { de Edimburgo. }\end{array}$ & $\begin{array}{l}\text { Pesquisa com } \\
\text { amostragem. }\end{array}$ & $\begin{array}{l}\text { Os participantes } \\
\text { parecem } \\
\text { apresentar } \\
\text { lateralidade destra } \\
\text { e, também, melhor } \\
\text { desempenho com a } \\
\text { mão preferida em } \\
\text { uma tarefa de } \\
\text { destreza manual. }\end{array}$ \\
\hline $\begin{array}{c}\text { Àlvares et al. } \\
(2021)\end{array}$ & $\begin{array}{c}\text { Verificar se a } \\
\text { função cognitiva } \\
\text { está associada e } \\
\text { pode predizer } \\
\text { desfechos do } \\
\text { desenvolvimento } \\
\text { motor grosso em } \\
\text { crianças. }\end{array}$ & $\begin{array}{l}24 \text { crianças com } \\
\text { transtorno do } \\
\text { neurodesenvolvimento } \\
\text { entre } 5 \text { a } 10 \text { anos. }\end{array}$ & $\begin{array}{c}\text { Mini exame do } \\
\text { estado mental e o } \\
\text { teste de } \\
\text { desenvolvimento } \\
\text { Motor Grosso- } \\
\text { segunda edição } \\
\text { (TGMD-2). }\end{array}$ & $\begin{array}{l}\text { Estudo transversal } \\
\text { exploratório. }\end{array}$ & $\begin{array}{l}\text { Forte associação } \\
\text { entre a função } \\
\text { cognitiva e o } \\
\text { desenvolvimento } \\
\text { motor grosso de } \\
\text { crianças com TND. }\end{array}$ \\
\hline Nascimento; & Identificar os & Pessoas com TEA. & . & Revisão literária. & A inter-relação \\
\hline
\end{tabular}




\begin{tabular}{|c|c|c|c|}
\hline $\begin{array}{c}\text { Bitencourt Fleig } \\
(2021)\end{array}$ & fatores que & & entre social, \\
& dificultam as & & aprendizagem \\
intervenções & motora e & percepções \\
& terapêuticas & & sensoriais são mais \\
& motoras em & & significativas para o \\
& crianças com & & bom desfecho das \\
& transtorno do & intervenções & terapêuticas em \\
& espectro autista. & & crianças com TEA. \\
\hline
\end{tabular}




\section{DISCUSSÃO}

Muito temos visto da dificuldade no desempenho da escrita em crianças com atraso no desenvolvimento, tais como: questões percepto-visuais, noção espacial, preensão do lápis (manutenção e ajuste), ajuste postural, estabilidade proximal, estabilização ocular para cópia, estabilização do papel com a mão não dominante, tônus, força e resistência. Tais dificuldades não são características específicas das crianças com desenvolvimento atípico, mas podem surgir no decorrer da vida acadêmica.

Atualmente, é recorrente a questão a respeito das mudanças na forma e espaço do brincar, devido à disseminação da violência, ao uso da tecnologia, ao cenário epidemiológico da COVID-19, entre outros. Sendo assim, a construção da escrita sofre danos devido à privação de estímulos sensórios motores necessários ao corpo do indivíduo que escreve.

A proficiência da escrita envolve a maturação neurológica e integração dos sistemas sensoriais, motor e cognitivo. A escrita, sendo uma atividade complexa, refinada e própria do ser humano, requer pré-requisitos em cada um dos sistemas. Willians e Shellembergeer (1996) sugerem uma pirâmide que nos ajuda a compreender como o processamento das informações dos sistemas sensoriais precede as habilidades motoras, perceptivas e cognitivas, construindo um alicerce do aprendizado e comportamento. Dessa forma, tendo como base o sistema sensorial e como exigência máxima de aprendizado das funções acadêmicas (escrita), observa-se a importância de se ter um sistema sensorial em perfeito funcionamento, desde a recepção dos estímulos até uma resposta adaptativa esperada.

Dessa forma, podemos refletir a respeito do conceito de práxis. Segundo Ayres (1989, p. 27):

É a habilidade pela qual descobrimos como usar nossas mãos e nosso corpo em tarefas especializadas, como brincar com brinquedos; usando ferramentas, incluindo um lápis ou garfo; construir uma estrutura, seja uma torre de bloco de brinquedo ou uma casa; arrumar uma sala; ou se engajar em muitas ocupações [...]

[...] para seu desenvolvimento são necessárias habilidades do processamento sensorial, habilidades motoras básicas e de cognição.

Durante o desenvolvimento de sua teoria, Ayres descreveu a relação entre Integração Sensorial e práxis, sendo esta uma organização fundamental que 
envolve ideação, planejamento motor e execução de novas tarefas motoras. A praxia exige interação com o mundo e não depende apenas da maturação do sistema nervoso central. São necessárias experiências sensório-motoras para que uma criança atinja todo o seu potencial de aprendizagem. A dispraxia pode estar associada ao Transtorno do Processamento Sensorial, pois o sistema nervoso precisa de informações sensoriais eficientes para formular planos de ação. Se a informação não é percebida ou processada com eficiência é difícil agir sobre ela (MAILLOUX; BURKE, 2002.) A dificuldade do desempenho da escrita pode ser impactada pela disfunção do processamento sensorial, e, assim, um indicador de dispraxia.

\section{CONSIDERAÇÕES FINAIS}

Podemos concluir que a ciência da Integração Sensorial é potencialmente eficaz para promover a funcionalidade da escrita, pois é a base que alicerça o desempenho motor, perceptivo, cognitivo e social, contribuindo para o desempenho da escrita, por meio do uso de estímulos táteis, proprioceptivos, vestibulares, integração viso-motora, entre outros, em crianças que apresentam prejuízo na escrita. É primordial uma avaliação abrangente a fim de identificar as hipóteses que impactam no desempenho ocupacional da escrita de cada indivíduo.

Durante a pesquisa, a principal limitação encontrada refere-se ao fato do termo "Integração Sensorial" não ser um descritor na plataforma DECs, dificultando a seleção de artigos mais específicos a respeito da temática proposta, definidos nos critérios de inclusão e exclusão.

Considera-se necessário o desenvolvimento de estudos mais aprofundados, investigando o desempenho da escrita com base sensório-motora, visto que a maioria dos artigos encontrados entraram nos critérios de exclusão, pois eram relativos a discussões não correlatas com o tema pesquisado, bem como os trabalhos encontrados não consideram de forma explícita o processamento sensorial.

\section{REFERÊNCIAS BIBLIOGRÁFICAS}

ALMEIDA R. Análise das Estratégias de Escrita de Crianças Pré-Escolares em Português do Brasil. Psicol. Esc. Educ., v. 20, n. 3, p. 591-600, 2016. 
ÁLVARES, I. M. et al. Association between cognitive function and gross motor development in children with neurodevelopmental disorders. J. Physiother. Res., Salvador, v. 11, n. 2, p. 393-400, maio 2021. doi: http://dx.doi.org/10.17267/22382704rpf.v11i2.3779.

ARDENGUE, A. et al. Relação da força de preensão manual, a competência motora e a qualidade da escrita de crianças em processo de aprendizagem de escrita. J. Phys. Educ., v. 30, 2019. doi: https://doi.org/10.4025/jphyseduc.v30i1.3070.

AYRES, A. J. Sensory integration and learning disorders. Los Angeles: Western Psychological Services, 1972.

AYRES, A. J. Sensory Integration and the Child. Los Angeles: Western Psychological Services, 1979.

AYRES, A. J. Sensory Integration and Praxis Tests: SIPT manual. Los Angeles: Western Psychological Services, 1989.

BARANEK, G. T.; FOSTER, L. G.; BERKSON, G. Tactile defensiveness and stereotyped behaviors. Am J Occup Ther, v. 51, n. 2, 1997.

BELTRAME, T. S. et al. Prevalência do Transtorno do Desenvolvimento da Coordenação em uma amostra de crianças brasileiras. Cad. Ter. Ocup. UFSCar, São Carlos, v. 25, n. 1, p. 105-113, 2017. doi: http://dx.doi.org/10.4322/01044931.ctoAO0777.

CAMINHA, R. C. Autismo: um transtorno de natureza sensorial? 71 f. Dissertação (Mestrado em Psicologia) - Pontifícia Universidade Católica do Rio de Janeiro, Rio de Janeiro, RJ, 2008.

CAMINHA, R.; LAMPREIA, C. Findings on sensory deficits in autism: Implications for understanding the disorder. Psychology \& Neuroscience, v. 5, n. 2, p. 231-237, 2012.

CARDOSO, Ana Amélia et al. Relação entre integração visomotora e destreza manual em crianças com transtorno do desenvolvimento da coordenação. Cadernos Brasileiros de Terapia Ocupacional, v. 28, n. 3, p. 890-899, 2020.

COPPEDE, A. C.; OKUDA, P. M. M.; CAPELLINI, S. M. Desempenho de escolares com dificuldades de aprendizagem em função motora fina e escrita. Journal of Human Growth and Development, v. 22, n. 3, p. 297-306, 2012. doi:

https://doi.org/10.7322/jhgd.46379.

FEDER, Katya, ANNETTE, Majnemer; ANNE, Synnes. Handwriting: Current trends in occupational therapy practice. Canadian Journal of Occupational Therapy, v. 67, n. 2, p. 197-204, 2000.

FERNANDES, L. A. et al. Análise da Lateralidade e Destreza Manual em Crianças com Transtorno do Espectro Autista. Rev. bras. educ. espec., v. 26, n. 4, out./dez. 2020. doi: https://doi.org/10.1590/1980-54702020v26e0084. 
FONSECA, V. Integração Sensorial e aprendizagem: uma introdução à obra de Ayres. In: FONSECA, $V$ (Org). Desenvolvimento psicomotor e aprendizagem. Porto Alegre: Artmed, 2008. p. 325-365.

GOMES, E. et al., M. B. Hipersensibilidade auditiva no transtorno do espectro autístico. Pró-Fono R. Atual. Cient., v. 20, n. 4, p. 279-284, 2014.

HONG, S.-Y.; JUNG, N.-H.; KYEONG, M. K. The correlation between proprioception and handwriting legibility in children. J. Phys. Ther. Sci., v. 28, p. 2849-2851, 2016.

IWAMIZU, J.; DANTAS, L. E. Tradução e adaptação transcultural de um instrumento para identificação do perfil motor de crianças entre 3 e 5 anos. J. Phys. Educ., v. 29, p. e2921, 2018. doi: https://doi.org/10.4025/jphyseduc.v29i1.2921.

LAMBERTUCCI, M. Terapia Ocupacional nos transtornos do espectro autista de alto funcionamento. In: CAMARGOS JÚNIOR, W. (Org.). Síndrome de Asperger e outros transtornos do espectro do Autismo de alto funcionamento: da avaliação ao tratamento. Belo Horizonte: Arte Sã, 2013. p. 329-348.

LANE, S. J. et al.Towards a consensus in terminology in sensory integration theory and practice: part 2: sensory integration: patterns of function and dysfunction.

Sensory Integration Special Interest Section Quarterly, v. 23, n. 2, p. 1-3, 2000.

MAGALHÃES, C. L.; NASCIMENTO, V. C. S.; REZENDE, M. B. Avaliação da coordenação e destreza motora - ACOORDEM: etapas de criação de perspectivas de validação. Rev. Ter. Ocup. Univ., São Paulo, v. 15, n. 1, p. 17-25, jan./abr. 2004. doi: https://doi.org/10.11606/issn.2238-6149.v15i1p17-25.

MAGALHÃES, L. C. Integração Sensorial: uma abordagem específica da Terapia Ocupacional. In: DRUMMOND, A. F.; REZENDE, M. B. (Orgs.) Intervenções da Terapia Ocupacional. Belo Horizonte: UFMG, 2008. p. 44-69.

MAILLOUX, Z.; BURKE, J. P. (2002). A recreação e a abrangência da Integração Sensorial. In: BURKE, Janice P.; MAILLOUX, Zoe in FAZIO, Linda S; PARHAM, L. Diane. A recreação na Terapia Ocupacional pediátrica. São Paulo: Santos, 2002. p. $112-125$.

MILLER, L. J. Sensational Kids: Hope and Help for Children with Sensory Processing Disorder (SPD). New York G. P.: Putnam's Sons, 2006.

MILLER, L. et al. Concept evolution in sensory integration: a proposed nosology for diagnosis. American Journal Occupational Therapy, v. 61, p. 135-140, 2007.

MOMO, A.; SILVESTRE, C. Integração Sensorial nos transtornos do espectro do Autismo. In: SCHWARTZMAN, J.; ARAÚJO, C. A. (Orgs.) Transtornos do espectro do Autismo. São Paulo: Memnon, 2011. p. 297-313.

NASCIMENTO, I. B.; BITENCOURT, C. R.; FLEIG, R. Estratégias para o Transtorno do Espectro Autista: interação social e intervenções terapêuticas. J. bras. 
psiquiatr., v. 70, n. 2, abr./jun. 2021. doi: https://doi.org/10.1590/00472085000000326.

ROSA NETO, Francisco. Manual de avaliação motora. Porto Alegre: Artmed, 2002. $136 \mathrm{p}$.

OMAIRI, C. Integração Sensorial e o Transtorno do Espectro Autista. In: OMARIRI, C. Autismo: perspectivas no dia a dia. Curitiba: Ithala, 2013. p. 139-152.

RODRIGUES, A. A. Validade da Avaliação da Coordenação e Destreza Motora ACOORDEM para Crianças de 7 e 8 anos de Idade. Belo Horizonte: Escola de Educação Física, Fisioterapia e Terapia Ocupacional da UFMG, 2011. 194 p.

SANTOS, S.; DANTAS, L.; OLIVEIRA, J. A. Desenvolvimento motor de crianças, de idosos e de pessoas com transtorno na coordenação. Revista Paulista de Educação Física, São Paulo, v. 18, n. esp., p. 33-44, 2004.

SCHAAF, R.; LANE, A. E. Toward a best-practice for assessment of sensory feature in ASD. J Autism Dev Disord, v. 45, n. 5, p. 1380-1395, 2014.

SCHNECK, C. M.; HENDERSON, A. Descriptive analysis of the developmental progression of grip position for pencil and crayon control in nondysfunctional children. Am J Occup Ther, v. 44, n. 10, p. 893-900, 1990.

SERRANA, Paula. A Integração Sensorial no Desenvolvimento da Aprendizagem da criança. Portugal: Papa Letras, 2016.

SMITH, J. Effectiveness of School-Based Occupational Therapy Intervention on Handwriting. The American Journal of Occupational Therapy, v. 56, p. 17-25, jan./fev. 2002. doi: https://doi.org/10.5014/ajot.56.1.17.

SOUZA, R.; TEIXEIRA, L. A. Sobre a Relação entre Filogenia e Ontogenia no Desenvolvimento da Lateralidade na Infância. Psicol. Reflex. Crit., v. 24, n. 1, 2011. doi: https://doi.org/10.1590/S0102-79722011000100008.

TAYLOR, K. M.; TROTT, M. A. How Does Your Engine Run?"® A leader's guide to the Alert Program ${ }^{\circledR}$ for self-regulation. Albuquerque, NM: Therapy Works, Inc., 1996. 


\title{
REFLEXÕES SOBRE AS POSSÍVEIS PRIVAÇÕES SENSORIAIS CAUSADAS PELA PANDEMIA DO COVID-19 E SUAS REPERCUSSÕES PARA O DESENVOLVIMENTO INFANTIL
}

\author{
Maria Carolina Ferreira Neves ${ }^{1}$ \\ Maria de Fátima Góes da Costa ${ }^{1}$ \\ Ana Irene Alves de Oliveira ${ }^{2}$
}

\section{RESUMO}

O desenvolvimento infantil é considerado um processo que é influenciado por múltiplos fatores, dentre eles, destaca-se: o desenvolvimento e funcionamento adequado dos sistemas sensoriais (visual, auditivo, olfativo, vestibular, tátil e proprioceptivo) e as condições ambientais. Com a pandemia de COVID-19, medidas restritivas de isolamento e distanciamento social tiveram que ser adotadas, causando várias mudanças nos contextos ambientais, com privação do uso de espaços, como: escolas, parques, praças e outros espaços de convivência. Assumese que privações ambientais levam a privações sensoriais, que tem repercussões para o desenvolvimento infantil. $O$ objetivo desta pesquisa foi o de identificar as possíveis privações sensoriais ocasionadas pela pandemia de COVID-19 e relacionar suas implicações para o desenvolvimento infantil. Trata-se de uma pesquisa bibliográfica do tipo revisão narrativa, com caráter descritivo e exploratório e abordagem qualitativa. Para a abordagem do tema é apresentado o desenvolvimento infantil, com foco no desenvolvimento dos sistemas sensoriais, descritos por Jean Ayres e discutida a relação entre as mudanças causadas pela pandemia e suas repercussões para o desenvolvimento. De acordo com os achados da pesquisa, foi possível identificar mudanças causadas pela pandemia, com comprometimento de sistemas sensoriais e inferir possíveis repercussões para o desenvolvimento infantil, que poderão impactar diferentes aspectos, entre eles: linguagem, socialização, aprendizagem, práxis e afeto, que poderão ter influência negativa sobre a funcionalidade da criança, o desempenho de Atividades de Vida Diária e em ocupações, como: o brincar, o descanso e o sono. Sugere-se a elaboração de pesquisas futuras, como estudos empíricos para investigação em curto, médio e longo prazo de tais repercussões.

Palavras-chave: Desenvolvimento Infantil. Privação Sensorial. COVID-19.

\section{INTRODUÇÃO}

O desenvolvimento infantil se caracteriza por um processo de mudança que visa tornar a criança o mais independente possível. Este processo depende do desenvolvimento e funcionamento adequado dos sistemas sensoriais (visual, auditivo, olfativo, vestibular, tátil e proprioceptivo) e pode ser influenciado por

\footnotetext{
${ }^{1}$ Terapeutas Ocupacionais.

${ }^{2}$ Terapeuta Ocupacional, Bacharel em Psicologia, Doutorado em Teoria e Pesquisa do Comportamento. Docente Titular da Universidade do Estado do Pará.
} 
diferentes fatores, dentre eles, os ambientais, que podem trazer consequências negativas, devido a privações ambientais e privações sensoriais (BOLTON; HATTIE, 2017; MACHADO et al., 2017; BRITTO et al., 2020).

Desde o final do ano de 2019 o mundo vem enfrentando uma pandemia, provocada pelo novo coronavírus, do inglês, Severe Acute Respiratory Syndrome Coronavirus 2 (SARS-COV-2, Síndrome Respiratória Aguda Grave 2), que leva a Coronavirus Disease 2019 (COVID-19), detectada pela primeira vez na China, em 2019 (OPAS, [s.d.]). Sem tratamento farmacológico comprovadamente eficaz e com a inexistência de vacinas, adotou-se como estratégia para controlar a disseminação do vírus o distanciamento e isolamento social, com diminuição do contato físico e mobilidade das pessoas. Liang (2020) já afirmava que o distanciamento social poderia trazer impactos negativos aos diferentes contextos de desenvolvimento, afetando desde as relações econômicas até os contextos mais imediatos do desenvolvimento, ambiente familiar, comunidades, cidades, estados e países.

As pesquisas sobre os impactos das medidas de distanciamento social, bem como outras consequências ocasionadas pela COVID-19, têm sido realizadas de acordo com a evolução da pandemia. Linhares e Enumo (2020) afirmam que o arcabouço de conhecimento sobre os aspectos psicológicos, considerando o contexto pandêmico, precisa ser construído. Revisões de literatura têm contribuído para a compreensão de diferentes aspectos, visto que o conhecimento empírico ainda é inexistente.

Linhares e Enumo (2020) reiteram que acerca desta temática é fundamental compreender os diferentes aspectos do contexto pandêmico, seja análise de dados epidemiológicos e da evolução da COVID-19, seja estudos de impactos psicológicos na área de saúde mental. Dessa forma, enfatiza-se a relevância deste artigo, que tem como objetivo identificar as possíveis privações sensoriais ocasionadas pela pandemia de COVID-19 e relacionar suas implicações para o desenvolvimento infantil.

\section{METODOLOGIA}

O presente trabalho trata-se de uma pesquisa bibliográfica do tipo revisão narrativa, descritiva e exploratória, com abordagem qualitativa. Segundo Lakatus e Marconi (2003), a pesquisa bibliográfica possibilita o acesso a conteúdos e levantamento de referências sobre determinado assunto. Souza e Nunes (2019) referem que a revisão narrativa permite descrever e discutir o assunto estudado, 
sem a necessidade de aplicação de critérios explícitos e sistemáticos de busca e análise, permitindo que a seleção dos estudos e as interpretações das informações estejam sujeitas à subjetividade dos autores.

O caráter descritivo-exploratório, de acordo com Pereira et al. (2018), referese à pesquisa que apresenta a natureza do levantamento bibliográfico, permitindo análise e descrição do assunto estudado. Para este trabalho foi realizada busca bibliográfica em plataformas de pesquisas científicas, como: Google Acadêmico, Portal de Periódicos da Capes, periódicos de revistas científicas, repositórios de instituições de ensino superior e no Banco de Dados da Certificação Brasileira em Integração Sensorial. Sendo utilizados, de forma isolada e combinada, os seguintes termos de busca: "Desenvolvimento infantil", "Privação sensorial", "Integração Sensorial" e "COVID-19".

Além disso, foram utilizados livros da área, que abordavam temáticas como o desenvolvimento infantil, principalmente em relação aos sistemas sensoriais, que serviram de base para a discussão de alguns construtos importantes para a compreensão do tema. E outros estudos que constavam nas listas de referências de alguns artigos selecionados das plataformas científicas, que se mostraram relevantes para este trabalho.

\section{RESULTADOS E DISCUSSÃo}

\subsection{Desenvolvimento infantil e privações sensoriais}

O Sistema Nervoso Central (SNC) da espécie humana possui organização morfológica e funcional, ocorrendo o seu desenvolvimento e especialização desde a embriogênese até após o nascimento. O bom desenvolvimento do SNC é essencial para que as informações dos diversos sistemas sensoriais, tais como: visão, audição, olfato, paladar, tato, vestibular, propriocepção e interocepção, sejam interpretadas, de modo adequado, e gerem respostas adaptativas (RESTREPO; BECERRA-HERNÁNDEZ, 2020).

A maturação do SNC, bem como os inputs sensoriais e ambientais, proporciona um bom desenvolvimento neuropsicomotor e a adaptação em sociedade, a partir da percepção sensorial, controle autônomo ou vegetativo dos órgãos, emoções e controle de processos cognitivo superiores, como: atenção, pensamento, linguagem, raciocínio, memória, aprendizagem e funções executivas. A junção dos processamentos cognitivos superiores com os sistemas sensoriais, dos 
mais primitivos aos mais complexos, dão origem ao processamento sensorial (RESTREPO; BECERRA-HERNÁNDEZ, 2020; TOMASI et al., 2018).

O processamento sensorial é parte importante no desenvolvimento infantil e desempenho das atividades cotidianas. Quando está em sua atividade típica promove oportunidades de aprendizado. Este processamento envolve o registro e modulação das informações sensoriais, a organização interna proporciona comportamentos adaptativos que são importantes para o desempenho das tarefas rotineiras (LITTLE et al., 2017; PAVÃO; ROCHA, 2017).

Jean Ayres, Terapeuta Ocupacional e neurocientista, foi precursora na descrição do funcionamento neurocomportamental e a influência dos aspectos perceptivos e motores na aprendizagem. Ancorada nos pressupostos da neurobiologia, epistemologia genética de Piaget e em abordagens neurodesenvolvimentistas de reabilitação motora, desenvolveu um modelo teórico de processamento neurológico que denominou como Integração Sensorial (IS) (SOUZA; NUNES, 2019).

$\mathrm{Na}$ teoria de IS de Ayres os sistemas sensoriais apresentam papel de extrema importância. O sistema tátil é apresentado como o sistema primário de contato com o mundo externo. Este sistema apresenta duas funções básicas: a função de defesa e de descriminação, ou seja, atua na identificação das características do objeto; no planejamento de movimentos finos com as mãos; na aprendizagem acadêmica; segurança emocional e habilidades sociais. Este é o primeiro sistema a funcionar ainda no útero materno, além de apresentar receptores amplamente distribuídos no corpo humano (BUNDY; LANE, 2019; ABIS, 2021).

O sistema proprioceptivo fornece informação do nosso corpo em relação ao espaço, tendo os seus receptores localizados no músculo, ligamentos, articulações e tendões, os quais dão informação acerca da necessidade de força e pressão que utilizamos durante a realização das tarefas cotidianas. Portanto, possibilita compreender a posição do nosso corpo e controlar e planejar o movimento (BUNDY; LANE, 2019; ABIS, 2021).

O sistema vestibular apresenta componentes dos sistemas periféricos e centrais, fornece informação ao SNC acerca da posição que a cabeça se move e a posição do corpo em relação à gravidade terrestre. Considerando uma perspectiva funcional, demonstra estreita interação com o sistema proprioceptivo, influenciando o esquema corporal, a noção espacial e a coordenação olho-mão (BUNDY; LANE, 2019; ABIS, 2021). 
Responsável por receber os sons, o sistema auditivo tem os seus componentes do SNC localizado no ouvido interno, onde as informações recebidas do ambiente começam a ser processadas. O bom desenvolvimento deste sistema é extremamente importante para discriminar diferentes sons, prestar atenção na fala, interpretar palavras e definir quais sons estão em primeiro plano e quais são ruídos de fundo no ambiente (BUNDY; LANE, 2019; ABIS, 2021).

Apesar da importante natureza dos demais sistemas sensoriais, as informações visuais para as funções diárias são de valor ímpar. O sistema visual auxilia a julgar a velocidade e distância, tamanho, cor dos objetos; identificar alimentos e pessoas ao redor; além de ter seu efetivo funcionamento associado a outros sistemas, por exemplo, ao sistema vestibular, onde exerce papel de extrema importância no desenvolvimento e aprendizagem, motivando, guiando e corrigindo comportamentos que auxiliam na interação e sobrevivência no mundo (BUNDY; LANE, 2019; ABIS, 2021).

Os dois últimos sistemas sensoriais descritos são considerados sistemas quimiorreceptores, paladar e olfato, que respondem a produtos químicos em seus ambientes. Os receptores gustativos, pertencentes ao sistema gustativo, estão localizados na língua, céu da boca, ao redor da boca e bochechas; estes fornecem informações para que o corpo responda adequadamente ao sugar, morder, mastigar, engolir e até mesmo falar. Os receptores do sistema olfativo estão localizados no nosso nariz, informando quais odores estamos sentindo; além de atuar com a função de proteção. Estes dois últimos sistemas estão intimamente relacionados (BUNDY; LANE, 2019; ABIS, 2021).

Nesse sentido, ainda na infância, as funções associadas à Integração Sensorial se desenvolvem em uma ordem natural em todas as crianças; apesar dessa agilidade variar em cada indivíduo, todos seguem basicamente o mesmo percurso. Nos primeiros sete anos de vida, as crianças iniciam o processo de organização das sensações do Sistema Nervoso (SN), sendo as respostas adaptativas de origem motora, portanto, este período é definido como sensório motor. As primeiras sensações do bebê ainda estão estritamente ligadas aos sistemas sensoriais mais básicos: visão, audição, tato e propriocepção, sendo ainda interpretado de modo mais simplificado, devido a não estar suficientemente maduro. Posteriormente, os movimentos mais grosseiros e desajeitados tornam-se mais suaves e direcionados, controle postural melhora e a criança começa a organizar as sensações e as emoções (AYRES, 2018). 
Hadders-Algra (2018) refere que ainda nos 2-3 meses de vida a criança começa a adquirir o controle de cabeça na posição pronada e ao final do quarto mês o controle na posição sentada com apoio. Até o final do sexto mês é esperada a estabilização de pescoço e tronco. Este controle motor inicial, bem como os inputs proprioceptivos e táteis, é de extrema importância para que nos próximos meses as crianças adquiram o sentar sem apoio (5-8 meses), manter-se na posição ortostática (9-13 meses) e a marcha (10-14 meses).

Nos primeiros meses de vida, iniciam-se os ajustes posturais antecipatórios de braços e pernas. Estes primeiros sinais ainda são de maneira automática, com muita influência dos sistemas vestibulares, proprioceptivos e táteis. Entre o terceiro e quarto mês, gradualmente, os bebês realizam a aprendizagem por tentativa e erro, levantam a cabeça e a parte superior do corpo e, ao final do quarto mês, iniciam a transferência de objetos de uma mão para a outra. Neste processo ocorre a melhora da coordenação visomotora (HADDERS-ALGRA, 2018; AYRES, 2019).

No que tange aos sinais de alerta, do nascimento até o sexto mês, os bebês já podem demonstrar: incapacidade de manter um padrão de sono regular, dificilmente fica em um estado calmo, padrões de alimentação pobre, dificuldade em atividade que exigem mudança de temperatura (por exemplo, o banho), o bebê pode ficar tenso ao pegarem no colo, evitar o contato com pares da mesma idade, não realiza exploração de pés e mãos, pobre extensão de tronco, baixo nível de atividade, entre outras características (SERRANO, 2018).

Aos nove meses de vida aumenta-se o grau da contração muscular, o que auxilia na mudança de posição sentada para em pé, melhor controle de cintura escapular e cintura pélvica, cruzamento da linha média e integração bilateral. Entre 10 e 14 meses é necessário atingir a macha, mas sabe-se que a qualidade deste deambular desenvolve-se à medida que a exploração do ambiente e a interação social tornam-se mais prazerosas. Neste sentido, percebemos a importância do desenvolvimento adequado das reações vestibulares-posturais adequadas (vestibular e proprioceptivo), vestíbulo-ocular (sistemas visual e vestibular) e do sistema tátil (HADDERS-ALGRA, 2018; SERRANO, 2018; AYRES, 2019).

Como sinais de alerta para possíveis alterações no desenvolvimento, dos seis aos 12 meses temos: resposta inadequada aos estímulos táteis e proprioceptivos, evitam carregar objetos pesados nas mãos, dificuldade na posição em pé e/ou para deambular, pobre esquema corporal, movimentos descoordenados e padrões de movimentos imaturos. Os sinais de alerta nesta fase, em sua grande maioria, 
apresentam origem na alteração dos sistemas tátil e proprioceptivo (SERRANO, 2018).

Desse modo, Jean Ayres, além de descrever os sistemas sensoriais, seu processamento e inter-relações, caracterizou os déficits de Integração Sensorial como sendo inabilidade do SNC em modular, discriminar, organizar e coordenar as sensações adequadamente, os identificando como Transtornos de Processamento Sensorial (TPS), os quais foram subdivididos em três grandes grupos denominados: Transtornos Motores de Base Sensorial (dificuldade do indivíduo em utilizar o corpo de modo eficiente no ambiente); Transtorno de Discriminação Sensorial (déficits na capacidade de interpretar estímulos sensoriais e usar essa interpretação no ambiente, assim como de distinguir as qualidades temporais e espaciais de estímulos) e Transtorno de Modulação Sensorial (resposta consistentemente desproporcional à magnitude da experiência sensorial, podendo ser de três subtipos: hiper-resposta, hiporesposta e busca sensorial (SOUZA; NUNES, 2019; PAVÃO; ROCHA, 2017; BUNDY; LANE, 2019).

Souza e Nunes (2019) definem como hiper-responsivos indivíduos que apresentam baixo limitar sensorial, portanto, respondem de forma mais intensa ao input sensorial. No padrão de hiporesposta verifica-se uma diminuição das respostas frente a diversos estímulos ou respostas mais lentificadas, apresentando alto limiar sensorial. Enquanto a busca sensorial é caracterizada pela procura por estímulos intensos, com maior duração e frequência.

Autores como Torres (2021) e Oliveira (2018), consideram que, ainda na infância, quando há privação de informações sensoriais por fatores ambientais, sanitários, de saúde, maus-tratos, psicológicos, prematuridade, pobreza, pandemias, entre outros, o desenvolvimento infantil pode ser diretamente afetado.

Os primeiros conceitos de privação ambiental e as repercussões no desenvolvimento infantil surgem com John Bowlby, em 1951, onde demonstrava casos de exposição de crianças a uma menor proporção de diversidade de estímulos e o isolamento social. Posteriormente, George Tarjan, em 1968, refere que crianças em situação de pobreza extrema eram privadas de estímulos táteis, proprioceptivos, vestibulares, auditivos e visuais, concluindo, portanto, que a privação de estímulos ambientais desencadeia a privação sensorial (RESTREPO; BECERRA-HERNÁNDEZ, 2020).

Machado et al. (2017) refere que as primeiras experiências sensoriais das crianças são extremamente importantes para o desenvolvimento adequado dos 
sistemas sensoriais. Embora nem todos os sistemas desempenhem igual importância na conectividade inicial, contribuem para a maturação e apropriada conexão para o encéfalo que está se desenvolvendo. Desse modo, percebe-se que, apesar dos fatores ambientais que dificultam as experiências sensoriais, é importante a exposição dessas crianças a ambientes ricos em informações sensoriais.

Dessa forma, percebe-se que há relação entre privação ambiental levando à privação sensorial e repercussões no desenvolvimento infantil. Nesse sentido, faz-se necessário refletir sobre quais as possíveis privações sensoriais causadas pelo contexto atual de pandemia da COVID-19 e suas relações com o desenvolvimento infantil.

3.2 O contexto da pandemia de COVID-19 e as possíveis privações sensoriais ao desenvolvimento infantil

Como medidas de contenção ao avanço da disseminação da COVID-19, as medidas de distanciamento social, segundo Linhares e Enumo (2020), tiveram como resultado muitas mudanças para a vida das pessoas, que passaram a conviver por período prolongado, dentre elas, destacam-se: o fechamento das escolas, creches, núcleos assistenciais, esporte e lazer; medidas de alteração nas modalidades de trabalho, com implantação de modalidade de trabalho realizado à distância, questões econômicas relacionadas ao aumento do desemprego e problemas financeiros; ausência ou diminuição de assistência prestada por serviços de saúde, conflitos familiares, entre outros.

Zimmermann e Curtis (2020) reafirmam que a exposição de crianças ao novo Coronavírus, em comparação com adultos, traz menos repercussões para a saúde. Entretanto, atenção especial deve ser dada à saúde mental das crianças no contexto pandêmico, devido ao distanciamento ou isolamento social, constituindo-se, desta forma, em população vulnerável. Segundo Cruz et al. (2021), as crianças têm convivido com efeitos disruptivos ao desenvolvimento dessas medidas, que têm promovido privação da convivência social, seja familiar e/ou comunitária, além do acesso à educação e à saúde.

Tendo em vista que por conta das medidas de distanciamento social, além do fechamento das instituições de ensino, às famílias enfrentam a necessidade de restringir o contato físico de crianças com outras pessoas, ainda que sejam da família, como os avós, considerados mais vulneráveis ao desenvolvimento da forma 
grave da doença, limitando possibilidades de cuidados formais ou parental (YERKES et al., 2020).

Estudos de Jiao et al. (2020) destacam como riscos a crianças que enfrentam longos períodos de isolamento social alterações psicológicas e fisiológicas, relatadas por cuidadores e/ou por crianças, dentre elas: alterações de sono, ocorrências de pesadelos, ausência de apetite, agitação, desatenção, alterações no apego, manifestação de angústia ao ser questionada sobre a sua vida e o futuro. Cruz et al. (2021) afirmam que tais alterações sugerem elementos favoráveis para surgimento de alto nível de estresse psicológico, com efeitos negativos para a saúde mental das crianças.

O estudo de Wang et al. (2020) investigou o confinamento de 220 milhões de crianças e adolescentes chineses, sendo destes 180 milhões de estudantes de ensino fundamental e médio e 47 milhões de crianças pré-escolares. Revelou que o confinamento produzirá impactos psicológicos, tendo em vista que esta população está sujeita a fatores estressantes com duração prolongada, dentre eles: medo de adoecer, frustração, tédio, distanciamento social, falta de espaço físico em casa e até problemas financeiros enfrentados pelas famílias.

Para Linhares e Enumo (2020), é evidente que o meio ambiente é extremamente importante como determinante para o neurodesenvolvimento, tanto em relação aos aspectos neuroquímicos, quanto anatômicos. No ambiente familiar, de modo geral, existem múltiplos fatores de risco ao desenvolvimento, tais como: falta ou pouca estimulação, violência, maus tratos, práticas parentais, disciplina abusiva ou coercitiva, desnutrição, baixa escolaridade, desemprego, instabilidade financeira, alta densidade habitacional no lar, problemas de saúde mental dos pais, entre outros (EVANS; WACHS, 2010).

Durante a pandemia, tais fatores de risco ao desenvolvimento no contexto familiar podem ser agravados. Autores como Benner e Mistry (2020) apontam, neste contexto, outros fatores específicos como: o estresse e as incertezas que acompanham a pandemia; as mudanças, como alterações no trabalho dos pais, questões econômicas; o fechamento das instituições de ensino e as mudanças da modalidade de ensino presencial para a aprendizagem remota ou on-line.

Devido ao distanciamento social, as crianças estão impedidas de frequentar as escolas, ambiente essencial ao desenvolvimento e aprendizagem. Segundo a Sociedade Brasileira de Pediatria (2020), para além do comprometimento do processo de aprendizagem formal, as crianças estão privadas da necessária 
socialização com os pares, que promove aprendizados significativos para 0 desenvolvimento humano, tais como: experiências lúdicas compartilhadas, resultante da interação com o outro e o contato proximal, face a face; cooperação; convivência que permite vivenciar as diferenças; compartilhamento e enfrentamento de decisões e desafios; gerenciamento de situações de conflitos, com solução de problemas; adiamento de gratificações, exercitando a paciência, necessária para o desenvolvimento de requisitos como espera de turno e controle de impulsos, entre outras habilidades.

A Sociedade Brasileira de Pediatria (2020) e outros autores, como Holmes et al. (2020) e Wang et al. (2020), consideram que as modalidades de aprendizagem à distância podem gerar excesso do uso de telas, padrões de sono irregulares e estar relacionada à diminuição de atividade física e dietas menos apropriadas em crianças e adolescentes.

O estudo de Rosen et al. (2013), que é anterior ao contexto pandêmico, investigou o impacto negativo do uso de mídias em crianças (de quatro a oito anos), pré-adolescentes (de nove a 12 anos) e em adolescentes (de 13 a 18 anos) e já demonstrava que há correlação entre o tempo do uso de tela com: alimentação não saudável, ausência de prática de atividades físicas, sensação de mal-estar geral, diminuição de atenção e problemas de ordem física.

Figueiredo et al. (2020) enfatiza que o uso excessivo de telas também tem sido favorecido pelas mudanças ocasionadas na rotina por conta da pandemia, em relação ao ambiente onde pode ser desenvolvido o brincar. Com as medidas de distanciamento e isolamento social, as crianças e adolescentes foram privados de explorar áreas externas e, consequentemente, brincadeiras não estruturadas, o que implica em usar telas por mais tempo.

É evidenciado na literatura, conforme afirma Restrepo e Becerra-Hernández (2020), que a privação de estímulos ambientais desencadeia a privação sensorial. Isto posto, infere-se que diferentes sistemas sensoriais podem ter sido afetados pelas mudanças ocasionadas pela pandemia de COVID-19, considerando as restrições impostas pelo confinamento e distanciamento social.

Dessa forma, com base no conhecimento produzido por Jean Ayres sobre o desenvolvimento infantil e funcionamento dos sistemas sensoriais e os trabalhos científicos consultados que descrevem o contexto pandêmico, identificou-se as mudanças causadas pela pandemia de COVID-19, relacionando-as com os sistemas 
sensoriais, inferindo-se possíveis repercussões para o desenvolvimento infantil, as quais foram esquematizadas e apresentadas no Quadro 1.

Quadro 1 - Mudanças causadas pela pandemia de COVID-19, os sistemas sensoriais e as possíveis repercussões para o desenvolvimento infantil

\begin{tabular}{|c|c|c|}
\hline $\begin{array}{c}\text { SISTEMA } \\
\text { SENSORIA } \\
\text { L }\end{array}$ & $\begin{array}{l}\text { MUDANÇAS CAUSADAS } \\
\text { PELA PANDEMIA }\end{array}$ & $\begin{array}{l}\text { POSSÍVEIS REPERCUSSÕES } \\
\text { PARA O DESENVOLVIMENTO }\end{array}$ \\
\hline Tátil & $\begin{array}{l}\text { - Restrição do contato } \\
\text { físico; } \\
\text { - Uso de álcool em gel; } \\
\text { - Uso de equipamentos de } \\
\text { proteção como: luvas, } \\
\text { toucas e máscaras; } \\
\text { - Restrição do contato com } \\
\text { texturas presentes em } \\
\text { ambientes externos ao } \\
\text { domicílio. }\end{array}$ & $\begin{array}{l}\text { - Alteração da percepção tátil } \\
\text { e consciência corporal; } \\
\text { - Repercussões sobre } \\
\text { competências sociais e } \\
\text { desenvolvimento do afeto, } \\
\text { tanto para apego excessivo, } \\
\text { principalmente dos pares, } \\
\text { quanto para a recusa de } \\
\text { contato com estranhos; } \\
\text { - Implicações negativas sobre } \\
\text { o desempenho de Atividades } \\
\text { de Vida Diária, como } \\
\text { alimentação, vestuário, } \\
\text { banho e higiene. E em } \\
\text { ocupações, como o brincar, o } \\
\text { descanso e sono; } \\
\text { - Comprometimento da } \\
\text { aprendizagem escolar. }\end{array}$ \\
\hline $\begin{array}{l}\text { Propriocepti } \\
\text { vo }\end{array}$ & $\begin{array}{l}\text { - Restrição do uso de } \\
\text { ambientes externos, como } \\
\text { parques, praças, quadras, } \\
\text { entre outros; } \\
\text { - Fechamento das escolas. }\end{array}$ & 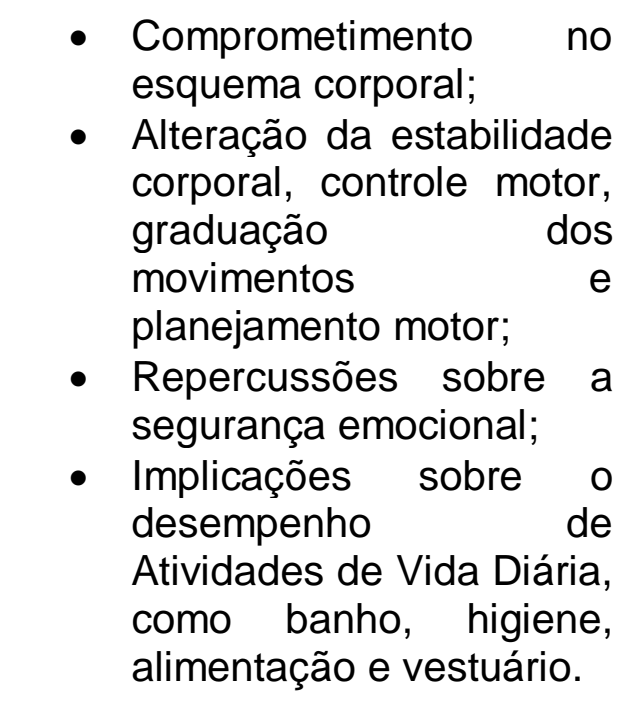 \\
\hline Vestibular & $\begin{array}{l}\text { - Diminuição no contato } \\
\text { com ambientes que } \\
\text { proporcionem diferentes } \\
\text { posições de cabeça e } \\
\text { corpo no espaço. }\end{array}$ & $\begin{array}{l}\text { - Dificuldades no controle } \\
\text { postural, equilíbrio, } \\
\text { discriminação de } \\
\text { movimentos, pessoas e } \\
\text { objetos do meio; } \\
\text { - Comprometimento da } \\
\text { coordenação motora, planejamento } \\
\text { bilateral, }\end{array}$ \\
\hline
\end{tabular}




\begin{tabular}{|c|c|c|}
\hline & & 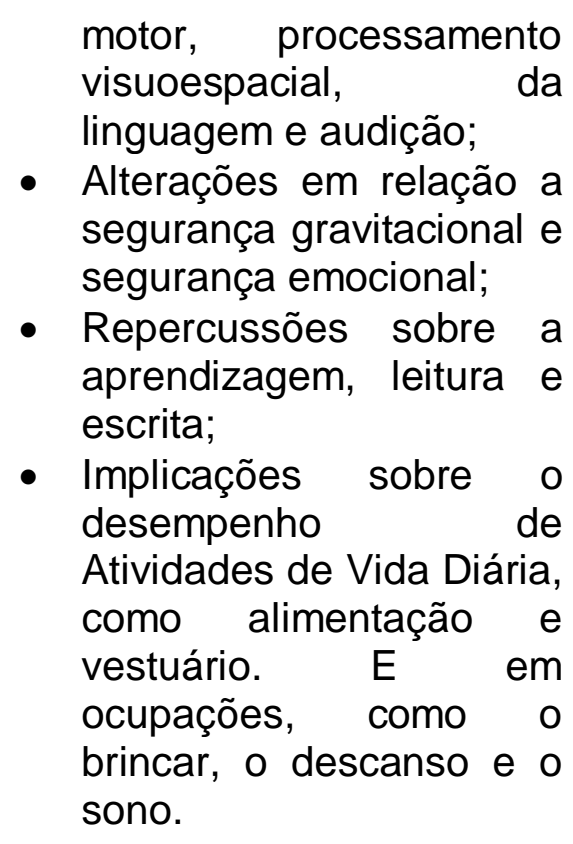 \\
\hline Auditivo & $\begin{array}{l}\text { - Uso de máscara, que } \\
\text { pode alterar a intensidade } \\
\text { da voz humana; } \\
\text { - Restrição de contato com } \\
\text { pessoas, externas à } \\
\text { família. }\end{array}$ & 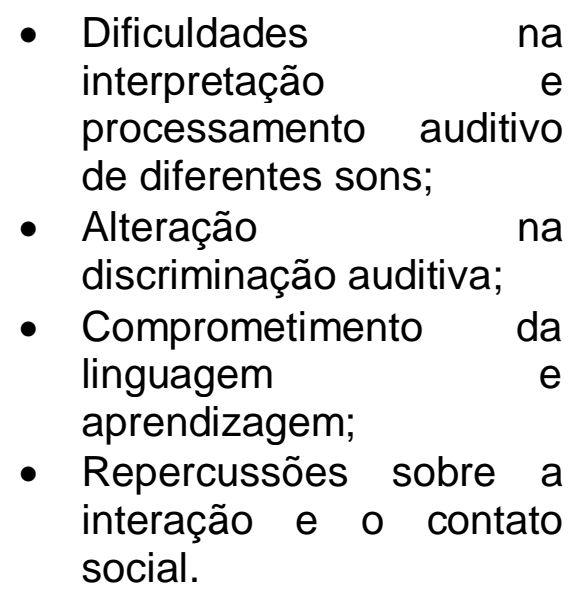 \\
\hline Olfativo & - Uso de máscaras. & 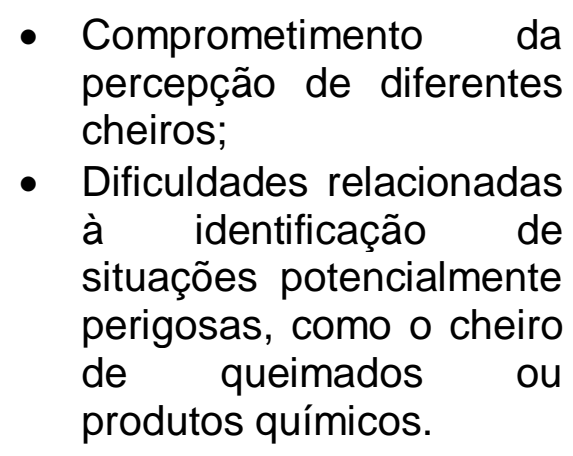 \\
\hline Visual & $\begin{array}{l}\text { - Uso de máscaras; } \\
\text { - Fechamento das } \\
\text { escolas; } \\
\text { - Uso abusivo de telas; } \\
\text { - Poucos estímulos } \\
\text { visuais externos ao } \\
\text { domicílio. }\end{array}$ & $\begin{array}{l}\text { - Dificuldades quanto à } \\
\text { percepção visual; } \\
\text { - Comprometimento de } \\
\text { habilidades relacionadas } \\
\text { ao controle postural, } \\
\text { movimentos, equilíbrio, } \\
\text { coordenação motora e } \\
\text { noção espacial; } \\
\text { - Comprometimento do } \\
\text { estabelecimento de } \\
\text { vínculo; }\end{array}$ \\
\hline
\end{tabular}




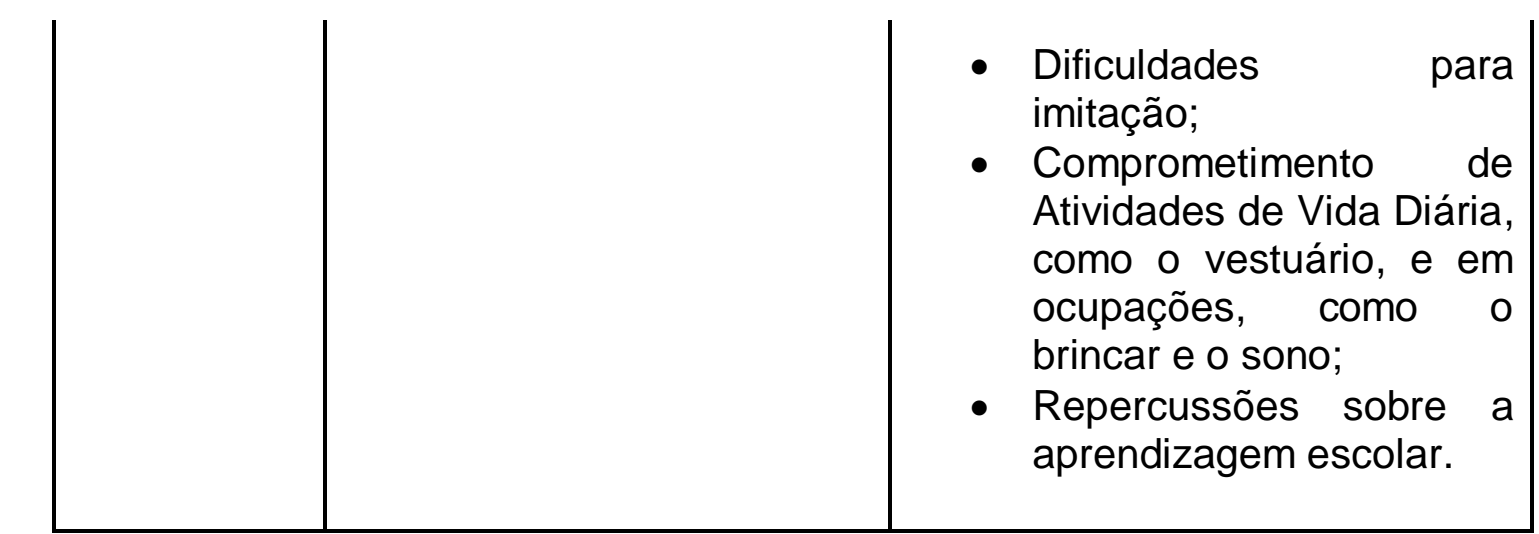

Fonte: Elaborado pelos autores.

Tendo em vista as alterações ocasionadas nas rotinas das crianças, pelo atual contexto pandêmico, infere-se que estas estão expostas a privações ambientais que tem levado a privações sensoriais, atingindo diferentes sistemas: tátil, vestibular, proprioceptivo, olfativo, auditivo e visual, com repercussões em diversos aspectos do desenvolvimento, comprometendo habilidades motoras, cognitivas, de linguagem e sociais. Sugere-se que tais repercussões terão impacto na funcionalidade da criança, implicando em dificuldades no desempenho de Atividades de Vida Diária (AVDs) e em ocupações, como o brincar, o descanso e o sono.

Ainda não temos estudos empíricos que relacionem os sistemas sensoriais, as mudanças ocasionadas pela pandemia de COVID-19 e as repercussões destas mudanças para cada sistema, em longo e curto prazo, e nem de que forma essas mudanças impactarão no desenvolvimento infantil, em seus diferentes aspectos. Entretanto, este trabalho traz esse olhar sensorial para estas mudanças e suas possíveis repercussões para que possa subsidiar pesquisas futuras sobre o tema, que tragam impactos positivos para o desenvolvimento infantil, seja de forma preventiva ou intervencionista.

\section{CONCLUSÃO}

O desenvolvimento infantil adequado é dependente do desenvolvimento dos sistemas sensoriais, de seu processamento e da influência dos contextos ambientais. Quando ocorrem alterações no ambiente, como privações ambientais, podem ocorrer privações de ordem sensorial que apresentam repercussões para o desenvolvimento infantil saudável.

As medidas sanitárias recomendadas pela Organização Mundial de Saúde para conter o avanço e disseminação do coronavírus, tais como: isolamento social, 
restrição do contato físico, uso de equipamentos de proteção individual (máscaras, álcool em gel, luvas, entre outros), fechamento de escolas, creches, espaços de convivência, levaram a mudanças nas rotinas de todas as pessoas, especialmente de crianças.

Este artigo permitiu identificar as mudanças causadas pelo contexto da pandemia de COVID-19, relacionando-as com os sistemas sensoriais, descritos por Jean Ayres, refletindo e inferindo as possíveis repercussões de tais mudanças para o desenvolvimento infantil, conforme é esquematizado e apresentado no Quadro 1.

Através destes resultados, foi possível perceber a importância da descrição de Jean Ayres dos sistemas sensoriais, da Teoria de Integração Sensorial e dos Transtornos de Processamento Sensorial para a compreensão do desenvolvimento infantil, no que se refere ao atual contexto pandêmico. Considerando que ao se lançar mão dos conhecimentos produzidos por Ayres pode-se compreender comportamentos específicos adotados pelas crianças, em diferentes ambientes, que poderão subsidiar o desenvolvimento de estratégias para a prevenção, estimulação, e, inclusive, intervenção, a fim de produzir respostas adaptativas adequadas ao meio, favorecendo a funcionalidade da criança e o desenvolvimento saudável.

Dessa forma, este trabalho constitui-se em uma ferramenta que pode subsidiar a compreensão do atual contexto de pandemia e suas repercussões sobre o desenvolvimento infantil, podendo contribuir para o desenvolvimento de pesquisas futuras. Sugere-se a elaboração de materiais instrucionais para pais e cuidadores de creches e escolas, tomando como base as inferências aqui apresentadas, com o intuito de alertar para sinais de prováveis alterações sensoriais; a realização de estudos empíricos sobre essa relação; avaliando repercussões ao desenvolvimento em curto, médio ou longo prazo; abordando inclusive estratégias de prevenção de agravos ao desenvolvimento; promovendo atividades favorecedoras para cada sistema sensorial comprometido.

\section{REFERÊNCIAS BIBLIOGRÁFICAS}

ABIS - Associação Brasileira de Integração Sensorial. Secretaria Nacional do Direito das Pessoas com Deficiência (SNDPD). Cartilha de Orientação de brincadeira para família com crianças com Transtorno do Espectro Autista. Brasília: Ministério da Mulher, da Família e dos Direitos Humanos, 2021.

AYRES, E. Sensory Integration and the Child: Understanding hidden sensory challenges. 5. ed. Москва: Теревинфр, 2018. 
BENNER, A.; MISTRY, R. Child development during the COVID-19 pandemic through a life course theory lens. Child development perspectives, v. 14, n. 4, p. 236-243, 2020.

BOLTON, S.; HATTIE, J. Cognitive and Brain Development: Executive Function, Piaget, and the Prefrontal Cortex. Archives of Psychology, v. 1, n. 3, p. 02-36, 2017.

BRITTO, B. et al. Processamento sensorial no período da infância em crianças nascidas pré-termo: revisão sistemática. Revista de Terapia Ocupacional da Universidade de São Paulo, v. 31, p. 09-16, São Paulo, 2020.

BUNDY, A.; LANE, S. Sensory Integration: Theory and Practice. 3. ed. Philadelphia: F. A. Davis Company, 2019.

CRUZ, D. et al. Institucionalização e isolamento social: reflexões acerca da saúde mental de crianças e adolescentes. In: Saúde mental no século XXI: Indivíduo e coletivo pandêmico, p. 165-177, 2021. Disponível em:

https://downloads.editoracientifica.org/articles/210303479.pdf. Acesso em: 30 nov. 2021.

EVANS, G.W.; WACHS, T. D. Chaos and its influence on children's development: an ecological perspective. American Psychological Association, 2010. doi: https://doi.org, 10.1037/12057-000.

FIGUEIREDO, C. et al. COVID-19 pandemic impact on children and adolescents' mental health: Biological, environmental, and social factors. Progress in Neuropsychopharmacology \& Biological Psychiatry, v. 106, 2020.

FIGUEIREDO, M.; ALEGRETTI, A.; MAGALHÂES, L. COVID-19 e desenvolvimento infantil: material educativo para familiares. Revista Brasileira de Saúde Materna Infantil, v. 21, 2021.

HADDERS-ALGRA, M. Early human motor development: From variation to the ability to vary and adapt. Neuroscience and Biobehavioral Reviews, n. 90, 2018.

HOLMES, E. A. et al. Multidisciplinary research priorities for the COVID-19 pandemic: a call for action for mental health science. The lancet Psychiatry, v. 15, n. 2, p. 1-4, 2020. doi: http://dx.doi.org/10.1016/S2215-0366(20)30160-1.

JIAO, W. Y. et al. Behavioral and emotional disorders children during the COVID-19 epidemic. The Journal of Pediatrics, p. 1-4. 2020.

LAKATUS, E. M.; MARCONI, M. A. Fundamentos da metodologia científica. 5. ed. São Paulo: Atlas, 2003.

LIANG, T. Handbook of COVID-19: prevention and treatment. Zhejiang University School of Medicine. UNESCO, 20 mar. 2020. Disponível em: http://www.zju.edu.cn/english/2020/0323/c19573a1987520/page.htm. Acesso em: 27 nov. 2021. 
LINHARES, M. B. M.; ENUMO, S. R. F. Reflexões baseadas na psicologia sobre efeito da pandemia de COVID-19 no desenvolvimento infantil. Estudos de Psicologia, Campinas, v. 37, 2020. doi: http://doi.org/10.1590/1982-0275202037.

LITTLE, L. et al. Classifying sensory profiles of children in the general population. Child: care, health and development, v. 43, n. 1, p. 81-88, 2017.

MACHADO, A. et al. Processamento sensorial no período da infância em crianças nascidas pré-termo: revisão sistemática. Revista Paulista de Pediatria, v. 35, n. 1, 2017.

OLIVEIRA, L. Componente de interação binaural do Potencial Evocado Auditivo Cortical em crianças com histórico de otite de repetição. Dissertação (Mestrado em Fonoaudiologia) - Universidade Estadual Paulista, Marília, 2018.

OPAS - Organização Pan-Americana de Saúde. Histórico da pandemia de COVID19. [s.d.]. Disponível em: https://www.paho.org/pt/covid19/historico-da-pandemiacovid-19. Acesso em: 27 nov. 2021

PAVÃO, S.; ROCHA, N. Sensory processing disorders in children with cerebral palsy. Infant Behavior and Development, v. 46, p. 1-6, 2017.

PEREIRA, A. S. et al. Metodologia da Pesquisa Científica. Santa Maria: UFSM, 2018.

RESTREPO, J.; BECERRA-HERNÁNDEZ, L. Privación sensorial temprana durante el neuro de sarrollo y sus consecuencias cognitivas. Revista de Medicina da U.P.B., v. 39, n. 2, p. 49-55, 2020.

ROSEN, L. D. et al. The Media and Technology Usage and Attitudes Scale: An empirical investigation. Computers in human behavior, v. 29, p. 2501-2511, 2013.

SERRANO, P. A Integração Sensorial no desenvolvimento e aprendizagem da criança. 3. ed. Lisboa: Papa-Letras, 2018.

SBP - Sociedade Brasileira de Pediatria. SBP atualiza recomendações sobre saúde de crianças e adolescentes na era digital. 11 fev. 2020. Disponível em: https://www.sbp.com.br/imprensa/detalhe/nid/sbp-atualiza-recomendacoes-sobresaude-de-criancas-e-adolescentes-na-era-digital/. Acesso em: 27 nov. 2021.

SOUZA, R.; NUNES, D. Transtornos do processamento sensorial no Autismo: algumas considerações. Revista Educação Especial, v. 32, 2019.

TOMASI, M. et al. Sinestesia e o Transtorno do Espectro do Autismo (TEA). Revista de Atenção à Saúde, São Caetano do Sul, v. 16, n. 55, p. 81-88, jan./mar. 2018.

TORRES, L. Os efeitos da privação sensorial auditiva no desenvolvimento da linguagem e fala da criança pré-lingual. Trabalho de Conclusão de Curso (Graduação em Fonoaudiologia) -UniCesumar, Maringá, 2021.

WANG, G. et al. Mitigate the effects of home confinement on children during the COVID-19 outbreak. The Lancet, v. 395, p. 945-947, 2020. 
YERKES, M. A. et al. Intelligent lockdown, intelligent effects? The impact of the dutch COVID-19 "intelligent lockdown" on gendered work and family dynamics among parents. Plos One, p. 1-24, 2020. doi: https://doi.org/10.1371/journal.pone.0242249.

ZIMMERMANN, P.; CURTIS, N. Coronavirus infections in children including COVID19: an overview of the epidemiology, clinical features, diagnosis, treatment and prevention options in children. Pediatric Infectous Disease Journal, v. 39, p. 355368, 2020. doi: http://dx.doi.org/10.1097/INF. 000000000002660. 


\title{
O TRATAMENTO DA SELETIVIDADE ALIMENTAR EM CRIANÇAS COM TRANSTORNO DO ESPECTRO AUTISTA (TEA), SOB A PERSPECTIVA DA INTEGRAÇÃO SENSORIAL: uma revisão da literatura
}

\author{
Brenda Maíra Fernandes de Andrade ${ }^{1}$ \\ Bruna Leal Lopes ${ }^{1}$ \\ Cristiane Pinheiro Matias ${ }^{1}$ \\ Vanessa Rafaelle Brasil ${ }^{2}$
}

\section{RESUMO}

O Transtorno do Espectro Autista (TEA) é uma condição do neurodesenvolvimento com sintomas presentes desde o início da infância, caracterizado por prejuízos na comunicação e interação social; padrões restritos, repetitivos e estereotipados de comportamentos, interesses ou atividades; e alterações sensoriais. Um dos problemas encontrados na alimentação das crianças no TEA é a seletividade alimentar, seu tratamento deve ser realizado por uma equipe multidisciplinar em parceria com a família da criança. Podendo haver intervenção na abordagem de Integração Sensorial de Ayres, quando há presença de disfunções sensoriais, frequentemente encontradas no TEA. Foi realizada uma revisão de literatura do tipo revisão narrativa. Utilizou-se como descritores os termos: "Integração Sensorial e seletividade alimentar", "Seletividade alimentar e Autismo", "Terapia Ocupacional e seletividade alimentar". A pesquisa ocorreu nos seguintes bancos de dados: SciELO, Pubmed, LILACS, American Journal of Occupational Therapy e a Revista Chilena de Terapia Ocupacional. Foram encontrados 378 estudos, dos quais quatro satisfizeram os critérios de inclusão, entretanto, nenhum dos artigos trata diretamente sobre a intervenção de Integração Sensorial com crianças que apresentam seletividade alimentar. Após a revisão, os estudos evidenciaram ainda o risco de problemas nutricionais nas crianças que apresentam seletividade alimentar, um fator preocupante, haja vista que a fase da infância tem influência direta em longo prazo. Finalmente, sugere-se que estudos posteriores realizem mais investigações acerca da presença de seletividade alimentar e consumo de micronutrientes em indivíduos com TEA, bem como a necessidade de intervençãoespecífica e o uso da Integração Sensorial nas sessões de Terapia Ocupacional.

Palavras-chaves: Processamento sensorial. Transtorno do Espectro Autista. Seletividade Alimentar. Terapia Ocupacional.

\section{INTRODUÇÃO}

O Autismo, também conhecido como Transtorno do Espectro Autista (TEA), é definido como um transtorno do neurodesenvolvimento que compromete 0 desenvolvimento motor e psiconeurológico, dificultando a cognição, a linguagem e a interação social da criança (LOPEZ-PISON, 2014).

\footnotetext{
${ }^{1}$ Terapeutas Ocupacionais.

${ }^{2}$ Terapeuta Ocupacional/UEPA, Msc. em Psicologia UFPA, Certificação em IS - WPS/USC, Docente do Curso de Certificação Brasileira em IS - Integris/UEPA. Orientadora do trabalho.
} 
O TEA é uma condição do neurodesenvolvimento com sintomas presentes desde o início da infância, caracterizado por prejuízos centrais em três domínios: 1) prejuízos persistentes na comunicação e interação social; 2) padrões restritos, repetitivos e estereotipadosde comportamentos, interesses ou atividades; 3) hiper ou hiporreatividade a estímulos sensoriais ou interesse incomum por aspectos sensoriais do ambiente (AMERICAN PSYCHIATRIC ASSOCIATION, 2014).

Quando falamos em "espectro", incluímos desde pessoas que não são verbais, que apresentam deficiência intelectual, maiores comprometimentos na independência e autonomia, até aqueles que são verbais, que conseguem se comunicar mesmo que não verbalmente e se desenvolvem de maneira mais funcional; diante disso, o DSM-V aponta que o TEA apresenta níveis de gravidade, desde a necessidade de muito apoio à necessidade de apoio leve (AMERICAN PSYCHIATRIC ASSOCIATION, 2014).

Um dos fatores de maior dificuldade para pessoas com TEA é o déficit na socialização, muitas vezes prejudicada pela forma que estas pessoas respondem aos estímulos externos, o que aponta para a dificuldade no processamento sensorial, que pode ser resultante de uma hipo ou hiper-reatividade aos estímulos sensoriais. Pessoas com Autismo apresentam, de maneira mais ou menos intensa, alterações na forma como respondem aos estímulos do ambiente em uma ou mais portas sensoriais (visão, audição, olfato, tato, paladar, propriocepção e sistema vestibular).

Tais alterações sensoriais foram incluídas nos critérios diagnósticos após a última revisão do DSM, em sua quinta edição (AMERICAN PSYCHIATRIC ASSOCIATION, 2014). Alguns exemplos incluem: indiferença à dor; aversão ao toque, enquanto outros procuram por toques mais intensos; seletividade alimentar, que pode ser consequente à aversão a determinadas texturas dos alimentos, odores, paladar, percepção visual (como comer alimentos de uma única cor); alteração de equilíbrio, marcha na ponta dos pés, entre outros. Há um universo de possibilidades sintomatológicas dentro do espectro que irão impactar na gravidade, nos planos individuais de tratamento e ao longo da vida desse indivíduo (ANDRADE, 2012).

Nesse contexto, um dos problemas encontrados na alimentação das crianças é a seletividade alimentar, que, segundo Rocha et al. (2019), pode ser caracterizada por três fatores: pouco apetite, recusa alimentar e desinteresse pelo alimento. Crianças seletivas ingerem uma quantidade limitada e menor de alimentos, com resistência para a inserção de outros novos à sua rotina alimentar. Isto pode gerar 
carências nutricionais e prejudicar o organismo, visto que a ingestão de nutrientes é essencial para o bom funcionamento do organismo e para a saúde.

É comum que crianças com TEA apresentem padrões de inflexibilidade mental, inclusive com dificuldade em ingerir novos alimentos, podendo gerar falta de nutrientes necessários parao corpo, um problema comum decorrente da seletividade alimentar (SILVA, 2011).

Outro fator que também gera a seletividade está relacionado à sensorialidade oral, neste caso, ocorre quando a criança demonstra maior sensibilidade a certos tipos de texturas e consistência das comidas (ROCHA et al., 2019).

Por esse motivo, o tratamento da seletividade alimentar deve ser realizado pelo trabalho de uma equipe multidisciplinar em parceria com a família da criança, pois a alimentação é de grande importância para seu desenvolvimento neuropsicomotor, afetando, consequentemente, seu desempenho cognitivo e social.

A seletividade alimentar e essas alterações sensoriais das crianças com TEA também podem afetar seu comportamento em atividades diárias, por exemplo, comer, dormir e brincar, e no contexto fora de casa essas alterações podem criar maiores problemas, por exemplo, ao viajar e participar de eventos na comunidade. Apesar de vários profissionais utilizarem do processo de avaliação e intervenção desse aspecto junto às pessoas com Autismo, apenas o Terapeuta Ocupacional é o profissional que atribui o foco nas ocupações em sua intervenção (AOTA, 2015)

Segundo a Aota (2015), a Terapia Ocupacional tem como objeto de intervenção e estudoa ocupação humana, e uma dessas ocupações são as Atividades de Vida Diária (AVDs), as quaissão de grande importância e desempenhadas desde a infância; podendo ser consideradas: "Atividades orientadas para o cuidado do indivíduo com seu próprio corpo" (AOTA, 2015, p. 19). As AVDS englobam alimentação, tomar banho, usar o sanitário e higiene íntima, vestir roupa, deglutir/comer, mobilidade funcional, cuidado com objetos pessoais e higiene pessoal.

Portanto, com técnicas específicas e raciocínio clínico para a análise da tarefa e da ocupação, o Terapeuta Ocupacional é o profissional habilitado para avaliar e participar do tratamento multidisciplinar voltado para a alimentação.

Desde o início da vida, o ser humano é envolvido por sensações, as quais são necessárias para o desempenho de todas as ocupações. Nosso corpo possui oito sistemas sensoriais: visão, olfato, paladar, audição, tato, propriocepção, vestibular e interocepção. As informações dos estímulos sensoriais são enviadas ao Sistema 
Nervoso Central (SNC), que interpreta e processa as informações de todos os sistemas para gerar uma resposta adaptativa às exigências do meio (SERRANO, 2016).

Além disso, há pouco tempo, iniciou-se os estudos e atuação sobre o oitavo sentido: interocepção, que, segundo Tavares (2019), é "[...] definida como o ato de sentir, interpretar e integrar as informações dos sistemas internos do corpo conscientemente." O sistema interoceptivo tem seus receptores localizados nos órgãos viscerais e é responsável pelas sensações de fome, saciedade, cansaço, regulação emocional e sensibilidade a dor.

Nesse contexto, surge a teoria da Integração Sensorial (IS), que vem sendo cada vez mais discutida em nosso país, embora os trabalhos tenham começado nesta área há mais de 40 anos. Por ter uma maior quantidade de publicações em língua inglesa, isso vem a dificultar o acesso aos modelos de tratamento mais tradicionais e mais bem pesquisados na Terapia Ocupacional, especialmente para quem não domina o idioma inglês (PARHAM; MAILLOUX, 2005).

A Teoria de Integração Sensorial busca compreender a interligação entre as sensações corporais com os mecanismos cerebrais e a aprendizagem. Portanto, a Integração Sensorial foi definida como "[...] o processo neurológico que organiza as sensações do próprio corpo e do ambiente de forma a ser possível a geração de respostas adaptativas adequadas, a partir do uso eficiente do corpo no ambiente." (AYRES, 1972, p. 1072).

Assim, observa-se que é uma habilidade inata do indivíduo, onde ele consegue organizar, interpretar e responder sensorialmente a demandas do ambiente, de modo a conseguir desempenhar suas atividades do cotidiano de forma satisfatória.

Ademais, na Teoria de Integração Sensorial temos que todas as informações sensoriais, incluindo a informação tátil, proprioceptiva, visual, vestibular e auditiva, a qual ocorre em diversas regiões do córtex cerebral, contribuem para o controle do movimento voluntário, da cognição e das emoções (SHUMMAY-COOK; WOOLLACOTT, 2010).

Nesse sentido, pode-se afirmar que a alimentação é uma ocupação de grande relevânciae que também exige respostas adaptativas, as quais necessitam de um adequado processamento sensorial dos estímulos presentes no ambiente durante os momentos de refeição. Assim, torna-se necessária a intervenção de Terapia Ocupacional com enfoque na abordagem da Integração Sensorial com 
crianças que apresentam seletividade alimentar, decorrente de desordens sensoriais, frequentemente encontradas no TEA.

Nesse contexto, o interesse pela presente pesquisa surgiu diante do aumento da demanda de crianças com Transtorno do Espectro Autista (TEA) com seletividade alimentar nos consultórios privados de Terapia Ocupacional. Além disso, observou-se que tem sido encaminhado um número cada vez maior de crianças neurotípicas com dificuldades na alimentação, o que significa que outros profissionais e os familiares já compreendem a importância do acompanhamento terapêutico ocupacional diante deste desafio.

Durante eventos de Terapia Ocupacional, leitura e pesquisa de materiais relacionados aseletividade alimentar e Integração Sensorial, notou-se que esse tema ainda é pouco falado, principalmente no idioma brasileiro, sendo necessário que pesquisas abordem mais sobre $o$ assunto.

Portanto, este estudo visa contribuir com a literatura e a prática de terapeutas ocupacionais, especialmente brasileiros que atuam junto a esse público; apontando para a continuidade de pesquisas que abordam tal tema.

Nesse sentido, esta pesquisa tem como objetivo compreender como ocorre a atuação do Terapeuta Ocupacional, com base na abordagem da Integração Sensorial de Ayres, com foco notratamento da seletividade alimentar em crianças com Transtorno do Espectro Autista.

Sendo os objetivos específicos: identificar o impacto da intervenção na participação das crianças na ocupação da alimentação, assim como identificar quais fatores relacionados ao TEA podem contribuir para o surgimento ou aumento da seletividade alimentar.

\section{PROCEDIMENTO METODOLÓGICO}

A partir disso, foi realizada uma revisão de literatura do tipo revisão narrativa. Segundo Cordeiro et al. (2007), a revisão narrativa ou tradicional pode ser definida como um estudo com "[...] temática mais aberta; dificilmente parte de uma questão específica bem definida, não exigindo um protocolo rígido para sua confecção; a busca das fontes não é pré-determinada e específica, sendo frequentemente menos abrangente." Ocorre uma seleção arbitrária dos artigos, contendo a influência da percepção de seus autores no resultado final (CORDEIRO et al., 2007).

Dessa forma, a primeira etapa da pesquisa consistiu em estabelecer a metodologia do estudo com os critérios de inclusão e exclusão, assim como os 
descritores a serem investigados; a segunda etapa consistiu em pesquisar nos bancos de dados e livros o tema proposto; já a terceira etapa consistiu na leitura prévia dos resumos de artigos encontrados, para escolher quaispublicações atendem aos objetivos do presente estudo. Assim, seguimos para a quarta etapa, que consistiu na leitura completa dos artigos selecionados. E, por fim, na quinta etapa, onde ocorreu aanálise dos artigos para a escrita dos resultados e discussão.

Os critérios de inclusão para a pré-seleção da pesquisa foram: artigos em português, espanhol e inglês publicados nos periódicos nos últimos 10 anos (20112021), com resumo e artigo disponível gratuitamente e que utilizassem um dos descritores deste estudo como palavra-chave. Utilizamos como descritores os termos: "Integração Sensorial e seletividade alimentar", "seletividade alimentar e Autismo", "Terapia Ocupacional e seletividade alimentar". Foram utilizados os seguintes bancos de dados: SciELO, Pubmed, LILACS, American Journal of Occupational Therapy e a Revista Chilena de Terapia Ocupacional. Foram selecionados inicialmente 378 artigos, sendo incluídos quatro e excluídos 374 .

Os critérios de inclusão utilizados foram: estudos que incluíssem crianças com até 12 anos, artigos escritos por terapeutas ocupacionais, artigos com resumo e disponíveis gratuitamente para leitura e publicados nos últimos 10 anos (2011-2021).

Já os critérios de exclusão foram: pesquisas com pessoas acima de 12 anos de idade, artigo sem resumo e não disponíveis para leitura de forma gratuita, ou publicados em período anteriorao ano de 2011.

\section{RESULTADOS E DISCUSSÃO}

Nesta pesquisa realizou-se a busca em cinco bancos de dados, os quais são: SciELO, Pubmed, LILACS, American Journal of Occupational Therapy e a Revista Chilena de Terapia Ocupacional.

Os critérios de inclusão para a pré-seleção dos resultados foram: artigos em português, espanhol e inglês publicados nos periódicos já mencionados, que abordassem o tema Seletividade Alimentar e Integração Sensorial, sendo estabelecido o limite quanto ao ano de publicação, entre 2011-2021.

Utilizamos como descritores os termos: "seletividade alimentar e Integração Sensorial"; "seletividade alimentar e Transtorno do Espectro Autista"; "seletividade alimentar e Terapia Ocupacional”, nos idiomas em português, inglês e espanhol (Quadro 1). 
Quadro 1 - Descritores utilizados nas bases de dados selecionadas

\begin{tabular}{|c|c|}
\hline Bases de Dados & Descritores \\
\hline SciELO & Seletividade alimentar e Integração \\
\hline Pubmed & Sensorial; seletividade alimentar e \\
\hline LILACS & Transtorno do Espectro Autista; seletividade \\
\hline $\begin{array}{l}\text { American Journal of } \\
\text { Occupational Therapy }\end{array}$ & alimentar e Terapia Ocupacional. \\
\hline $\begin{array}{l}\text { Revista Chilena de Terapia } \\
\text { Ocupacional }\end{array}$ & $\begin{array}{l}\text { Food selectivity and sensory integration; } \\
\text { food selectivity and autism spectrum } \\
\text { disorder; food selectivity and occupational } \\
\text { therapy. } \\
\text { Selectividad alimentaria y integración } \\
\text { sensorial; selectividad alimentaria y } \\
\text { desorden del espectro autista; selectividad } \\
\text { alimentaria y Terapia Ocupacional. }\end{array}$ \\
\hline
\end{tabular}

Fonte: Elaborado pelos autores.

No Quadro 2 apresentam-se os resultados obtidos com a varredura realizada para a seleção de artigos, que pudessem subsidiar os achados sobre seletividade alimentar. Assim, na primeira varredura, a qual constituiu-se dos resumos, obteve-se 378 artigos, na segunda varredura, a qual consistiu-se na leitura dos resumos dos artigos, obteve-se seis trabalhos na temática; na terceira varredura ficaram quatro artigos, que foram selecionados para leitura completa e, como resultado final, obteve-se quatro artigos, os quais não relacionavam-se diretamente com as temáticas de interesse deste estudo, porém, perpassam a discussão sobre o tema.

Quadro 2 - Distribuição da seleção de publicações de bases de dados de acordo com os critérios estabelecidos paraa inclusão de estudos

\begin{tabular}{|c|c|c|c|c|c|}
\hline $\begin{array}{c}\text { Base de } \\
\text { dados }\end{array}$ & $\begin{array}{c}\text { Descritore } \\
\text { s }\end{array}$ & $\begin{array}{c}\text { Artigos } \\
\text { encontrad } \\
\text { os }\end{array}$ & $\begin{array}{c}\text { Resumos } \\
\text { dos } \\
\text { artigos } \\
\text { seleciona } \\
\text { dos para } \\
\text { leitura }\end{array}$ & $\begin{array}{c}\text { Artigos } \\
\text { seleciona } \\
\text { dos para } \\
\text { leitura } \\
\text { completa }\end{array}$ & $\begin{array}{c}\text { Artigos } \\
\text { seleciona } \\
\text { dos para } \\
\text { a } \\
\text { pesquisa }\end{array}$ \\
\hline $\begin{array}{c}\text { Revista } \\
\text { Chilena de } \\
\text { Terapia } \\
\text { Ocupacional }\end{array}$ & $\begin{array}{l}\text { Selectivid } \\
\text { ad } \\
\text { alimentari } \\
\text { a e } \\
\text { integració } \\
n\end{array}$ & 0 & 0 & 0 & 0 \\
& $\begin{array}{l}\text { sensorial; } \\
\text { selectivid }\end{array}$ & & & & \\
\hline
\end{tabular}




\begin{tabular}{|c|c|c|c|c|c|}
\hline & $\begin{array}{l}\text { ad } \\
\text { alimentari } \\
\text { a y } \\
\text { Terapia } \\
\text { Ocupacio } \\
\text { nal }\end{array}$ & & & & \\
\hline & $\begin{array}{l}\text { selectivid } \\
\text { ad } \\
\text { alimentari } \\
\text { a y y } \\
\text { desorden } \\
\text { del } \\
\text { espectro } \\
\text { autista }\end{array}$ & 0 & 0 & 0 & 0 \\
\hline & $\begin{array}{l}\text { selectivid } \\
\text { ad } \\
\text { alimentari } \\
\text { a } \\
\text { ocupacio } \\
\text { nal }\end{array}$ & 0 & 0 & 0 & 0 \\
\hline \multirow[t]{5}{*}{ SciELO } & $\begin{array}{l}\text { Seletivida } \\
\text { de } \\
\text { alimentar } \\
\text { e } \\
\text { Integraçã } \\
\text { o } \\
\text { Sensorial }\end{array}$ & 0 & 0 & 0 & 0 \\
\hline & $\begin{array}{l}\text { seletivida } \\
\text { de } \\
\text { alimentar } \\
\text { e } \\
\text { Transtorn } \\
\text { o do } \\
\text { Espectro } \\
\text { Autista }\end{array}$ & 3 & 2 & 1 & 1 \\
\hline & $\begin{array}{l}\text { seletivida } \\
\text { de } \\
\text { alimentar } \\
\text { e Terapia } \\
\text { Ocupacio } \\
\text { nal }\end{array}$ & 0 & 0 & 0 & 0 \\
\hline & $\begin{array}{l}\text { Food } \\
\text { selectivity } \\
\text { and } \\
\text { sensory } \\
\text { integratio } \\
\mathrm{n}\end{array}$ & 0 & 0 & 0 & 0 \\
\hline & $\begin{array}{l}\text { Food } \\
\text { selectivity } \\
\text { and } \\
\text { autism } \\
\text { spectrum }\end{array}$ & 0 & 0 & 0 & 0 \\
\hline
\end{tabular}




\begin{tabular}{|c|c|c|c|c|c|}
\hline & disorder & & & & \\
\hline & $\begin{array}{l}\text { Food } \\
\text { selectivity } \\
\text { and } \\
\text { occupatio } \\
\text { nal } \\
\text { therapy }\end{array}$ & 0 & 0 & 0 & 0 \\
\hline \multirow[t]{3}{*}{$\begin{array}{l}\text { American } \\
\text { Journal } \\
\text { Occupatio } \\
\text { nal } \\
\text { of Therapy }\end{array}$} & $\begin{array}{l}\text { Food } \\
\text { selectivity } \\
\text { and } \\
\text { sensory } \\
\text { integration }\end{array}$ & 1 & 1 & 0 & 0 \\
\hline & $\begin{array}{l}\text { Food } \\
\text { selectivity } \\
\text { and } \\
\text { autism } \\
\text { spectrum } \\
\text { disorder }\end{array}$ & 1 & 0 & 0 & 0 \\
\hline & $\begin{array}{l}\text { Food } \\
\text { selectivity } \\
\text { and } \\
\text { occupation } \\
\text { altherapy }\end{array}$ & 4 & 1 & 1 & 1 \\
\hline \multirow[t]{5}{*}{ Pubmed } & $\begin{array}{l}\text { Food } \\
\text { selectivity } \\
\text { and } \\
\text { sensory } \\
\text { integratio } \\
\mathrm{n}\end{array}$ & 137 & 1 & 0 & 0 \\
\hline & $\begin{array}{l}\text { Food } \\
\text { selectivity } \\
\text { and } \\
\text { autism } \\
\text { spectrum } \\
\text { disorder }\end{array}$ & 160 & 1 & 1 & 1 \\
\hline & $\begin{array}{l}\text { Food } \\
\text { selectivity } \\
\text { and } \\
\text { occupatio } \\
\text { nal } \\
\text { therapy. }\end{array}$ & 72 & 0 & 0 & 0 \\
\hline & $\begin{array}{l}\text { Selectivid } \\
\text { ad } \\
\text { alimentari } \\
\text { a e } \\
\text { integració } \\
\mathrm{n} \\
\text { sensorial }\end{array}$ & 0 & 0 & 0 & 0 \\
\hline & $\begin{array}{l}\text { Seletivida } \\
\text { de } \\
\text { alimentar } \\
\text { e }\end{array}$ & 0 & 0 & 0 & 0 \\
\hline
\end{tabular}




\begin{tabular}{|l|l|l|l|l|l|}
\hline & $\begin{array}{l}\text { Transtorn } \\
\text { o do } \\
\text { Espectro } \\
\text { Autista }\end{array}$ & & & & \\
\hline $\begin{array}{l}\text { Seletivida } \\
\text { de } \\
\text { alimentar } \\
\text { teTerapia } \\
\text { Ocupacio } \\
\text { nal }\end{array}$ & $\mathbf{0}$ & $\mathbf{0}$ & $\mathbf{0}$ & $\mathbf{0}$ \\
\hline TOTAL & $\mathbf{3 7 8}$ & $\mathbf{6}$ & & \\
\hline
\end{tabular}

Fonte: Elaborado pelos autores.

Após as leituras e as análises dos trabalhos selecionados, foi realizada uma breve descrição dos estudos, sendo feita uma transição dos dados mais relevantes de cada pesquisa, no intuito de identificar os que mais se identificavam com o foco desta pesquisa em específico.

O Quadro 3 corresponde aos critérios de seleção dos artigos, o processo de seleção se deu após a leitura dos trabalhos, onde os trabalhos descrevem sobre a análise da alimentação de crianças com Autismo, considerada inadequada pela seletividade alimentar ou pela dificuldade de interação nos momentos das refeições, atribuídas a alterações no processamento sensorial e a dificuldades sociais, comunicativas e cognitivas descritas como presentes no transtorno. 
Quadro 3 - Caracterização dos artigos analisados

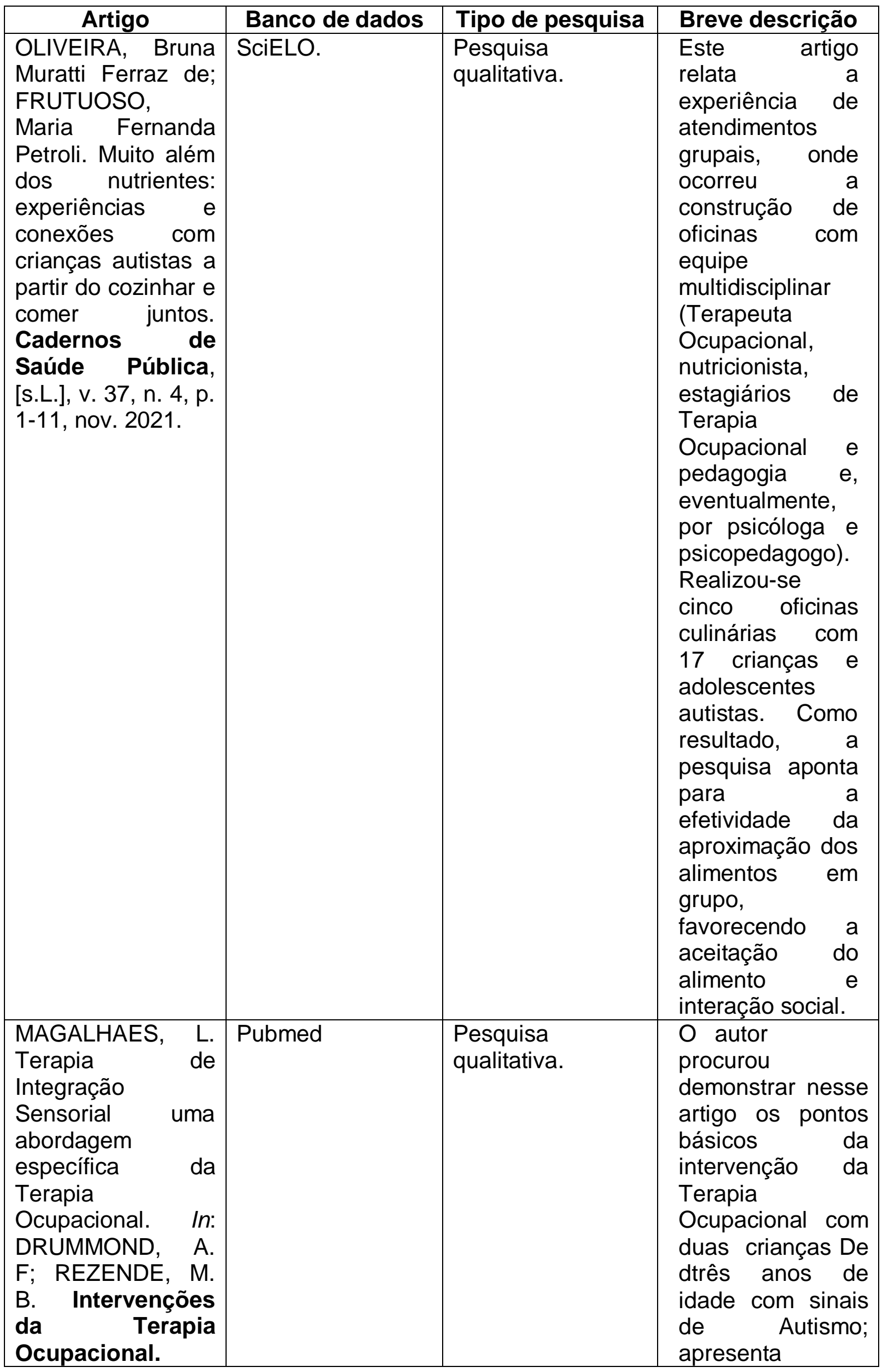




\begin{tabular}{|c|c|c|c|}
\hline $\begin{array}{ll}\text { Editora } & \text { UFMG: } \\
\text { Belo } & \text { Horizonte, } \\
2011 . & \end{array}$ & & & $\begin{array}{ll}\text { também } & \\
\text { dificuldades } & \text { em } \\
\text { responder aos } \\
\text { estímulos } \\
\text { sensoriais. }\end{array}$ \\
\hline 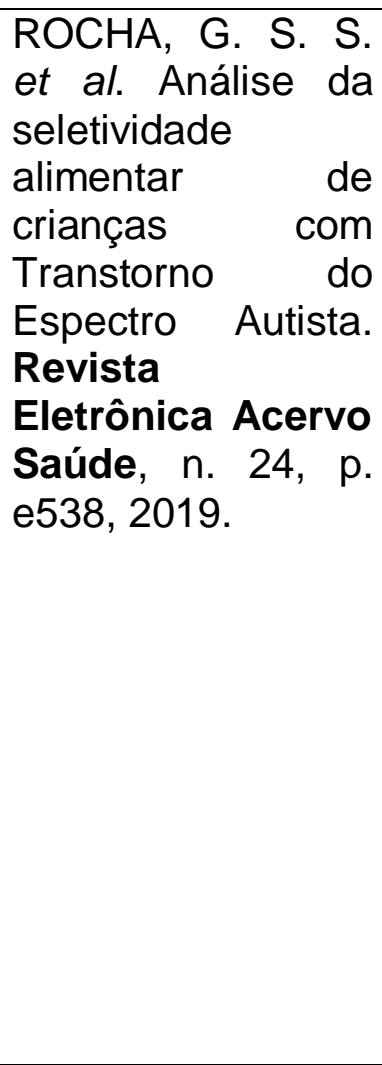 & LILACS. & $\begin{array}{c}\text { Pesquisa } \\
\text { quantitativa. }\end{array}$ & 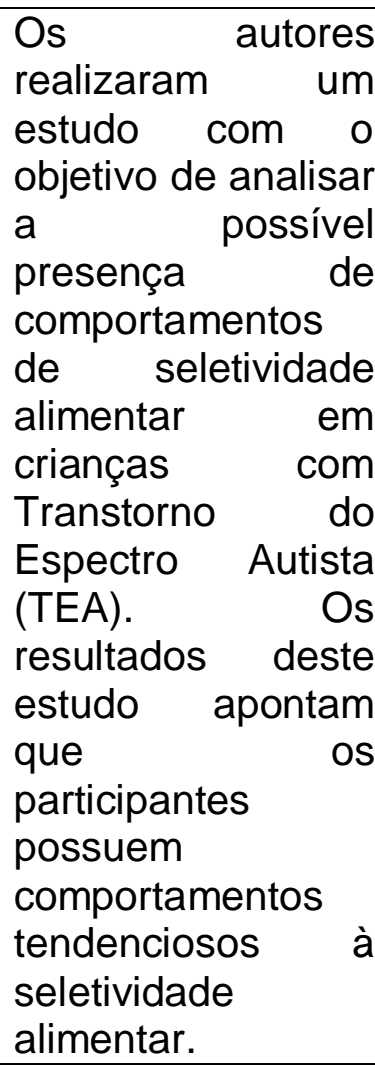 \\
\hline $\begin{array}{lr}\text { AHEARN, } & \text { William } \\
\mathrm{H} . \quad \text { et al. } & \text { Uma } \\
\text { avaliação } & \text { da } \\
\text { aceitação } & \text { de } \\
\text { alimentos } & \text { em } \\
\text { crianças } & \text { com } \\
\text { Autismo } & \text { ou } \\
\text { Desordem } & \text { de } \\
\text { Desenvolvimento } \\
\text { Pervasivo. 2011. }\end{array}$ & $\begin{array}{l}\text { American Journal } \\
\text { of Occupational } \\
\text { Therapy. }\end{array}$ & $\begin{array}{c}\text { Pesquisa } \\
\text { quantitativa. }\end{array}$ & $\begin{array}{lr}\text { Os autores } \\
\text { abordaram } \\
\text { estudo de caso } \\
\text { com crianças com } \\
\text { Autismo e } \\
\text { NOS, de forma } \\
\text { a classificar os } \\
\text { problemas } \\
\text { alimentares de } \\
\text { indivíduos com } \\
\text { alterações físicas } \\
\text { ou } & \text { de } \\
\text { desenvolvimento, } \\
\text { através de uma } \\
\text { avaliação } \\
\text { meio por } \\
\text { observação } \\
\text { direta. }\end{array}$ \\
\hline
\end{tabular}

Fonte: Elaborado pelos autores.

Oliveira e Frutuoso (2021) analisaram a alimentação de crianças autistas, considerada inadequada pela seletividade alimentar ou pela dificuldade de interação 
nos momentos das refeições, atribuídas a alterações no processamento sensorial e a dificuldades sociais, comunicativas e cognitivas descritas no transtorno.

A investigação constatou que a nutrição adequada durante a infância e nos primeiros anos de vida garante o crescimento e o desenvolvimento normal da criança. Quando se menciona crescimento de crianças, geralmente está relacionado ao crescimento que reflete o crescimento ósseo no corpo, mas cada sistema orgânico também está em desenvolvimento, incluindo o sistema nervoso central. 0 crescimento do corpo como um todo depende de uma nutrição adequada.

Magalhães (2011) desenvolveu uma pesquisa qualitativa, falando sobre a Integração Sensorial e a seletividade alimentar, o trabalho demonstra o uso da terapia de Integração Sensorial, uma abordagem com o intuito de reorganizar o processamento sensorial da criança, para que ela possa responder de forma positiva aos estímulos provocados pelo ambiente.

A análise dos estudos permitiu concluir sobre a necessidade da avaliação sensorial, com Terapeuta Ocupacional com formação na abordagem de Integração Sensorial, de casos de restrição alimentar, além das avaliações já realizadas com os demais profissionais da saúde, como pediatra, gastropediatra, nutricionista e fonoaudiólogo, pois ficou claro que as dificuldades do grupo de crianças com TEA tem origem em questões sensoriais.

William et al. (2011) investigou sobre o comportamento alimentar de indivíduos com Transtorno do Espectro Autista. O estudo comprovou que os problemas na alimentação são comuns entre crianças com TEA, mas a avaliação do comportamento alimentar nesta populaçãotem recebido pouca atenção. Examinar a natureza específica desses problemas proporcionará interferências clínicas e comportamentais mais específicas.

Ressalta-se ainda que conforme dados analisados dos artigos selecionados para compor este estudo, os resultados obtidos referiam que crianças com Transtorno do Espectro Autista (TEA), em algum momento de sua vida, apresentaram ou apresentarão algum grau de seletividade alimentar ou aversão aos alimentos, ambos relacionados a desordens sensoriais, características dos alimentos, textura, consistência, aparência visual e o comportamento das crianças diante das refeições.

Vale dizer ainda, conforme a revisão dos artigos, as crianças com TEA possuem comportamentos tendenciosos à seletividade alimentar. Evidencia ainda risco de problemas nutricionais, um fator preocupante, haja vista que a fase da 
infância tem influência direta em longo prazo.

Entretanto, nenhum dos trabalhos encontrados, de fato, aborda sobre o tratamento daseletividade alimentar utilizando a abordagem de Integração Sensorial nas sessões de Terapia Ocupacional, o estudo que mais se aproximou do tema desta pesquisa apontou para intervenções grupais e com participação multidisciplinar, não sendo realizado o tratamento com ambiente, recursos e técnicas da IS.

Nesse contexto, se torna necessário mais pesquisas nessa área, que apontem para a necessidade e eficácia da intervenção em crianças com seletividade alimentar decorrente de disfunção sensorial.

\section{CONCLUSÃo}

Dentre todos os trabalhos analisados, tiveram a predominância da pesquisa qualitativa do tipo descritiva, estudo de caso e observou-se também a pesquisa de campo. Em sua maioria, os estudos analisados apontam que as crianças com Autismo possuem comportamentos tendenciosos à seletividade alimentar.

Destacamos o objetivo central do estudo, que foi para compreender como ocorre a atuaçãodo Terapeuta Ocupacional, com base na abordagem da Integração Sensorial de Ayres, com foco no tratamento da seletividade alimentar em crianças com Transtorno do Espectro Autista, e, nesse contexto, seguindo os critérios de inclusão, nenhum trabalho atendeu a esta proposta, pois as pesquisas trazem sobre a prevalência de seletividade alimentar e disfunções sensoriais, mas nenhuma aborda sobre o tratamento utilizando-se da Integração Sensorial; o único estudo sobrerelato de caso é sobre intervenções grupais, com participação do Terapeuta Ocupacional junto à equipe multidisciplinar, empregando a estimulação sensorial em contexto de interação entre pares e atividades alimentares.

É necessário que estudos posteriores realizem mais investigações acerca da presençade seletividade alimentar e consumo de micronutrientes em indivíduos com TEA; sugere-se queessas crianças recebam intervenção adequada no que tange ao acompanhamento nutricional, pois se observa uma carência de informação ofertada aos pais/cuidadores acerca da importância da alimentação no TEA. Por fim, percebemos a importância da educação em saúde, orientação parental, bem como a necessidade de intervenção específica e o uso da Integração Sensorial nas sessões de Terapia Ocupacional; além disso, existe uma lacuna na literatura sobre o tema, sendo relevante que mais estudos sejam produzidos para agregar com a prática profissional. 


\section{REFERÊNCIAS}

AHEARN, William $\mathrm{H}$. et al. Uma avaliação da aceitação de alimentos em crianças com Autismo ou Desordem de Desenvolvimento Pervasivo. 2011.

AYRES. A. J. Integração Sensorial e distúrbios de aprendizagem. Los Angeles: Westem Psychological Services, 1972.

AMERICAN PSYCHIATRIC ASSOCIATION. Manual diagnóstico e estatístico de transtornos mentais: DSM-5. 5. ed. Porto Alegre: Artmed, 2014.

AOTA - American Occupational Therapy Association. Estrutura da prática da Terapia Ocupacional: domínio \& processo. Revista de Terapia Ocupacionalda USP, São Paulo, v. 26, p. 01-49, 2015.

CORDEIRO, Alexander Magno et al. Revisão Sistemática: uma revisão narrativa. Comunicação Científica: uma revisão narrativa, [s.L.], v. 34, n. 6, p. 428-431, dez. 2007.

BROOME, M. E. Revisões integrativas da literatura para o desenvolvimento de conceitos. In: RODGERS, B. L.; KNAFL, K. A. (Eds.). Desenvolvimento de conceitos em enfermagem: fundamentos, técnicas e aplicações. Filadélfia: W.B Saunders Company, 2000. p. 231-250.

BUGALHO, P.; CORREA, B.; VIANA-BAPTISTA, M. Papel do cerebelo nas funções cognitivas e comportamentais: bases científicas e modelos de estudo. Acta Medica Portuguesa, v. 19, n. 3, p. 260, 2006.

LOPEZ-PISON J, Garcia-Jimenez et al. Nossa experiência com o diagnóstico etiológico de atraso global de desenvolvimento e deficiência intelectual: 2006-2010. Neurologia, v. 29, n. 7, p. 402-407, 2014.

LACY, T. J.; HUGES, J. D. Uma abordagem de sistemas à neurobiologia comportamental: integrando asicodinâmica e a neurociência em um currículo psiquiátrico. J Amer Acad Psychoanal, v. 34, n. 1, p. 43-74, 2006.

MAGALHÃES, L. Terapia de Integração Sensorial uma abordagem específica da Terapia Ocupacional. In: DRUMMOND, A. F.; REZENDE, M. B. Intervenções da Terapia Ocupacional. Editora UFMG:Belo Horizonte, 2011.

OLIVEIRA, K. G.; SERTIÉ, A. L. Transtornos do espectro do Autismo: um guia atualizado para aconselhamento genético. Einstein, São Paulo, v. 15, n. 2, p. 233238, 2017.

OLIVEIRA, Bruna Muratti Ferraz de; FRUTUOSO, Maria Fernanda Petroli. Muito além dos nutrientes: experiências e conexões com crianças autistas a partir do cozinhar e comer juntos. Cadernos de Saúde Pública, [s.L.], v. 37, n. 4, p. 1-11, nov. 2021.

PARHAM, L. D; MAILLOUX, Z. Integração Sensorial. In: CASE-SMITH, J. Terapia Ocupacional para Crianças. Lovis: Mosby, 2005. p. 356-409. 
POLIT, D. F.; BECK, C. T. Usando pesquisas na prática de enfermagem baseada em evidências. In: POLIT, D. F.; BECK, C. T. (Eds.). Fundamentos da pesquisa em enfermagem: métodos, avaliação e utilização. Filadélfia: LippincottWilliams \& Wilkins, 2006. p. 457-94.

ROCHA, G. S. S. et al. Análise da seletividade alimentar de crianças com Transtorno do Espectro Autista. Revista Eletrônica Acervo Saúde, n. 24, p. e538, 2019. doi: https://doi.org/10.25248/reas.e538.2019.

ROMANELLI EJ. Neuropsicologia aplicada aos distúrbios de aprendizagem: prevenção e terapia. In: MELO, M. M.; RIBEIRO, L. A. (Eds.). Temas em educação II. Curitiba: Futuro Congressos e Eventos, 2003. p. 49-62.

SERRANO, P. A Integração Sensorial no desenvolvimento da aprendizagem da criança. Lisboa: Papa Letras, 2016.

SILVA, N. I. da. Relações entre hábito alimentar e síndrome do espectro autista. 135 f. Dissertação (Mestre em Ciências) - Escola Superior de Agricultura "Luiz de Queiroz", Universidade de São Paulo, Piracicaba, 2011.

SHUMWAY-COOK, A.; WOOLLACOTT, M. H. Controle motor: teoria e aplicações práticas. 3. ed. Barueri: Manole, 2010.

TAVARES, Marília Padilha Martins. Influência da interocepção sobre a regulação do esforço físico e as respostas psicofisiológicas em adolescentes. 2019. $76 \mathrm{f}$. Dissertação (Mestrado em Educação Física) - Universidade Federal do Rio Grande do Norte, Natal, 2019. 


\title{
Coletânea de Estudos em Integração Sensorial
}

\author{
Ana Irene Alves de Oliveira \\ Danielle Alves Zaparoli \\ Marcilene Alves Pinheiro
}

(Organizadoras)

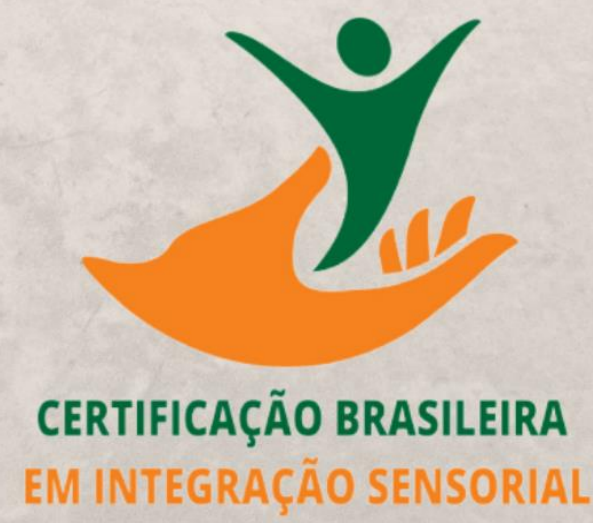

EM INTEGRAÇÃO SENSORIAL

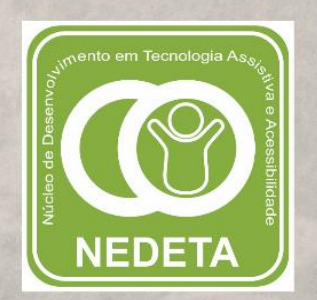

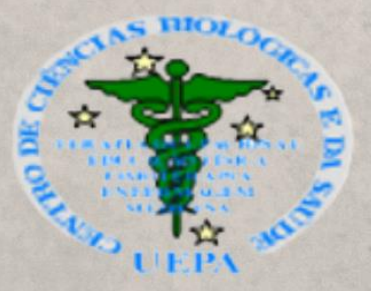

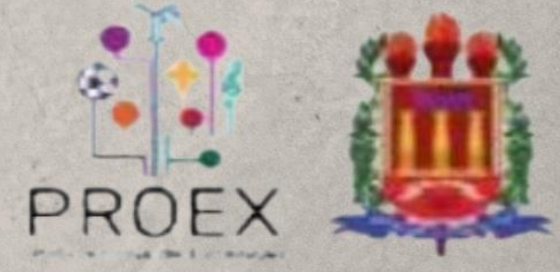

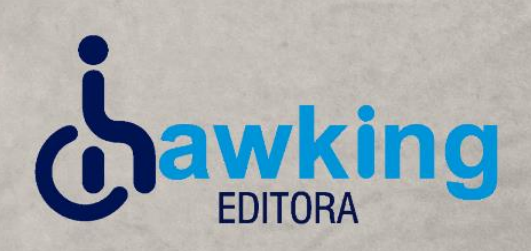

